\title{
Review of Technologies for the Pretreatment of Retrieved Single-Shell Tank Waste at Hanford
}

\author{
M. A. Gerber
}

August 1992

Prepared for the U.S. Department of Energy under Contract DE-AC06-76RLO 1830

Pacific Northwest Laboratory Operated for the U.S. Department of Energy by Battelle Mernorial Institute

Baftelle 


\title{
DISCLAIMER
}

This report was prepared as an account of work sponsored by an agency of the United States Covernment. Neither the United States Government nor any agency thereof, nor Battelle Memorial Institute, nor any of their employees, makes any warranty, expreseed or implied, or assumes any legal liability or responsibility for the accuracy, completeness, or usefulness of any information, apparatus, product, or process disclosed, or represents that its use would not infringe privately owned rights. Reference herein to any specific commercial product, process, or service by trade name, trademark, manufacturer, or otherwise does not necessarily constitute or imply its endorsememt, recommendation, of favoring by the United States Government or any agency thereof, or Battelle Memorial Institute. The views and opinions of authors expressed herein do not necessarily state or reflect those of the United States Government or any agency thereof.

\author{
PACIFIC NORTHWEST LABORATORY \\ operated by \\ BATTELI.E MEMORIAL INSTITUTE. \\ for the \\ UNITED STATES DEPARTMENT OF ENERCY \\ under Contract DE-AC.06-76RLO 1830
}

Printed in the United States of Ainerica

Avallable to DOE and DOE contractors froin the

Office of Scientific and Jechnical Information, P.O. Box 62, Oas Ridge, TN 37831; prices avallable from (615) 576-8401. FTS 626-8401.

Available to the public trom the National Technical Information Service,
U.S. Department of Commerce, 5285 Port Royal Rd. Springfeld, VA 22161. 
M. A. Gerber

August 1992

Prepared for the U.S. Department of Energy under Contract DE-ACO6-76RLO 1830

Pacific Northwest Laboratory

Richland, Washington 99352

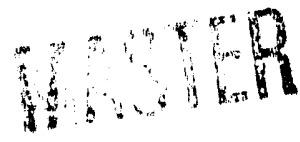




\section{SUMMARY}

The purpose of the study reported here was to identify and evaluate innovative processes that could be used to pretreat mixed waste retrieved from the 149 single-shell tanks (SSTs) on the U.S. Department of Energy's (DOE) Hanford site. The information was collected as part of the Single Shell Tank Waste Treatment project at Pacific Northwest Laboratory (PNL). The project is being conducted for Westinghouse Hanford Company under their SST Disposal Program.

Complete closure of the SSTs has been targeted at June 2018 under the Hanford Federal Facility Agreement and Consent Order (1989), a Tri-Party Agreement with DOE, the U.S. Environmental Protection Agency, and the Washington State Department of Ecology. The agreement also contains milestones for demonstrating technologies leading up to the closure. These milestones include techniques for retrieving the waste for treatment and packaging for final disposal.

In this study, pretreatment refers to any processing performed on the waste before preparation of a final waste form suitable for disposal. The final waste forms being considered are glass and grout. The treatment objectives used as the basis for evaluating technologies in this study are listed below:

- removal and/or destruction of specific components of concern from a regulatory standpoint or troublesome for glass and grout waste forms

- separation, recovery, recycle, or separate disposal of nonradioactive components in the waste

- improved partitioning of radioactive waste components for disposal or reuse

- minimization of total waste quantities.

This document contains a compilation of technologies that could have application to SST wastes. A broad literature search was performed to identify all treatment processes currently under development or deployed. Specifically, 19 potential pretreatment technologies are discussed. 
To begin the evaluation, some general assumptions had to be made about the chemical content and the types of waste streams that could be encountered in the treatment of SST waste. The first step was to group the tank chemical components into categories based on similar regulatory and/or chemical processing constraints. These categories are transuranics (TRU), strontium, cesium, technetium, uranium, heavy metals, sodium nitrate, organics, and other constituents. Water is not treated as a component category but as a major characteristic of the process streams.

Nine generic process streams were defined to represent the range of waste characteristics anticipated from the initial treatment of the retrieved waste and subsequent treatment of various new waste streams generated by the treatment method employed:

- Primary Waste Streams

- initial waste

- insolubie sludge

- nitrate brine

- Secondary Wasté Streams

- aqueous waste

- sodium nitrate salt

- aqueous slurry

- Tertiary Waste Streams

- tertiary wastewater

- flue/residual gas

- process solids/sludge.

Nearly 150 different processes were identified from the literature review that could possibly be used for the treatment of SST wastes. However, many of the processes shared similar objectives and engineering features. Those processes that shared similar features were grouped into one technology. Once the processes were grouped together, 35 technologies were identified for treating liquid and solid hazardous wastes and radioactive waste.

Each of the 35 technologies was then screened to eliminate those that did not appear appropriate for either the anticipated waste streams or the contaminants identified. Nineteen technologies were ultimately retained for further evaluation: 
- dissolution

- beneficiation

- liquid phase particle separation

- solvent extraction

- adsorption/ion exchange

- membrane separation

- precipitation

- bioaccumulation

- biodegradation

- crystallization
- freeze crystallization

- evaporation

- chemical oxidation

- chemical reduction

- high temperature water treatment

- roasting

- calcining

- incineration

- molten solid separation.

These 19 technologies are described separately in the report and addressed in terms of applicability to SST wastes and potential process improvements. Information on cost and safety factors is also given when available.

Using the information gathered in the study, PNL identified a number of innovative technologies that would meet specific treatment objectives for each of the anticipated waste streams. However, because of the limited amount of information available regarding tank constituents it was not possible to fully assess the applicability of most of the technologies, and it is recommended that further characterization consider data requirements for the more promising technologies. Furthermore, as elements are identified that need to be removed from either final waste form, a literature search specific to each element should be conducted to identify any unique processes andior process requirements.

Process cost and safety considerations presented in this report are of limited vaiue without knowing the interactions among the various treatment processes. Consequently, a systems analys is is recommended as treatment objectives are identified in order to beiter assess the impact of the treatment alternatives on overall cost and safety. 


\section{ACKNOWLEDGMENTS}

Funding for this work was provided by the U.S. Department of Energy Office of Technology Development through the Westinghouse Hanford Company, Partitioning and Process Integration Group managed by $\mathrm{J}$. A. Hunter. The cognizant engineer was G. R. Bloom; his assistance and cooperation are especially appreciated. 


\section{CONTENTS}

SUMMARY ..................................... i i

ACKNOWLEDGMENTS .............................. vii

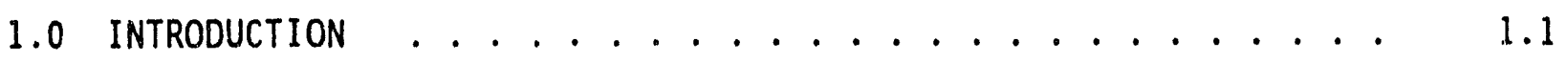

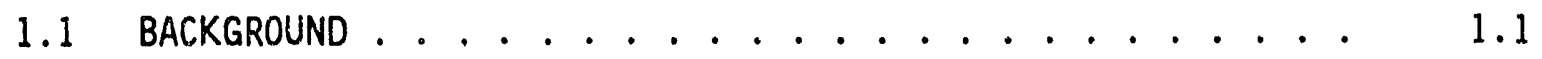

1.2 OBJECTIVES . . . . . . . . . . . . . . . 1.2

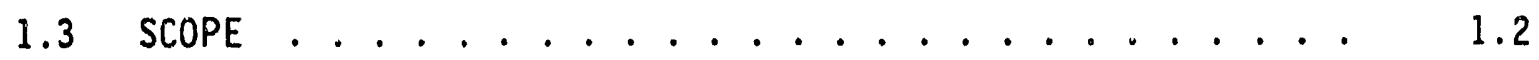

1.4 APPROACH ................................. 1.3

1.5 REFERENCES . . . . . . . . . . . . . 1.6

2.0 CONCLUSIONS AND RECOMMENDATIONS . . . . . . . . . . . . . 2.1

2.1 TREATMENT OF SST WASTE STREAMS . . . . . . . . . . 2.1

2.1.1 Primary Waste Streams ............. 2.1

2.1.2 Secondary Waste Streams . . . . . . . . . 2.2

2.1.3 Tertiary Waste Streams . . . . . . . . . 2.3

2.2 GENERAL CONCLUSIONS AND RECOMMENDATIONS . . . . . . . 2.4

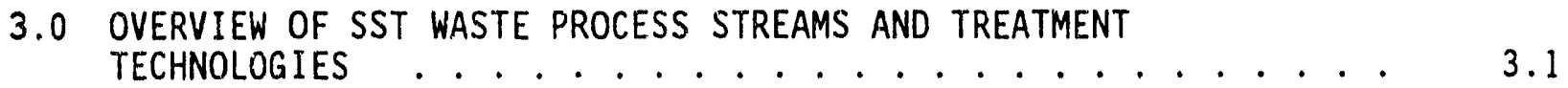

3.1 SST COMPONENT CATEGORIES . . . . . . . . . . . . . . 3.1

3.1.1 Transuranics ................ 3.1

3.1.2 Strontium ................. 3.1

3.1.3 Cesium . . . . . . . . . . . . . . 3.2

3.1 .4 Technetium ................. . . 3.2

3.1 .5 Uranium ................. 3.2

3.1.6 Heavy Metals . . . . . . . . . . . . . . 3.2

3.1.7 Sodium Nitrate . . . . . . . . . . . . 3.3

3.1 .8 Organics . . . . . . . . . . . . . . 3.3 
3.1.9 Other Constituents ............. 3.3

3.2 ANTICIPATED PROCESS STREAMS . . . . . . . . . . . 3.3

3.2.1 Primary Waste Streams . . . . . . . . . . 3.4

3.2.2 Secondary Waste Streams . . . . . . . . . 3.5

3.2.3 Tertiary Waste Streams . . . . . . . . . . 3.6

3.3 CANDIDATE TREATMENT TECHNOLOGIES . . . . . . . . . 3.7

3.4 REFERENCES .......................... 3.10

4.0 DESCRIPTION OF TECHNOLOGIES . . . . . . . . . . . . . 4.1

4.1 DISSOLUTION ........................ 4.1

4.1.1 Process Description ............. 4.1

4.1.2 Applicability to SST Waste . . . . . . . . . 4.2

4.1 .3 Cost .................. 4.2

4.1.4 Opportunities for Process Improvement . . . . . 4.2

4.1.5 References ................. 4.3

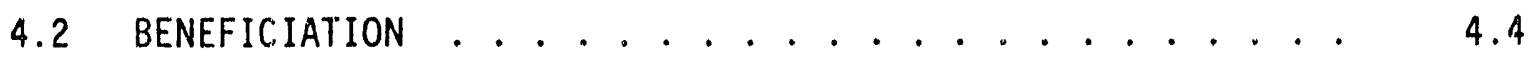

4.2.1 Process Description .............. 4.4

4.2.2 Applicability to SST Waste . . . . . . . . 4.7

4.2 .3 Cost . . . . . . . . . . . . . . . 4.8

4.2.4 Opportunities for Process Improvement . . . . . 4.8

4.2.5 References ................. . 4.9

4.3 LIQUID PHASE PARTICLE SEPARATION . . . . . . . . . . . 4.10

4.3.1 Process Description .............. 4.10

4.3.2 Applicability to SST Waste . . . . . . . . 4.12

4.3 .3 Cost . . . . . . . . . . . . . . . 4.12

4.3.4 Opportunities for Process Improvement . . . . . . 4.12

4.3.5 References .................. . 4.13 
4.4 SOLVENT EXTRACTION . . . . . . . . . . . . . . 4.14

4.4 .1 Process Description .......... 4.14

4.4.2 Applicability to SST Waste ......... 4.16

4.4 .3 Cost ................. 4.16

4.4.4 Opportunities for Improved Processing ...... 4.17

4.4 .5 References .............. . 4.20

4.5 ADSORPTION/ION EXCHANGE .................... 4.21

4.5.1 Process Description ........... 4. 4.21

4.5.2 Applicability to SST Waste ......... 4.23

4.5 .3 Cost . . . . . . . . . . . . 4.23

4.5.4 Opportunities for Improved Processing ..... 4.24

4.5 .5 References .............. . . 4.24

4.6 MEMBRANE SEPARATION ....................... 4.26

4.6.1 Process Description ........... 4.26

4.6.2 Applicability to SST Waste ......... 4.31

4.6 .3 Cost ................ 4.32

4.6.4 Opportunities for Improved Processing . . . . 4.32

4.6 .5 References .............. . . 4.32

4.7 PRECIPITATION . . . . . . . . . . . . . . . 4.33

4.7 .1 Process Description ........... 4.33

4.7.2 Applicability to SST Waste ......... . 4.35

4.7 .3 Cost .................. 4.35

4.7.4 Opportunitites for Improved Processing ..... 4.35

4.7 .5 References ............ . . . 4.36

4.8 BIOACCUMULATION . . . . . . . . . . . . . 4.37

4.8 .1 Process Description ........... . . 4.37 
4.8.2 Applicability to SST Waste . . . . . . . . 4.39

4.8 .3 Cost .................. . . 4.39

4.8.4 Opportunities for Improved Processing . . . . . 4.39

4.8.5 References ................ 4.40

4.9 BIOLOGICAL DEGRADATION ............... 4.41

4.9.1 Process Description .............. 4.41

4.9.2 Applicability to SST Waste .......... 4.42

4.9 .3 Cost .................. 4.42

4.9.4 Opportunities for Improved Processing . . . . . 4.42

4.9.5 References ................ 4.43

4.10 CRYSTALLIZATION ..................... 4.44

4.10.1 Process Description ............. 4.44

4.10.2 Applicability to SST Waste .......... 4.45

4.10.3 Process Cost ............. 4.45

4.10.4 Opportunities for Improved Processing . . . . . 4.46

4.10.5 References .............. 4.46

4.11 FREEZE CRYSTALIIZATION . . . . . . . . . . . 4.47

4.11.1 Process Description .............. 4.47

4.11.2 Applicability to SST Waste ......... . 4.47

4.11.3 Process Cost ................. 4.48

4.11.4 Opportunities for Improved Processing . . . . . 4.48

4.11.5 References ................. 4.48

4.12 EVAPORATION . . . . . . . . . . . . . . . 4.49

4.12.1 Process Description ........... . . 4.49

4.12.2 Applicability to SST Waste . . . . . . . . . 4.49

4.12 .3 Cost ............... . . . 4.50 
4.12.4 Opportunities for Improved Processing . . . . . 4.50

4.12.5 References ................ 4.50

4.13 CHEMICAL OXIDATION ................. 4.51

4.13.1 Process Description ............. 4.51

4.13.2 Applicability to SST Waste . . . . . . . . 4.52

4.13 .3 Cost ................... 4.53

4.13.4 Opportunities for Improved Processing . . . . . 4.53

4.13.5 References .............. . 4.53

4.14 CHEMICAL REDUCTION ................ 4.55

4.14.1 Process Description ............ . 4.55

4.14.2 Applicability to SST Waste . . . . . . . . 4.58

4.14.3 Process Cost . . . . . . . . . . . . . 4.58

4.14.4 Opportunities for Improved Processing . . . . . 4.58

4.14.5 References . . . . . . . . . . . . . 4.59

4.15 HIGH TEMPERATURE WATER TREATMENT . . . . . . . . . 4.60

4.15.1 Process Description ............ 4.60

4.15.2 Applicability to S\$T Waste . . . . . . . . 4.62

4.15.3 Process Cost ............... 4.62

4.15.4 Opportunities for Improved Processing . . . . . 4.63

4.15.5 References ................ 4.63

4.16 ROASTING ......................... 4.64

4.16.1 Process Description ........... . 4.64

4.16.2 Applicability to SST Waste . . . . . . . 4.64

4.16 .3 Cost .................. . . 4.65

4.16.4 Opportunities for Improved Processing . . . . . 4.65

4.16.5 References ................ 4.65 


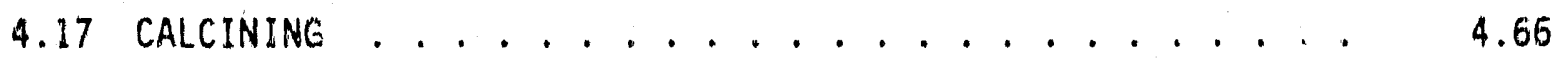

4.17 .1 Process Description ........... 4.66

4.17.2 Applicability to SST Waste ........ 4.66

4.17 .3 cost ................ 4.67

4.17.4 Opportunities for Improved Processing . . . . 4.67

4.17 .5 References ............. 4.67

4.18 INCINERATION $\ldots \ldots \ldots \ldots \ldots . \ldots \ldots$

4.18.1 Process Description ............ 4.68

4.18.2 Applicability to SST Waste ........ 4.75

4.18 .3 cost ............... 4.76

4.18.4 Opportunities for Improved Processing . . . . 4.76

4.18 .5 References ............. 4.76

4.19 MOLTEN SOLID SEPARATION ....................... 48

4.19 .1 Process Description ............ 4.78

4.19 .2 Applicability to SST Waste ......... 4.79

4.19 .3 cost ................ 4.80

4.19.4 Opportunities for Improved Processing . . . . . 4.80

4.19 .5 References .............. . 4.80

5.0 SAFETY CONSIDERATIONS . . . . . . . . . . . . . . . 5.1

APPENDIX A - POTENTIAL. CHEMICAL COMPONENTS OF CONCERN . . . . . . A.1

APPENDIX $B$ - ELIMINATION OF VARIOUS TREATMENT TECHNOLOGIES . . . . B B, 1

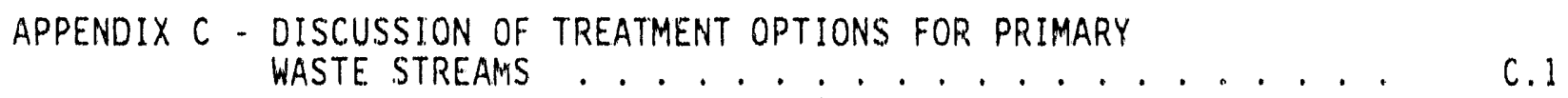

APPENDIX D - TREATMENT OPTIONS FOR SECONDARY WASTE STREAMS .... . 0.1

APPENDIX E - TREATMENT OPTIONS FOR TERTIARY WASTE STREAMS . . . . E.1 


\subsection{INTRODUCIION}

The information in this report was collected as part of the Single shell Tank (SST) Waste Pretreatment project at Pacific Northwest Laboratory (PAL.), (a) which is being conducted for Westinghouse Hanford Company (WHC) in support of their SST Disposal Program. WHC is the operaing contractor for the U.S. Department of Energy's (DOE) Hanford Site, and is responsible to DOE for remediation of the SST at the Site.

\subsection{BACKGROUND}

Defense operations at DOE's Hanford Site have resulted in the production of large quantities of high level radioactive (HLW) wastes, approximately $1.85 \times 10^{5} \mathrm{~m}^{3}$, which are now stored in various tank farms (Kupfer, Boldt, and Buelt 1988). Twelve of the tank farms, located in the 200 West and 200 East Areas, contain 149 SSTs. The SSTs were constructed between the years of 1943 and 1964 with no wastes added since November 1980. The SST capacities vary from 55,000 to 1 million gal.

The SST farms at Hanford are managed under a Part $A$ Permit (Interim Status). Closure of the tank farms as tank systems requires the renoval of the wastes from the tanks. The Hanford Federal Facility Agreement and Consent Order (1989) has a milestone of June 2018 for complete closure of the SSTs. This Tri-Party Agreement (DOE, U.S. Environmental Protection Agency, Washington State Department of Ecology) also sets milestones for the demonstration of technologies leading up to the closure of the SSTs. Developmental efforts are currently under way to demonstrate that the retrieval of SST wastes is possible. Once retrieval techniques are demonstrated, it wili likewise be demonstrated that a tank farm can be closed with the wastes being retrieved, processed, treated, and packaged in an acceptable manner for final disposal.

(a) Operated for the U.S. Department of Energy by Battelle Memorial Institute under Contract DE-ACO6-76RLO 1830. 


\subsection{OBJECTIVES}

The main goal of the study reported here was to identify and evaluate innovative processes that could be used to satisfy a number of treatment objectives. These objectives are as follows:

- removal and/or destruction of specific components of concern from a regulatory standpoint or troublesome for glass and grout waste forms

- separation, recovery, recycle, or separate disposal of nonradioactive components in the waste

- improved partitioning of the radioactive waste components for disposal or reuse

- minimization of total waste quantities.

This document contains a compilation of the treatment technologies identified that could have application to SST wastes. A broad literature search was performed to identify all treatment processes currently under development or being deployed. Out of the large number of treatment technologies examined, 19 are discussed in this report as potential pretreatment technologies that might be applied to the retrieved wastes. In the context of this report, pretreatment is defined as any treatment or partitioning that is performed before final treatment to make a waste form suitable for disposal. The final waste treatment options are assumed to be vitrification and grouting. Process evaluation was based on the ability to improve final waste form characteristics, partition specific components, destroy or detoxify, and reduce total waste volume.

\subsection{SCOPE}

In the original scope of work, promising treatment technologies were to be analyzed in an abbreviated cost-risk-benefit evaluation. A number of factors made this evaluation impractical at this time. First, the SSTs contain a unique, complex mixture of waste that varies considerably for different tanks. There is also inadequate information at this time regarding the mineral characteristics of the waste that are needed to evaluate many technologies. Also, at the time of this study, there was insufficient specific information 
regarding problem components, particularly in the context of tank variablilty. With these constraints, long-term risks could not be fully assessed based on improvement in the waste form. Only general observations regarding potentially significant volume reduction of certain components could be made for some of the processes.

Information regarding short-term risk was also found to be insufficient to conduct a satisfactory risk analysis, especially to determine radiological constraints on most of the processes, nor could short-term risk be accurately assessed without knowing the interactions of the various treatment processes needed. The only information that was readily obtained dealt with operating parameters such as pressure and temperature, which would give a partial indication of operational risk. A summary table of the range of these operating parameters for each technology is presented in Section 5.0 .

Cost information for the majority of the processes was found to be for the treatment of wastes that differ significantly from SST waste composition, or for nonwaste applications. Any extrapolation of this information would likely draw inaccurate conclusions regarding process costs. Furthermore, a number of processes would be necessary to treat all waste streams generated from the initial treatment of the waste. Without knowing the interactions of these various treatments it would be impossible to know the impacts of one process on the costs of subsequent processes. Costs for each technology for traditional applications are provided, however, in Section 4.0 when such information could be found.

\subsection{APPROACH}

A number of difficulties were encountered in evaluating the applicability of candidate technologies. First, there are a very large number of organic and inorganic compounds in the SST waste in concentrations and physical states that are not encountered elsewhere in the treatment of either hazardous or radioactive waste. Consequently, there is little precedence for anticipating specific treatments other than partitioning of the water soluble and insolubie fractions of the waste. Second, the specific composition of each tank is very complex and only generally known. Therefore, the presence 
and effects of undesirable components on certain treatments can only be speculated in many cases. Third, the composition of the tanks varies considerably from one tank to another. This factor can significantly affect the suitability of a number of treatment objectives as well as potential treatment options. Finally, specific compositional constraints of the waste disposal forms were not defined at the time the study was initiated. Therefore, specific treatment objectives were not well defined.

In order to evaluate treatment technologies for applicability to the SST tank waste within the above constraints, some general assumptions had to be made regarding the chemical content and the types of waste streams that could be encountered in the treatment of SST waste. The approach taken in this study was to group the tank chemical components into categories based on similar regulatory and/or chemical processing constraints. These categories and the basis for selecting them are described in Section 3.1. The potential chemical components of concern that were considered in developing these categories are detailed in Appendix $A$.

Nine generic process streams were also defined to represent the range of waste characteristics anticipated from the initial treatment of the retrieved waste and subsequent treatment of various new waste streams generated by the treatment method employed. This was necessary because the applicability of many of the technologies to treating various components was also constrained by a number of key parameters, such as the presence and quantity of suspended solids and certain dissolved solids, as well as the concentration of specific components to be treated. These process streams are discussed in section 3.2 .

The above process streams and component categories were used as a basis for analysis during a literature review and preliminary screening to identify potentially applicable technologies. The main emphasis of this litarature search was to identify technologies that have been used or seriously considered for the treatment of hazardous waste, as well as those used in mineral processing. Mineral processing was investigated because the methods are used to extract very small quantities of specific minerals from relatively complex rock formations. In addition, a limited amount of literature was reviewed to identify processes used to separate specific chemicals. After the processes 
were identified, they were sorted and grouped into technologies. Those that did not appear to be applicable were eliminated from further consideration. The technologies considered applicable to SST waste and process streams are summarized in Section 3.3, and more fully described in Section 4.0. Technologies that were eliminated are described in Appendix $B$.

The main objective of the detailed evaluation was to determine the general operating principles for each technology, any advantages and/or limitations that might expand or constrain its appiicability, and any special feed stream requirements that might involve pretreatment steps. Some of the technologies retained for further evaluation contained a number of unique processes that varied in their specific applicability. Therefore, each major process within a technology was considered separately where appropriate differences existed. Where possible, innovative concepts that might significantly improve a process were identified and evaluated. The above information was used to assess the applicability of each technology to individual process streams and for the treatment of specific chemical component categories. A summary evaluation of each technology is presented in Section 4.0.

As a common basis for comparison of the different processes descrived in Section 4.0, each of the nine streams was individually evaluated to identify key objectives that could be expected in the treatment of the various chemical components anticipated in the stream, as well as key constraints that 1 imited the applicability of specific technologies. These streams were divided into three major groups:

- primary waste streams

- secondary waste streams

- tertiary waste streams.

Each group is described separately in Appendices C, D, and E, respectively. The main objective of evaluating the technologies in this manner is to show which technologies address the different treatment objectives for each waste stream. It also provides a comparison of the manner in which potentially competing technologies would address specific objectives and to some extent the impact of each process on subsequent treatment requirements. 
Included in this analysis is an evaluation of innovative approaches being developed, as well as the state of development of these approaches.

\subsection{REFERENCES}

Hanford Federal Facility Agreement and Consent Order. 1939. Washington State Department of Ecology, U.S. Environmental Prutection Agency, and U.S.

Department of Energy.

Kupfer, M. J., A. L. Boldt, and J. L. Buelt. 1988. Process and Facility

Options for Pretreatment of Hanford Tank Waste. SD-WM-TA-015, Westinghouse Hanford Company, Richland, Washington. 


\subsection{CONCLUSIONS AND RECOMMENDATIONS}

The conclusions and recommendations discussed here cover the overall study itself and waste streams associated with SST treatment.

\subsection{TREATMENT OF SST WASTE STREAMS}

A number of conclusions can be made regarding the potential for treating the various wastes streams in order to achieve one or more of the treatment objectives, i.e., reduction of cost, volume, or toxicity of the waste and the recovery of components for recycling.

\subsubsection{Primary Waste Streams}

Issues associated with the primary waste streams can be examined with respect to the insoluble solids and the nitrate brine. The main problem associated with the insoluble solids is that because of the presence of transuranics (TRU) and strontium, disposal costs are expected to be extraordinarily high (on the order of $\$ 1$ million/ton of waste). Thus, any process ing that can successfully remove these components from the bulk of the solids can achieve a significant reduction in the volume and disposal cost of HLW and TRU waste. A second potential problem is that certain undesirable components in the insoluble sludge, such as chromium or phosphate, may require that the sludge be treated. One opportunity associated with the insoluble sludge is the presence of potentially recoverable quantities of uranium as well as other high value elements.

Treatment of the insoluble solids will necessarily be directed towards the removal of one or more of these key components. However, only a limited number of treatment options are available, and all are sensitive to variations in the mineral composition of the tanks. While it is possible that a single treatment of the waste will achieve the necessary partitioning of key components, more than one process will likely be necessary. Because of the significant potential benefits, the beneficiation, dissolution, and roasting technologies should be thoroughly explored to determine the optimum waste treatment scheme. For beneficiation and roasting, much of the initial research can be accomplished by obtaining a detailed characterization of the 
mineral composition of the SST waste. For dissolution technologies, extensive laboratory research will be needed to evaluate alternative leaching and dissolution techniques both individually and in combination.

The main issue associated with nitrate brine involves the enormous quantity of nitrate and nitrite contaminated with very soluble cesium and technetium compounds. The presence of the latter two compounds creates an enormous volume of low level waste (LLW). All three components are undesirable from the standpoint of the leaching characteristics of grout. Conversely, the large volume of sodium nitrate offers an opportunity to be recovered and purified in order to reduce the volume of LLW, improve the properties of the grout, and produce a significant byproduct credit.

There are a number of processes available for removing specific contaminants from the nitrate brine. However, these processes become somewhat limited for technetium and cesium. A literature search directed toward these elements may produce more appropriate processes. For recovering the nitrate, either as sodium nitrate or nitric acid, crystallization and a combination of sulfuric acid addition and evaporation offer potential. It is recommended that laboratory research be conducted to evaluate the suitability of these iwo processes. Calcining, incineration, and high temperature water treatment may be used to improve the waste by destroying the nitrate. While these technologies do not necessarily reduce volume they would result in a less leachable grout by destroying nitrate, which is very mobile, as well as organics, which could inhibit the performance of grout. These technologies should be investigated as alternatives to the treatment of the nitraie brine.

\subsubsection{Secondary Waste Streams}

In general, the issues associated with the sodium nitrate salt and aqueous slurry waste streams are the same as the insoluble sludge and nitrate brine described above. Similarly, it appears that treatment options discussed above would generally apply to these waste streams. Therefore, the above research recommendations should be extended to these waste streams as they are identified. 
The primary issue associated with the aqueous waste streams is the need to both selectively separate and concentrate key components such as TRU, Sr, Cs, and Tc, as well as others depending on the specific objective. Particular attention needs to be paid to concentration because the initial concentrations of most of the key components are expected to be very low (on the order of $10 \mathrm{ppm})$. As a result, the volume of new waste streams generated that contain the separated components will depend on the concentration achieved in each process. Therefore, further research should be directed towards the development of those processes that offer the opportunity for improved concentration. The promising techniques include freeze crystallization; recent advances in solvent extraction, using thermally unstable complexants (TUCS) and transport facilitated membranes; and adsorption/ion exchange materials and techniques, such as those using molecular recognition technology. The latter two techniques also offer potentially significant improvements in the selectivity of separation for key components. Another traditional technology that may also warrant consideration is chemical reduction, which includes cementation and electrochemical reduction techniques. This technology has the potential to recover heavy metals in forms suitable for a variety of metallurgical purification techniques.

A second issue associated with the secondary waste stream is the presence of a number of organic compounds that interfere with many of the processes and with the performance of the grout. Chemical oxidation technology, including electrochemical oxidation techniques, warrant further investigation. The high temperature water treatment processes, such as wet air oxidation and catalytic destruction, may also warrant further review because of their potential for destroying both organics and nitrates by converting them to nonhazardous gases.

\subsubsection{Tertiary Waste Streams}

The main issue associated with the tertiary waste streams is the potentially large quantity of water used for pr essing that may require final treatment before it can be discharged to the environment. Contaminants may include any of the major components present in the SST waste, as well as new chemicals added in the treatment of the waste. While these wastes have a much 
lower safety and health risk than the other waste streams, successful treatment strategies are just as important. The treatments that appear to offer the greatest opportunity are the adsorption/ion exchange and the biological processes. Recent advances have been made in these processes, and both can be tailored to the types of wastes anticipated. Other innovative techniques such as the use of facilitated transport membranes in solvent extraction may warrant consideration should they show promise in achieving the necessary degree of concentration in the treatment of secondary wastes.

\subsection{GENERAL CONCLUSIONS AND RECOMMENDATIONS}

The various technologies could have been more rigorously evaluated if more substantive information had been available on the SST components. Consequently, it is recommended that further tank characterization include data regarding specific compounds, minerals, and physical characteristics.

While there is some data available regarding the presence of specific elements and isotopes in the SSTs, there is an absence of data on the specific compounds present based on actual samples. These data would particularly be critical for any of the processes that treat the insoluble solids in the tanks because the treatment processes are often sensitive to the mineral composition of the waste. In particular, the specific mineral compounds and crystal size determine the physical properties of the key components such as magnetic susceptibility and specific gravity, which are used in beneficiation processes to achieve separation. Similarly, the suitability of certain acids and other extractants for the dissolution of specific compounds from the solids is often sensitive to the presence of other compounds. In mineral processing this factor often determines whether a mineral can be recovered from the ore. For SSTs, it may determine whether a treatment strategy for the insoluble solids should be directed towards removal of TRU and $\mathrm{Sr}$ in order to decontaminate the bulk of the solids or instead only remove undesirable compounds in order to improve the properties of the final waste form (glass).

The literature search further demonstrated that certain treatments are specific to an individual element or compound. However, descriptions of technologies often overlook these special applications. A typical example 
would be the use of $\mathrm{HCl}$ to precipitate silver cations. This process is unique because $\mathrm{HCl}$ is usually used to dissolve metals. Similar unique processing can be found for a number of elements which may be of concern in the tanks. It is recommended, then, that as an eiement is identified as requiring removal, a Titerature search be conducted specific to that element to define both standard and unique processes, as well as any unique problems that ma:' occur from the presence of other compounds.

Assessing the cost, safety, and health considerations for the various technologies also depencis on more individualized information. It appears that once a decision is made to pretreat the SST waste a number of processes will be required to treat the various secondary and tertiary waste streams that invariably will be produced. However, without knowing the interactions of these processes it is not possible to determine cost, health, or safety or ho' to reduce the problem caused by a primary treatment step. This problem will be compounded by the significant variability of tank constituents for the various tanks. Specifically, variations in tank composition can affect the need for certain processes, as well as determine their size and the operating parameters required to obtain a desired level of treatment. This in turn will affect the volume and composition of the secondary and tertiary waste streams and waste to be disposed of and the associated cost and risk involved. Therefore, it is recommended that systems studies be conducted is treatment objectives are identified in order to better assess the impact of various treatment alternatives. 


\subsection{OVERVIEW OF SST WASTE PROCESS STREAMS AND TREATMENT TECHNOLOGIES}

This section summarizes the components of the SST wastes, the process streams expected to be generated during treatment, and the 19 candidate treatment technologies that were identified as applicable to the SST wastes.

\subsection{SST COMPONENT CATEGORIES}

The major chemical constituents and radionuclides were grouped into component categories, which served as the basis for evaluating the applicability of treatment technologies. These groups are transuranics, strontium, cesium, technetium, uranium, heavy metals, sodium nitrate, organics, and other constituents. Water is not treated as a component category but as a major characteristic of the process streams described next.

The component category names are based on major component(s) in the category but in many cases contain other components with similar chemical characteristics. Each of these categories is described below. Additional information regarding potential chemicals of concern that was used in developing these categories is provided in Appendix $A$.

\subsubsection{Trailsuranics}

This waste category also includes samarium-151 because of its similar chemistry and the likelihood that it will not intentionally be separated from TRU in most processing of the TRU fraction. This category is anticipated to be entirely in the suspended solids of the initial stream. While average concentration of TRU waste is less than $100 \mathrm{ppm}$ in the SST waste, the desirability to separate it from the waste to minimize the total quantity of waste requiring disposal as TRU waste may justify consideration of recovering the individual isotopes as recyclable products.

\section{1 .2 Strontium}

Strontium is expected to be in the suspended solids of the initial waste. Its contribution to radiation levels would likely justify its separation from the sludge. 


\subsubsection{Cesium}

Cesium is expected to be ill the aqueous phase of the initial waste (except for wastes treated by nickel-ferrocyanide precipitation), and all subsequent processing for separation of other chemicals. Its contribution to radiation levels would likely justify its separation from the aqueous streams.

\subsubsection{Technetium}

Technetium is expected to be in the aqueous phase of the initial waste and all subsequent processing for separation of other chemicals. Its toxicity and adverse mobility in grout may justify its removal from the aqueous streams.

\subsubsection{Uranium}

Uranium is expected to be in the sludge of the initial waste and is generally expected to follow TRU in subsequent processing to separate TRU from nonradioactive components. There are approximately 1400 metric tons of uranium associated with the sludge in the SST waste (DOE 1987). This accounts for about $0.8 \%$ of the total tank contents and $2.6 \%$ of the sludge, which is well above levels found in commercially processed ore (Kent 1983). Therefore, it should be considered for separate recovery as a recyclable product if the opportunity arises. With an upper value of $\$ 30 / 1 \mathrm{~b}$, uranium in the tanks could represent $\$ 90$ million in byproduct credit.

\subsubsection{Heavy Metals}

This category includes all toxic heavy metals and selenium, as well as nonhazardous metals such as bismuth and iron. Radioactive isotopes of heavy metals such as tin-126, nickel-63, and cobalt-60 will also be included in this category. Heavy metals are expected to be predominantly in the suspended sludge with concentration in the aqueous phase dependent on complexant concentrations of the initial waste. Heavy metals are expected to collectively follow similar separation processing although specific chemistry could vary. Estimates made in an ongoing PNL study by P. F. Salter, N. K. Nakaoki, and G. A. Whyatt suggest that chromium could be present in quantities exceeding 700 tons and silver exceeding 600 tons. Collectively their value would be about $\$ 10$ million as byproducts. 


\subsubsection{Sodium Nitrate}

Both sodium nitrate and sodium nitrite are expected to be in the aqueous phase of the initial waste. There are approximately 130,000 tons of sodium nitrate in the SSTS (DOE 1987). Sodium nitrate valued at $\$ 200 /$ ton would represent up to $\$ 25$ million of byproduct credit.

\section{1 .8 Orqanics}

Solvents, extractants, complexants, organometallic compounds, cyanides, and ammonium compounds are all included here. These materials are expected to be distributed predominantily in the aqueous phase.

\subsubsection{Other Constituents}

This category encompasses those constituents of concern that do not belong to one of the other categories. Included are major constituents such as $\mathrm{F}, \mathrm{Mg}, \mathrm{PO}_{4}, \mathrm{Si}$, and $\mathrm{Al}$ that may have potentially adverse effects on the waste forms for disposal. Radioactive iodine and carbon also fall within this category because of regulatory concern. In general all of these components will respond to the same types of processes as the heavy metals because they are often found in the same compound. However, specific processes would be dependent on the mineralogy found within the tanks. Although sodium is mainly associated with the sodium nitrate category, many insoluble minerals containing aluminum and silica may also contain sodium. Sodium associated with these insoluble minerals is included within this category.

\subsection{ANTICIPATED PROCESS STREAMS}

The applicability of many of the technologies to treating the component categories is constrained by a number of key parameters such as the presence and quantity of suspended solids and certain dissolved solids, as well as the concentration of specific components to be treated. As a consequence, nine generic waste streams were defined to represent the range of characteristics anticipated in process streams generated by treatment of the retrieved waste and any other subsequent treatment processes. These waste streams were grouped into three categories as follows: 
- Primary Waste Streams

initial waste

insoluble sludge

nitrate brine

- Secondary Waste Streams

aqueous waste

sodium nitrate salt

aqueous slurry

- Tertiary Waste Streams

tertiary wastewater

flue/residual gas

process solids/sludge.

The primary waste streams include the initial waste retrieved from the SSTs and the two principal components of this waste stream. They are considered as primary waste streams because collectively they must be treated in any treatment scheme whose objective is to partition the major components. The three secondary waste streams represent the types of waste streams produced from treatment of the primary wastes or from one or more of the secondary waste streams. The tertiary waste streams represent the solid, liquid, and gaseous wastes that result from the treatment processes but which require additional treatment before they can be discharged to the enviroriment. Each of these waste streams is described below.

\subsubsection{Primary Waste Streams}

\section{Initial Waste}

The initial waste form is defined as an alkaline brine slurry of sludge and dissolved salt cake. The waste stream would contain all tank constituents, including organics. The main characteristics of this waste stream are that it essentialiy contains an aqueous sodium nitrate solution, with organics; all soluble inorganic species; and a significant quantity of suspended solids that have been ground to a size acceptable to primary treatment process requirements. This waste stream does not place prerequisites on the actual characteristics of the waste as it is removed from the tank. If a nonaqueous method of removing the tank contents is used, then the initial waste stream, as defined here, would need to be pretreated to dissolve the soluble 
components. Similarly, grinding and sizing the insoluble fraction to achieve a specific particle size for the slurry could be done outside the tank as a pretreatment.

\section{Insoluble Sludge}

The insoluble sludge is defined as those solids recovered from the initial waste following filtration and a water wash. It is assumed that the sludge is relatively free of nitrates, organics, cesium (except for sludge containing nickel-ferrocyanide), and technetium. The principal components associated with this fraction of the waste are the TRU, uranium, strontium, heavy metals, and many of the other constituents such as aluminum, phosphate, and silica.

\section{Nitrate Brine}

The nitrate brine is defined as the initial waste that has undergone treatment to remove a 17 suspended solids in order to meet subsequent treatment process specifications. This stream can be further specified in that organics may have previousiy been removed. The key characteristic of the waste is that it is primariily a sodium nitrate solution containing dissolved solids.

\subsubsection{Secondary Waste Streams}

\section{Aqueous waste}

This stream has been defined to include any waste stream generated in such a way that the nitrates have been removed. This would include the aqueous effluent from any process that treated the nitrate brine so that the nitrates were destroyed or separated from the dissolved aqueous portion of the stream. It would also include the effluent from a number of a secondary aqueous waste stream treatments that generate a nitrate-free aqueous solution containing dissolved solids and/or organics in solution.

\section{Sodium Nitrate Salt}

This stream is defined as a relatively "pure" solid sodium nitrate product produced through crystallization or evaporation following purification as a solution. A key characteristic other than being in solid form is that it is considered to contain only trace or undetectable amounts of contamination. 


\section{Aqueous Slurry}

This stream represents any of a number of potential process streams in which solids are present either due to undissolved sludge or from biological processes, precipitation, evaporation, or distillation. Organics may or may not be present.

\subsubsection{Tertiary Waste Streams}

\section{Tertiary Wastewater}

Tertiary wastewacer is defined as any aqueous waste stream that has undergone treatment to remove organics, suspended and dissolved solids, and nitrates but is not yet suitable for discharge to the environment because certain hazardous or radioactive components remain in residual amounts. Included within this category are process water such as evaporator condensate that is separated from a contaminated stream but still contains residual amounts of contamination. This stream has been included to recognize that SST waste processing may produce a large volume of process water that must be disposed of but still contains low levels of contamination.

\section{Flue/Residual Gas}

This stream represents any gaseous stream produced in a process which must eventually be discharged to the atmosphere. For example, processes that decompose organics or nitrates can be expected to produce a gaseous waste stream. Since most treatment technologies are unique for gas streams, they are discussed collectively in Appendix $E$.

\section{Process Solids/Sludge}

This stream represents any waste stream that has been treated to the point where it can be used as feedstock for disposal or can be recycled as a byproduct. Also included are contaminated solids such as spent adsorbents and ion exchange materials that also must be disposed. For the purposes of this study this stream is not considered for further treatment. However, it is recognized that some solids and sludges may not require disposal as a radioactive waste and thus other disposal options may be available. 


\subsection{CANDIDATE TREATMENT TECHNOLOGIES}

Nearly 150 different processes were identified from the literature review that could be applicabie to the treatment of SST wastes. However, many of the processes shared similar objectives and engineering features. Those processes that shared similar features were grouped into one technology. Once the processes were grouped together, 35 technologies were identified for treating liquid and solid hazardous wastes and radioactive waste.

Each of the 35 technologies was then screened to el iminate those that did not appear applicable to either the anticipated waste streams or to the contaminants identified. Nineteen technologies were ultimately retained for further evaluation. These technologies are listed below:

- dissolution

- beneficiation

- liquid phase particle separation

- solvent extraction

- adsorption/ion exchange

- membrane separation

- precipitation

- bioaccumulation

- biodegradation

- crystallization
- freeze crystallization

- evaporation

- chemical oxidation

- chemical reduction

- high temperature water treatment

- roasting

- calcining

- incineration

- moiten solid separation.

A description of each of these technologies and an evaluation of their applicability to the treatment of SST waste is given in Section 4.0, along with cost information and opportunities for process improvements. The suitability of these technologies to the SST components is summarized in Table 3.1. The applicability of these technologies to the primary, secondary, and tertiary waste streams is summarized in Table 3.2. Safety issues are considered separately in Section 5.0. Technologies that were eliminated are described in Appendix B. Flue/residual gas treatment is described in Appendix E. Process solids and sludge are assumed to have met the necessary requirements for disposal and are not considered. 


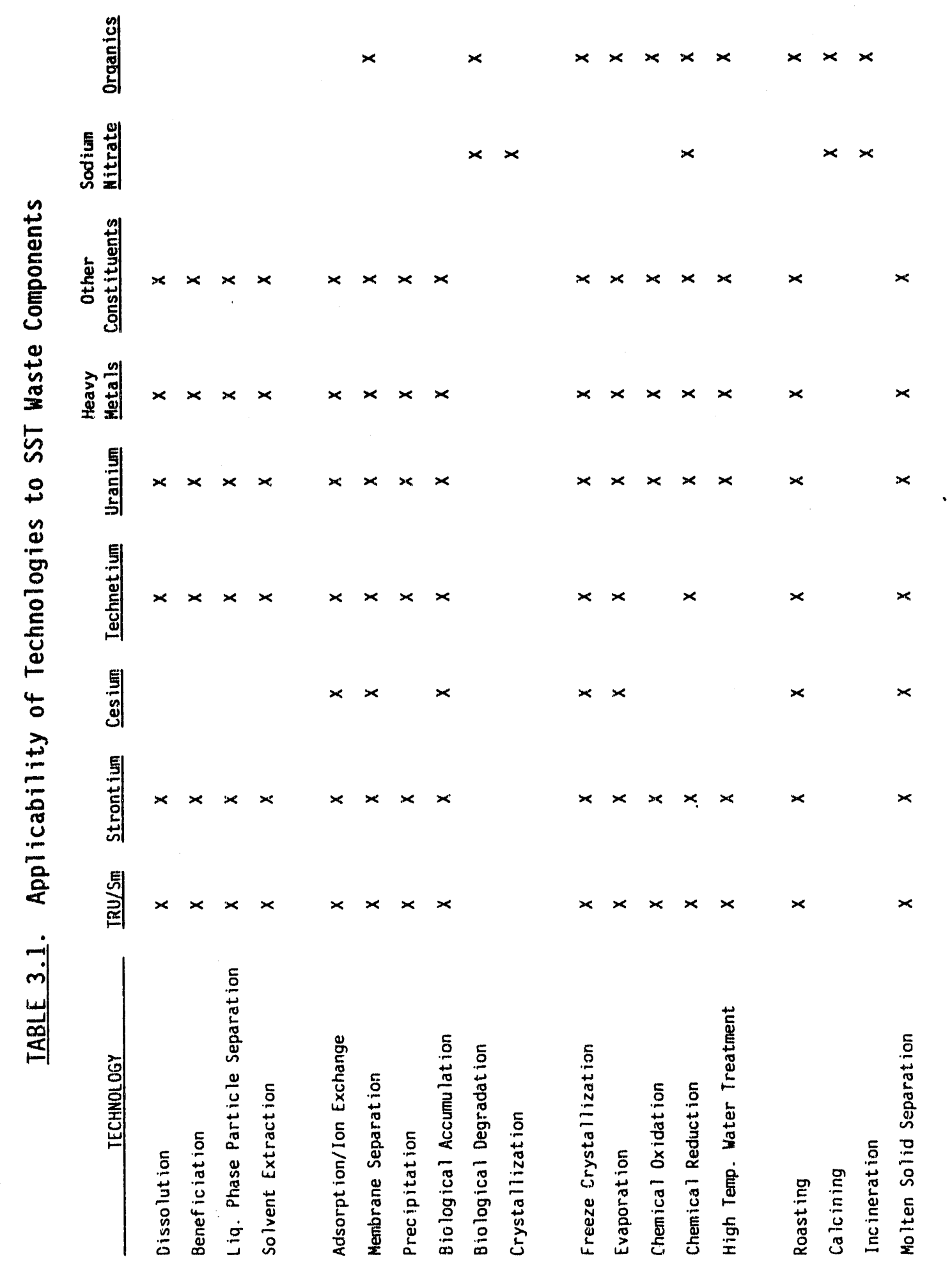

3.8 


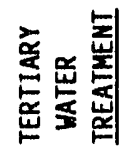

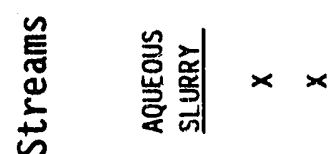

离

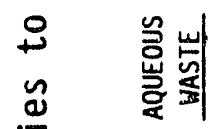

8

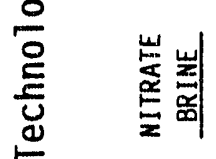

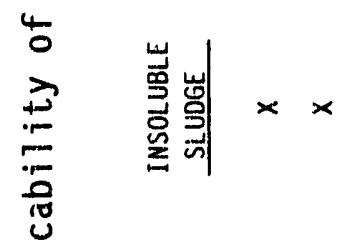

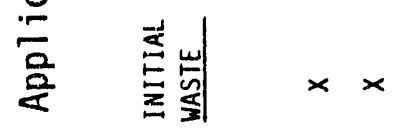

ํ.

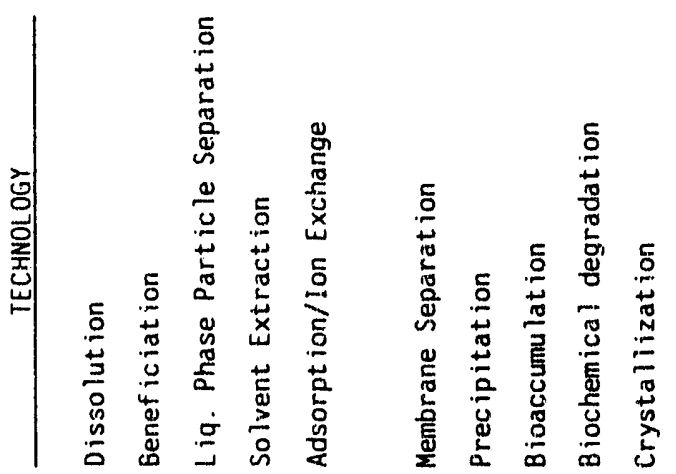

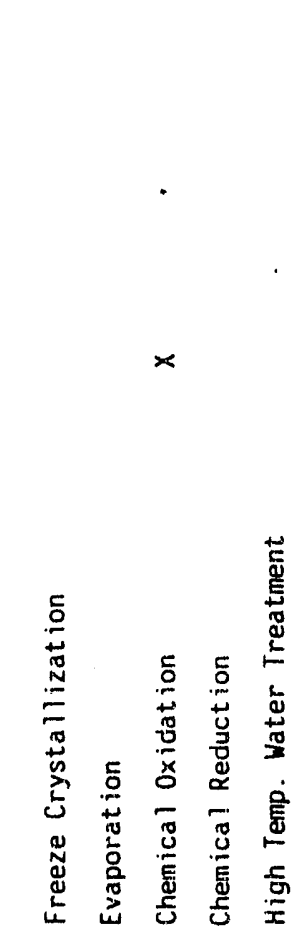
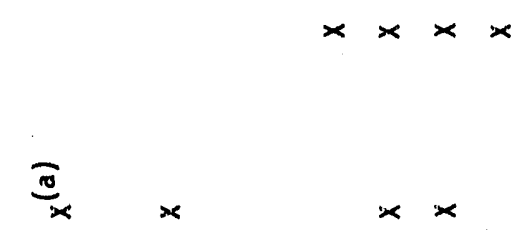

$x \times x x$

$x$

$x \times x \times x \frac{\frac{0}{4}}{\frac{4}{3}}$
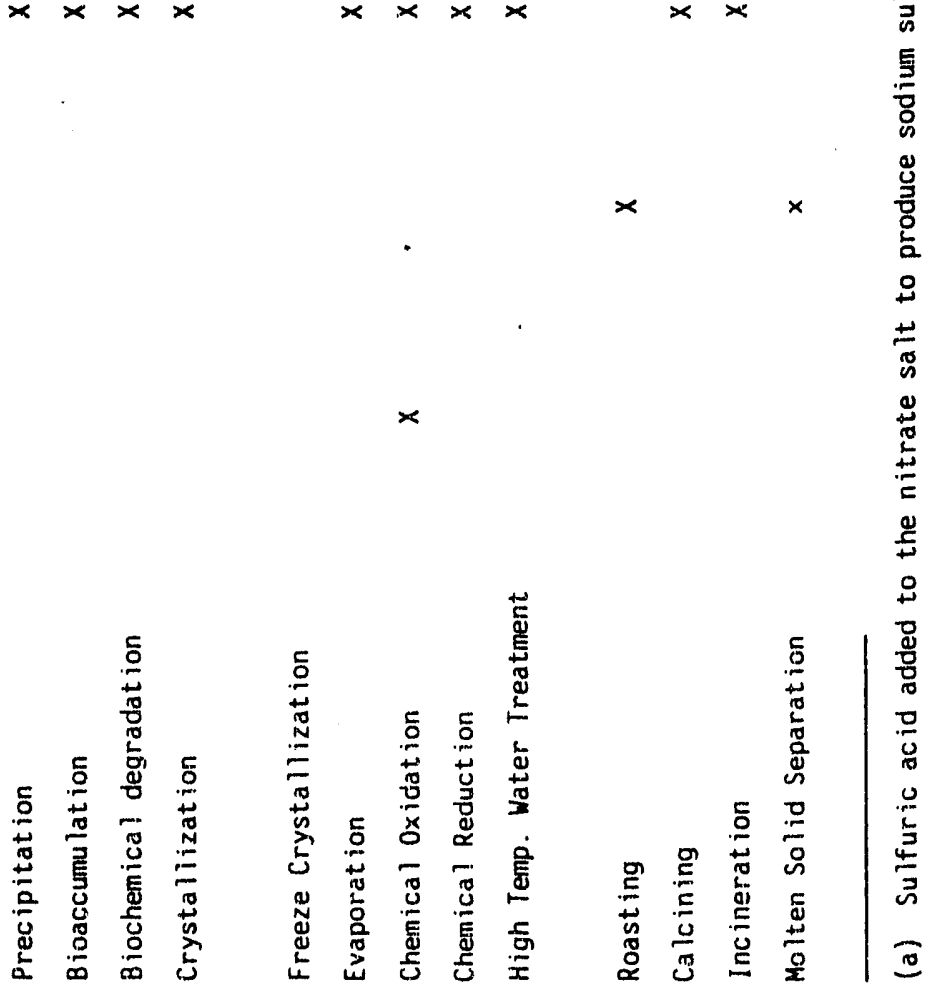

3.9 


\subsection{REFERENCES}

Kent, J. A. 1983. Riegel's Handbook of Industrial Chemistry. Van Nostrand Reinhold Company, New York.

U.S. Department of Energy (DOE). 1987. Environmental Impact Statement Disposal of Hanford Defense High-Level Transuranic and Tank Wastes, Volume 2. DOE/EIS-0113, Washington, DC. 


\subsection{DESCRIPTION OF TECHNOLOGIES}

The 19 technologies identified as potentially applicable to SST wastes are further described in this section. For each technology, the discussion contains five elements:

1. description of each process included within the technology, as well as the major variations of the process

2. assessment of the applicability of each technology to the treatment of SST waste

3. typical processing cost for each technology where available

4. opportunities for improvements where possible

5. references pertaining to the individual technology.

\subsection{DISSOLUTION}

Dissolution is a process in which all or specific components of a solid are dissolved and subsequently converted to a homogeneous fluid phase. Selective dissolution can alternatively be known as leaching or solid liquid solvent extraction.

\subsubsection{Process Description}

In selective dissolution processes, a solvent that may contain a separate extractant is brought into contact with a solid to cause certain compounds to preferentially be extracted from the solid and into the solvent. The loaded solvent is then separately processed in a stripper to regenerate the solvent and produce a second stream, which contains the separated components. Complexing agents may be added to facilitate leaching or the $\mathrm{pH}$ may be adjusted to alter the solubility of the minerals of concern. Alternatively, oxidizing agents may be added to convert certain elements into a higher, more soluble oxidation state (De Renzo 1978). This latter method is the basis of the Catalyzed Electrochemical Plutonium Oxide Dissolution (CEPOD) process being developed at PNL for treating LLW (Wheelwright, Bray, and Ryan 1988).

The advantage of selective dissolution is that good selectivity for specific components can often be accomplished. One disadvantage is that 
selectivity may be degraded to obtain sufficient decontamination of the remaining solids. Also, dissolution requires the addition of chemicals with the solvent in the form of complexing agents, acids, or caustic to obtain the proper leaching capabilities. Neutralization of caustic and acids will add to the total mass of solids needing further treatment and disposal. Complexing agents can interfere with many subsequent separation operations and may need to be removed and/or destroyed.

\subsubsection{Applicability to SST Waste}

Selective dissolution is considered a primary candidate for separating TRU from the insoluble sludge. In fact dissolution technically applies to water washing the sludge to remove any residual soluble components prior to dissolution to remove TRU. Dissolution of the insoluble sludge can also aid in removing other components (e.g., phosphates) from the sludge to improve its properties as a feedstock for a particular disposal form. Dissolution may have further application in selectively leaching heavy metals and/or radioactive materials from precipitates. For example, the solubility of hydroxidebased precipitates is significantly different for a number of heavy metals at different $\mathrm{pH}$ values and the differences in solubility can be used to recover individual components.

\section{1 .3 Cost}

Typical process costs are expected to range from about $\$ 50 /$ ton to $\$ 120 /$ ton (De Renzo 1978). Dissolution costs are very sensitive to the price of reagents required to process the solids, accounting for $30 \%$ to $70 \%$ of the total processing cost.

\subsubsection{Opportunities for Process Improvement}

Dissolution is already a well-developed technology. The areas of improvement for SST waste involve the identification and optimization of dissolution techniques to the specific mineralogy of the tank solids, as well as the specific components to be removed. The development and adaptation of novel dissolution techniques such as CEPOD might improve the decontamination of the remaining solid while retaining a high degree of selectivity. Arather area of opportunity lies in developing solvent systems that can easily be 
treated to remove or destroy complexants should they be used, or to avoid generation of additional salts needing further treatment. One class of solvents called TUCs (thermally unstable complexants) currentiy undergoing development in solvent extraction processes may have application in dissolution applications. TUCs are discussed in more detail under solvent extraction.

\subsubsection{References}

De Renzo, D. J., ed. 1978. Unit Operations for Treatment of Hazardous Industrial Wastes. Noyes Data Corp., Park Ridge, New Jersey.

Wheelwright, E. J., L. A. Bray, and J. L. Ryan. 1988. Development of the CEPOD Process for Dissolving Plutonium Oxide and Leaching Plutonium from Scrap or Wastes. PNL-6483, Pacific Northiwest Laboratory, Richland, Washington. 


\subsection{BENEFICIATION}

Beneficiation is a term given to a process used in extractive metallurgy, whereby an ore is concentrated in preparation for further processing such as smelting. This category includes hydraulic concentration, magnetic separation, dense media separation, and flotation. Also included are operations such as milling and grinding, screening, and hydrocyclonic classification. These processes are not considered in this section because they deal primarily with size reduction and classification. Roasting and calcination processes are sometimes included in this category; however, these processes are treated separately in Sections 4.16 and 4.17 , respectively.

\subsubsection{Process Description}

There are four major beneficiation process categories that are ured to process solids in aqueous slurries:

- hydraulic concentration

- magnetic separation

- dense media separation

- flotation.

Each of these categories is discussed below.

\section{Hydraulic Concentration}

Hydraulic concentration includes a variety of well-developed processes that separate minerals by using flowing water according to differences in particle size and density. In general, these technologies provide only a moderate level of separation because of the interdependence of both size and density. Thus, very distinct differences must exist between the components to be concentrated and the remaining material.

The three principal hydraulic concentration processes are jigs, concentration tables, and Humphrey's spiral classifiers. A simple jig is a slightly inclined box that has water pulsing up from its bottom. The pulsing water causes the solids to stratify according to density. The lighter material cascades over a weir at the lower end of the incline with the water. The 
heavy material is collected at the weir and removed as bottom material. Jigs perform best on material coarser than abrut 20 mesh $(841 \mu \mathrm{m})$ and only provide a relatively crude degree of separation on -65 mesh $(210 \mu \mathrm{m}$; Jigs typically require 1500 to $2500 \mathrm{gal}$ of water per ton of material (Perry and Chilton 1973).

Concentration tables typically consist of a flat surface covered with sheet rubber or linoleum and fitted with a series riffles (parallel wood or rubber strips attached to the surface). The table is tilted both transversely and longitudinally relative to the strips or grooves. The table is shaken longitudinally in a manner to move the particles down the length of the table. Slurry is introduced at the highest portion of the table. Water introduced $f$ om the higher side of the table washes lighter material across the table to tne lower side. The heavier material collects along the riffles and moved towards the far end of the table. Concentration tables process material ranging from 6 to 150 mesh ( 3360 to $105 \mu \mathrm{m}$ ) and consume approximately 1400 gal of water per ton of material (Perry and Chilton 1973).

Humphrey's spiral is a flowing film gravity concentrator consisting of a channel with a curved cross section spiraling down a vertical axis. Smaller heavy particles settle in the bottom of the channel, while lighter and larger particles ride up the outer side of the channel. Ports set at intervals in the bottom of the channel draw off the heavy concentrates or middlings (drawn off toward the bottom of the spiral), while the lighter particles discharge at the bottom of the spiral. Wash water is added continuously down the spiral to replenish the slurry. This method has been successfully used to recover chromite, monzanite, ilmenite, rutile, zircon, tin, and iron ore minerals from beach sand; hard rock iron ores; mica and phosphate ores; tailings from concentrating $p l a n t s$ (flotation and magnetic separation) that contain heavy minerals; and some coal fractions. Humphrey's spiral is typically used to process material ranging in size from 10 to 200 mesh (1680 to $74 \mu \mathrm{m}$ ) (Perry and Chilton 1973). Typical water requirements are about $900 \mathrm{gal} / \mathrm{ton}$ of material.

All three types of hydraulic concentrators have relatively large capacities. Jigs handle about 2 tons $/ \mathrm{h} / \mathrm{ft}^{2}$ of screen area and can be built in sizes 
as large as $80 \mathrm{ft}^{2}$. Concentration tables typically process about

0.02 tons $/ \mathrm{h} / \mathrm{ft}^{2}$ of table surface and are built as large as $136 \mathrm{ft}^{2}$ of surface. Spiral concentrators that typically process 1.5 tons $/ \mathrm{h}$ are $7 \mathrm{ft}$ high and occupy about $4 \mathrm{ft}^{2}$ of floor space, which is equal to 0.38 tons $/ \mathrm{h} / \mathrm{ft}^{2}$ (Perry and Chilton 1973).

\section{Magnetic Separation}

Magnetic separation includes conventional magnetic and high gradient separation (HGMS) processes. Conventional magnetic separation techniques remove a limited number of ferromagnetic materials, such as magnetite, and are considered to have only a low probability of application to SST wastes.

HGMS uses high intensity magnetic fields to separate both ferro- and para-magnetic materials from diamagnetic materials. Paramagnetic (weakly, magnetically attracted) materials include several compounds containing $\mathrm{Cu}$, $\mathrm{Cr}, \mathrm{Ni}, \mathrm{Fe}, \mathrm{Mn}, \mathrm{Ce}, \mathrm{Co}, \mathrm{Pu}, \mathrm{U}$, and Am (Weast 1985). Materials containing nitrates, sulfates, and phosphates of aluminum, sodium, bismuth, and zirconium are generally considered to be diamagnetic (magnetically repelled).

HGMS is best applied to very fine particles ranging from 1 to $100 \mu \mathrm{m}$ in diameter, with an optimum diameter of $30 \mu \mathrm{m}$ (De Renzo 1978). HGMS has also been used to separate solids from aqueous slurries produced from precipitation and/or coagulation using ferrous compounds. Advantages for HGMS are high capacity (6 to $1000 \mathrm{gpm}$ with $15 \%$ solids) and relatively simple design and operation. The main disadvantage is that particles may contain only a small portion of paramagnetic material causing net magnetic susceptibility of the particle to be correspondingly lower.

\section{Dense Media Separation}

Dense media separation is a sink-float method of gravity separation in which a finely ground dense material such as magnetite is mixed with water to produce a slurry that closely duplicates a true heavy liquid with a specific gravity that can be varied from 1.25 to 3.4. Dense media separation is limited to particles larger than 65 mesh $(210 \mu \mathrm{m})$ (Currie 1973). However, it is capable of separating particles differing in specific gravity by as little as 0.005 (Perry and Chilton 1973). Separation efficiencies above $90 \%$ can be 
obtained (American Cyanamid 1953). The advantages of dense media separation are its ability to separate materials of only slightly different specific gravities and its high capacity $(20$ to 200 tons $/ h)$. A disadvantage is that relatively large particle are required that may preclude efficient separation in SST wastes. This can only be determined by analysis of SST sludge.

\section{Flotation}

In the flotation process, a target mineral is separated from a slurry by creating conditions in which it selectively attaches to air bubbles passing through the siurry and collects in a froth at the surface. Flotation generally involves several steps. The ground solid mixture of minerals is slurried with water or an organic to a consistency ranging from $25 \%$ to $45 \%$ solids by weight (Currie 1973). Small quantities of surfactant chemicals are added to the slurry to modify the surfaces of a specific mineral. Another reagent is added to coat the mineral with a hydrophilic surface. A third reagent assists in establishing a stable froth at the surface. Air is then added by agitation or injection and the mineral-bearing froth rises to the surface where it is skimmed off.

Flotation is considered to be the principal means for concentrating many metal ores, including copper, silver, and nickel. Generally, flotation has been developed for processing sulfides of these minerals and would not be directly adaptable to SST wastes. It is generally applicable to particles ranging from 5 to $210 \mu \mathrm{m}$ (65 mesh) in diameter (Currie 1973). The main advantages of the technology are its large capacity (500 to 10,000 ton/day) and its tolerance of alkaline environments. One disadvantage of flotation is the need to add organic and inorganic compounds which could present a new environmental hazard. Also, flotation is usually used in ore that has only a few specific minerals to remove.

\subsubsection{Applicability to SST Waste}

Of the beneficiation technologies, HGMS offers the best opportunity for application to SST wastes. Its application may be directed towards the sep. aration of and concentration of minerals containing TRU elements or else to 
the separation and concentration of diamagnetic materials, such as the phosphate- and zirconium-containing compounds.

Humphrey's spiral and dense media separation also appear to offer opportunities for application to SST. However, selectivity for a specific mineral based on size and/or density may be less pronounced than its magnetic susceptibility. Thus, there is uncertainty whether suffirient specificity to target minerals can be obtained in a mixture as complex as SST waste. Flotation appears to have the least applicability because of the limitation on the number of minerals it can remove simultaneously and because of the need for additional organic rhemicals.

Suitability of all four of the beneficiation processes is contingent upon the mineral character of the SST sludge. Each process depends on differences in one or more physical properties to achieve a separation. However, achieving these differences depends on the specific mineral composition and crystal size obtained relative to the size of particles treatable by each process.

\subsubsection{Cost}

Humphrey's spiral has a process cost ranging from $\$ 0.04$ to $\$ 0.06 /$ tion of solids (Perry and ChiTton 1973). HGMS has a process cost ranging from $\$ 1$ to $\$ 5 / 1000 \mathrm{gal}$ (De Renzo 1978). Dense media has a process cost ranging from $\$ 4$ to $\$ 6 /$ ton (Perry and Chilton 1973 ). Flotation has a process cost ranging from $\$ 0.65$ to $\$ 2.40 /$ ton (De Renzo 1978).

\subsubsection{Opportunities for Process Improvement}

All of the above beneficiation technologies are considered to be mature technologies in which limited opportunities exist for improvements within the context of their current applications. In the context of SST waste solids, there is considerable opportunity for achieving a practical application through research. Research would have to be fairly broadly based in perspective because of the many different classes of elements that could be separated and concentrated. This research would need to characterize SST tank mineralogy to identify areas of opportunity as well as process research to adapt these technologies to the mineralogy of the tanks. 


\subsubsection{References}

American Cyanamid Company, Mineral Dressing Division. 1953. "Heavy-Media Separation Processes for Mineral Concentration." Mineral Dressing Notes, No. 19. New York.

Currie, J. M. 1973. Unit Operations In Mineral Processing. Best-Printer Co. LTD, Vancouver, B.C.

De Renzo, D. J., ed. 1978. Unit Operations for Treatment of Hazardous Industrial Wastes. Noyes Data Corp., Park Ridge, New Jersey.

Perry J. H., and C. H. Chilton, eds. 1973. Chemical Engineer's Handbook, 5th ed. McGraw-Hill Book Co., New York.

Weast, R. C., ed. 1985. CRC Handbook of Chemistry and Physics, 66th ed. CRC Press, Boca Raton, Florida. 


\subsection{LIOUID PHASE PARTICLE SEPARATION}

Liquid phase particle separation technology encompasses processes that separate suspended solids from the liquid phase. This technology includes processes that range from treating very dilute concentrations of solids to dewatering sludge. These processes include: classifiers, screens and sieves, centrifuge, cake filters, granular bed (sand) filtration, sedimentation/ clarification, flotation, microfiltration, and ultrafiltration. of these processes, classifiers and screens and sieves are expected to be applied in the initial processing of the retrieved waste and are not considered here.

\subsubsection{Process Description}

Liquid phase particle separation will likely be required in the pretreatment of liquid waste streams to separate the suspended solids from the liquid. It is also required as a post-treatment to remove solids produced during any subsequent solution processing of the sludge as well as the separation of solids produced as a result of precipitation and/or coagulation/ flocculation processes.

\section{Cake Filters}

Cake filters encompass a variety of barrier filter devices in which the filtrate accumulated on a porous medium serves as the principal means for removing fine particulate. This category includes vacuum filters and filter presses. Once the pressure across the barrier exceeds a maximum value, due to solids accumulation, the filtrate is removed from the porous surface. Cake filters used in processing sludge are generally used for treating concentrated slurries containing suspended solids in the range of a few percent. The cake filter technology is very well developed and should not require significant further development at this time.

\section{Granular Bed Filters}

Granular bed filtration uses a bed of particles such as sand to serve as the filter medium. Like cake filters, the pressure drop through the bed builds up as particles are trapped on top of or within the bed. Therefore, it must periodically be backwashed to remove the filtrate. Consequently, granular bed filters are usually applied to wastewater containing $200 \mathrm{mg} / \mathrm{L}$ or less 
of suspended particles (De Renzo 1978). Typical effluent concentrations range from 2 to $20 \mathrm{ppm}$ (Freeman 1989). Granular bed filtration is considered a standard process for treating wastewater to remove suspended particles that may be toxic.

\section{Sedimentation/Clarification}

Sedimentation is a process whereby wastewater is passed through a basin in which suspended particles are allowed to settle by gravity and collect at the bottom. Clarified supernate is drawn off the top, and sludge is drawn from the bottom of the basin. Sedimentation processes where applicable can concentrate solids from $3 \%$ to $7 \%$ and achieve aqueous effluent suspended solids concentrations ranging from 20 to $50 \mathrm{ppm}$ (McArdle, Arozarena, and Gallagher 1987). Sedimentation is a well-developed technology used to concentrate dilute slurries to produce a "clean" aqueous stream and a concentrated slurry.

Centrifuges can also be used in clarification to remove solids with centrifugal force. A slurry introduced into the centrifuge is spun in a rotating drum or bowl forcing the solids to the wall. Clarified water is skimmed from the surface. Centrifuges can achieve solids concentrations ranging from $1 \%$ to $40 \%$ with solids recovery ranging from $85 \%$ to $97 \%$.

\section{Flotation}

Flotation, although generally considered along with beneficiation technologies for the concentration of ore, has been used in the removal of particulate from aqueous waste streams. It has also been applied in $011 /$ water separation systems. While very little information is available regarding this application it appears that the process is capable of reducing typical particulate loadings of 100 to $1000 \mathrm{ppm}$ down to 20 to $100 \mathrm{ppm}$ (EPA 1983).

\section{Micro-/Ultrafiltration}

Microfiltration and ultrafiltration may be well suited to improved removal of suspended particles particularly those in the less than $10 \mu \mathrm{m}$ range. Micro- and ultrafiltration are relatively new membrane separation technologies that achieve separation solely on the basis of size. U1trafil. tration uses the smallest pore size and is capable of removing particles as small as $0.002 \mu \mathrm{m}$ (EPA 1988). In this size range it is also suitable for 
removing colloidal particles and very large molecules. Microfiltration has a lower $1 \mathrm{imit}$ of about $0.03 \mu \mathrm{m}$. Processing capacities of micro- and ultrafiltration range from 20 to $600 \mathrm{gpm}$. An advantage of microfiltration is the ability to process influent suspended solids ranging from as low as $10 \mathrm{ppm}$ (California DHS 1989). The treated aquecus stream can achieve suspended solid levels as low as $1 \mathrm{ppm}$, while the concentrated stream can tolerate concentrations as high as 20\% (Cushnie, Crampton, and Roberts 1983).

\subsubsection{Applicability to SST Waste}

Liquid particulate filtration is expected to be needed to separate suspended solids from liquid in the initial waste and to follow any other process in which solids are treated. While the overall technology is well established, particular attention may need to be given to the removal of low concentrations of small particles that may lead to unacceptably high levels of radioactive components in the treated aqueous streams. For example, an aqueous stream containing $2 \mathrm{ppm}(2 \mathrm{mg} / \mathrm{L})$ suspended solids of Am-241 would contribute $6.5 \mathrm{Ci} / \mathrm{m}^{3}$ of radioactivity in addition to that produced by the dissolved solids in the stream. Similarly, a 50-ppm level would correspond. to over $160 \mathrm{ci} / \mathrm{m}^{3}$. Ultrafiltration and microfiltration appear to be the two processes within this technology that could be used to achieve the desired levels of suspended particles.

\section{3 .3 Cost}

Typical process costs for filtration technologies are as follows:

- Cake Filters - $\$ 5$ to $\$ 7 / 1000$ gal (De Renzo 1978)

- Granular bed (sand) filtration - \$1/1000 gal (De Renzo 1978)

- Sedimentation/clarification - < \$1/1000 gal (De Renzo 1978)

- Flotation - (Unavailable for this application)

- Micro-/Uitrafiltration - $\$ 5$ to $\$ 10 / 1000$ gal (De Renzo 1978)

\subsubsection{Opportunities for Process Improvement}

Although this technology is expected to have a role in the treatment of SST waste, there does not appear to be any areas in which significant 
improvement can be anticipated from additional research. SST solids do not offer any unique properties that would result in an innovative application of any of the processes.

\subsubsection{References}

California Department of Health Services (DHS). 1989. Site Cleanup Treatment Technologies. Summaries of Responses to July 1988 Solicitation of Interest, Sacramento, California.

Cushnie, G. C. Jr., P. Crampton, and C. G. Roberts, 1983. An Investigation of Technologies for Hazardous Sludge Reduction at AFLW Industrial Waste Treatment Plants; Volume II: Literature Review of Available Technologies for Treating Heavy Metal Wastewaters. ESL-Tr-83-42, Engineering \& Services Laboratory, Air Force Engineering and Services Center, Tyndall Air Force Base, Florida.

De Renzo, D. J., ed. 1978. Unit Operations for Treatment of Hazardous Industrial Wastes. Noyes Data Corp., Park Ridge, New Jersey.

Freeman, H. M., ed. 1989. Standard Handbook of Hazardous Waste Treatment and Disposal. McGraw-Hill Book Company, New York.

McArdle, J. L., M. Arozarena, and W. E. Gallagher. 1987. A Handbook on Treatment of Hazardous Waste Leachate, PIE Associates, Inc., Cincinnati, Ohio. EPA/600/8-87/006, Hazardous Waste Engineering Research Laboratory, Office of Research and Development, U.S. Environmental Protection Agency, Cincinnati.

U.S. Environmental Protection Agency (EPA). 1988. Technological Approaches to the Cleanup of Radiologically Contaminated Superfund Sites. EPA/540/288/002, Washington, DC.

U.S. Environmental Protection Agency (EPA). 1983. Treatability Manual Volume Three Technology for Control/Removal of Pollutants. EPA/600/2-82-001c, Washington, DC. 


\subsection{SOLVENT EXTRACTION}

Solvent extraction is a physical process in which two immiscible liquids are brought into contact by mixing, and certain dissolved components are preferentially extracted from one of the liquids and into the other. Solvent extraction is a well-developed technology for selectively separating and recovering radionuclides and heavy metals from aqueous mixtures. Solvent extraction can be used for either organic or inorganic compounds, but it is not anticipated that solvent extraction would be used for organics in the SST waste.

\subsubsection{Process Description}

In a typical solvent extraction process a solvent such as heptane is mixed with an aqueous stream containing trace amounts of key dissolved components (solutes) to be extracted, as well as other unwanted components. The heptane solution may serve as the extractant or it may serve as the carrier of a small quantity of a separate extractant that is soluble in heptane but not water. After agitation to facilitate intimate contact between the two solutions, the resulting emulsion is sent to a settling tank where the two solutions are allowed to separate by gravity. Extraction is achieved if the key components preferentially dissolve in the heptane.

The treated aqueous stream, called raffinate, may need further treatment to remove dissolved trace quantities of the extractant. The extract containing the heptane solvent and solutes is sent to a second process called a stripper, whereby the solutes are separated from the heptane in a second extraction step and the regenerated heptane is recycled back to the first solvent extraction step. Usualiy the solvent in the stripper is an aqueous solution in which the $\mathrm{pH}$ has been adjusted to increase solubility over that in the original aqueous solution.

The main advantage of solvent extraction is its versatility in both the variety of components that can be separated and the selectivity of the process for a single component or for more than one component. In the latter case, 
however, the separation efficiency may vary widely for the different components. In addition, solvent extraction can be applied over a wide range of concentrations.

An important disadvantage of solvent extraction is that concentration of the extracted components is limited to a factor of about 10 (Peters, $\mathrm{Ku}$, and Bhattacharyya 1985). Other limitations are listed below:

- As much as $0.1 \%$ of suspended solids can interfere with column performance or retain sorbed contaminants in the aqueous phase (Breton et a1. 1988).

- Emulsions/organic droplets can interfere with mass transfer of solute into solvent (De Renzo 1978).

- Surfactants can adversely affect the phase separation (De Renzo 1978).

- Adsorption of one species may inhibit the adsorption of another species.

Successful design and application of solvent extraction to selectively extract inorganic compounds such as heavy metals relies on the identification of extractants that can meet a number of criteria: 1) ability to extract the metal at the required $\mathrm{pH}$ with good selectivity for the desired metal and rejection of undesired metals, 2) favorable kinetics for extraction and stripping operations, 3) high solubility in the organic phase and low solubility in the aqueous phase, and 4) chemical oxidation stability.

\section{Conventional Extractants}

Solvent extraction processes are based on either ion exchange extractants or solvating extractants. Ion exchange extractants extract ions from the aqueous solution in exchange for a counter ion such as $\mathrm{H}^{+}$. In this application the process is sometimes called liquid ion exchange. Ion exchange extractants may be acidic or basic and capable of extracting metal cations or anions, respectively.

Solvating extractants are used to extract neutral metal complexes. Since there is no net charge on the metal extracted, no counter ion is involved. Solvating extractants may form an adduct with the complexed metal, causing the entire complex to be soluble in the solvent. An example of this 
type of extractant is tributylphosphate (TBP), which is used in the plutoniumuranium extraction (PUREX) process at Hanford to extract the uranium nitrate complex. The extractant may also form its own stronger complex with the metal, causing it to be soluble in the solvent. This latter type of solvating extractant is called a chelating extractant.

\subsubsection{Applicability to SST Waste}

Solvent extraction is a well-developed technology used extensively in the nuclear industry for the separation and recovery of radionuclides. It is considered to be a primary candidate for treating SST wastes. Two specific solvent extraction processes, developed by E. Philip Horwitz of Argonne National Laboratory, that have applicability to SST wastes are TRUEX (TRU extraction) and SREX (strontium extraction).

TRUEX is a modification of the PUREX process in which tributylphosphate modified by a small amount of octyl (phenyl)-N,N-diisobutylcarbamoylmethylphosphine oxide (abbreviated CMPO) is added as the extractant for removal of trivalent, tetravalent, and hexavalent actinides from the waste stream (Logsdail and Mills 1985). These dissolved ions in the solvent are then subjected to two sequential solvent stripping processes. In the first stripper the solute is extracted with a dilute nitric acid solution in which the $\mathrm{pH}$ has been adjusted to selectively recover americium. In the second stripper another extraction using a dilute nitric acid/hydrofluoric acid mixture is used to recover plutonium and neptunium. The remaining solutes, such as uranium, and degradation products caused by decomposition of the solvent are recovered in subsequent ion exchange and scrubbing processes.

SREX uses cis-bicyclohexane-18-crown-b as an extractant to selectively separate strontium from solution. This process would provide an opportunity for removing strontium from any aqueous waste stream, thereby reducing its contribution to the total radioactivity of the final waste form.

\subsubsection{Cost}

Typical solvent extraction process costs range from about $\$ 3 / 1000$ gal to $\$ 12 / 1000$ gal (De Renzo 1978). However, costs ranging from as 10 as $\$ 0.17 / 1000 \mathrm{gal}$ to as high as $\$ 30 / 1000 \mathrm{gal}$ have been reported (Breton et al. 
1988). The latter case is based on an estimate for a $90 \mathrm{gpm} \mathrm{plant} \mathrm{using} 10$ stages of extraction to reducing phenol content in wastewater from $1.5 \%$ to $21 \mathrm{ppm}$. Costs were based on an estimate of $\$ 21 / 1000$ gal for a plant producing $75 \mathrm{ppm}$ effluent and requiring five stages and a distribution coefficient of 2 .

Solvent extraction costs are generally high compared with adsorption processes for the more dilute streams, even though lower concentrations can favor separation. An upper 1 imit of about $10 \mathrm{~g} / \mathrm{L}$ of metal ions can be tolerated before the quantity of extractant required makes the process impractical.

\subsubsection{Opportunities for Improved Processing}

One disadvantage of solvent extraction is that while good separation and recovery can often be achieved, the resulting concentration of the pure component after stripping is generally limited to a factor of about 10 . Consequently, a new dilute waste stream is produced that must be further treated before disposal. Improvements in concentration of the pure components may be possible through the development of solvents and extractants that are amenable to more efficient stripping operations. Three innovative concepts that have recently been proposed are thermally unstable complexants (TUCS), supercritical solvents, and facilitated transport membranes.

\section{Thermally Unstable Complexants}

TUCS possess several unique properties that make them potentially useful in solvent extraction processes, for example, a large solubility in water; a strong affinity for complexing $+4,+3$, and to a lesser extent +2 metal ions in strongly acidic aqueous media; and readily degrade into innocuous substances when heated the presence of moderate oxidizing agents.

These properties are very desirable in the stripping portion of a solvent extraction process. By complexing the stripped components, the metals are effectively taken "out of solution" and the capacity of the stripper solution is significantly enhanced. By increasing the capacity of the stripping solution, the overall concentration factor of the solute components can be greatly increased. Alternatively, TUCs can be used as the stripping agent instead of adjusting $\mathrm{pH}$ to facilitate solubility, thereby eliminating the 
generation of a waste that must subsequently be neutralized. In either application the stripper solution, after loading, would be heated to decompose the TUCS to innocuous gases leaving behind uncomplexed dissolved ions that are more readily treated by precipitation or ion exchange.

\section{Supercritical Solvents}

Supercritical solvent extraction involves the use of fluids in a thermodynamic state above critical pressure and temperature so that separate gas and liquid phases do not exist. At these conditions supercritical fluids have the solvent characteristics of liquids combined with the high mass transfer characteristics of gases. Supercritical solvent extraction has been undergoing development for several years as a means for extracting organics from soils and aqueous streams. The primary solvent investigated has been $\mathrm{CO}_{2}$ with a critical pressure and temperature of $73.8 \mathrm{~atm}$ and $31.1^{\circ} \mathrm{C}$. Other solvents tested have included ethylene, ethane, propane, and dichlorodifluoromethane.

Most research on supercritical solvents has been limited to bench scale. However, the concept has advanced to the pilot-scale stage for recyrling waste oil using supercritical ethane as the solvent (Freeman 1989). Recent iaboratory research has shown that upon the addition of metal chelating ligands to supercritical $\mathrm{CO}_{2}$ and $\mathrm{CO}_{2}$ /methanol binary mixtures, metal salts can be solubilized in the fluid. The main advantage of such a system is that the metal chelates can be separated from the solvent simply by decreasing the pressure of the system and allowing the $\mathrm{CO}_{2}$ to $\mathrm{flash}$ to gas, thereby achieving a very large concentration factor. The main disadvantage of using supercritical solvents is that the process would need to operate at high pressure, although the temperature would be near ambient conditions.

\section{Facilitated Transport Membranes}

Facilitated transport membranes is a relatively new concept for separating metal ions from water. The process includes two types of membrane configurations that incorporate both membrane separation and solvent extraction principles (Noble, Koval, and Pellegrino 1989).

In the first configuration, called immobilized liquid membranes or coupled transport membranes (Cushnie, Crampton, and Roberts 1983), microporous 
membranes are specially prepared and saturated with a water-immiscible organic solvent. The saturated membranes are used in the same manner as a solvent in liquid-liquid solvent extraction processes by placing the membranes between two aqueous streams with different properties such as $\mathrm{pH}$. One stream contains the metal ions to be extracted and the other stream acts as a stripper to recover the metals. The solvent within the membrane extracts specific components from one stream and in turn has them stripped by the other stream. The only difference between solvent extraction and separation using facilitated membranes is that transport of the metal ions between the extraction and stripping solution is accomplished via diffusion across the membranes.

The second configuration, called emulsion liquid membranes, is based on the same principles as described above but uses an emulsion composed of the organic solvent/ion carrier and the aqueous stripper solution. The organic solvent encapsulates the internal aqueous stripper. A surfactant mixed with the emulsion facilitates separation of the two phases. The emulsion is then dispersed in the bulk aqueous liquid to be extracted in the same way as solvent extraction. Again, the surfactant keeps the organic and aqueous phases separate. In this configuration, the encapiulated stripper solution acts as a sink for the solute, which greatly increases the extraction capacity of the dispersed solvent.

Advantages claimed by both processes are minimal solvent requirements, minimal loss of solvent to either aqueous solution, and the opportunity to achieve significant concentration of the metal ions in the stripping solution. For example, in a pilot-plant study where an emulsion liquid membrane was used to remove zinc, zinc concentration was reduced from about $1 \mathrm{~g} / \mathrm{L}$ to the $\mathrm{ppm}$ range (Noble, Koval, and Pellegrino 1989). The internal stripper phase achieved zinc concentrations as high as $50 \mathrm{~g} / \mathrm{L}$. Concentrations factors as high as 1000 have been claimed in laboratory tests.

This technology is still considered to be developmental; therefore, economics are still tentative. However comparative economic assessments for extraction of uranium were reported to be superior to solvent extraction and ion exchange for the same applications (Noble, Koval, and Pellegrino 1989). 


\subsubsection{References}

Breton, M, P. Frillici, S. Palmer, C. Spears, M. Arienti, M. Kravett, A. Shayer, and N. Suprenant. 1988. Treatment Technologies for Solvent Containing Wastes. Noyes Data Corp., Park Ridge, New Jersey.

Cushnie, G. C. Ir., P. Crampton, and C. G. Roberts. 1983. An Investigation of Technologies for Hazardous Sludge Reduction at AFLW Industrial Waste Treatment Plants; Volume II: Literature Review of Available Technologies for Treating Heavy Metal Wastewaters. ESL-Tr-83-42, Engineering \& Services Laboratory, Air Force Engineering and Services Center, Tyndall Air Force Base, Florida.

De Renzo, D. J., ed. 1978. Unit Operations for Treatment of Hazardous Industrial Wastes. Noyes Data Corp., Park Ridge, New Jersey.

Freeman, H. M., ed. 1989. Standard Handbook of Hazardous Waste Treatment and Disposal. McGraw-Hill Book Company, New York.

Logsdail, D. H., and A. L. Mills, eds. 1985. Solvent Extraction and Ion Exchange in the Nuclear Fuel Cycle. Ell is Harwood Limited, Chichester.

Noble, R. D., C. A. Koval, and J. J. Pellegrino. 1989. "Facilitated Transport Membrane Systems." Chemical Engineering Progress, March 1989.

Peters R. P., Y. Ku, and D. Bhattacharyya. 1985. "Evaluation of Recent Treatment Techniques for Remova? of Heavy Metals from Industrial. Wastewaters." In Separation of Heavy Metals and Other Trace Contaminants, R. W. Peters and B. M. Kim, eds., AICHE Symposium Series 243, Volume 81. American Institute of Chemical Engineers, New York. 


\subsection{ADSORPTION $/$ ION EXCHANGE}

Liquid phase adsorption/ion exchange technology encompasses those processes in which a solid material usually having a high surface area, active groups, and/or permeability is used to selectively remove inorganic ions and/ or organic comnounds from a dilute aqueous stream. This technology includes two processes, ion exchange and adsorption.

\subsubsection{Process Description}

Adsorption and ion exchange processes are essentially the same process differentiated by application and materials used rather than on operational principles. Both processes are analogous to solvent extraction (phase transfer), except a solid with selective adsorption properties is used instead of a liquid solvent.

Adsorption and ion exchange processes work on the principle that the flow of dissolved components having an affinity for the material is retarded compared with water flow. The greater the affinity, the greater the retardation. In a typical process, contaminated water is passed through a bed of solid sorbents. Contaminants are selectively extracted or adsorbed onto the surface of the solid. Selectivity is limited by the relative order and magnitude of retardation achieved by the various components within the contaminated stream. After the solid has reached maximum capacity for the contaminants, it is removed from service and regenerated. Regeneration of the solid can be accomplished using elution, and/or back exchange, or some form of thermal stripping for removal of volatile organics.

Adsorption/ion exchange technologies are particularly well suited to the treatment of dilute concentrations of contaminants, and are almost always used as a polishing step in the treatiment of wastewater even after treatment by another process such as precipitation. Ion exchange materials have been used to selectively remove $\mathrm{Sr}, \mathrm{Cs}$, and Pu from alkal ine waste (Bray et a 1. 1984). Strong base anion exchange resins may be feasible for the selective removal of pertechnate anions. Activated carbon is capable of adsorbing both cations and anions from solution in addition to organics. Research also suggests that 
activated carbon can adsorb complexed metals (Huang 1984). The main disadvantage of the technology particularly in the selective removal of ions is that concentration of the contaminants is often limited to about a factor of 30 . Also, eventually the adsorption/ion exchange material loses its capacity and must be disposed.

\section{Ion Exchange}

Ion exchange processes are used exclusively to selectively separate inorganic ions. Ion exchange materials contain adsorption sites on which ions, such as sodium cations, are loosely held. As contaminated water is passed through the ion exchanger, ions with greater affinity for the site displace the loosely held ions (called counter ions) so that electrical neutrality is maintained within the material. The result is the contaminated water becomes deficient in the ion contaminant and rich in counter ions. Common counter ions are $\mathrm{Na}^{+}, \mathrm{H}^{+}, \mathrm{Cl}^{-}$, and $\mathrm{OH}^{-}$ions. When the ion exchange material is regenerated, a solution rich in the counter ion (such as a $\mathrm{NaOH}$ solution) and at a ply that promotes extraction displaces the contaminant ions. In an ion exchange process, all ions of similar charge will compete for the same site in accordance with their relative affinity for the site. The net effect is that each ion is retarded as it flows through the ion exchanger. Those with the lowest affinity are the least retarded and first to emerge from the exchanger after a period of operation.

\section{Adsorption}

The main difference between adsorption and ion exchange is that the adsorption of organics is based on physical and chemical adsorption as well as ion exchange. Adsorption processes operate in the same manner as ion exchange in that organic compounds are retarded as they pass through the adsorbent according to their relative affinity for the adsorption sites. In general, higher affinity corresponds with lower volatility and solubility organics. Regeneration of an adsorbent can be accomplished using a solvent to extract the organics in the same manner as solvent extraction processes. However, the adsorbent is usually regenerated by thermally stripping the volatile components in a process such as steam stripping. One disadvantage of this latter method is that nonvolatile material will not be removed, which results in a 
loss of adsorbent capacity. Therefore, $0 i 1$ and grease are usually limited to about 10 to $70 \mathrm{mg} / \mathrm{L}$ (Breton et al. 1988).

In general, chemical adsorption is the principal mechanism responsible for the adsorption of organic contaminants. However, most adsorbents have significant ion exchange capabilities. For example, activated carbon has been used commercially to remove gold, silver cations, and chromium (VI) anions (De Renzo 1978). Activated carbon has also demonstrated effectiveness in removing heavy metal contaminants from contaminated water in systems designed primarily for the removal of organics (EPA 1983). Usually in these systems the counter ions are $\mathrm{H}^{+}$and $\mathrm{OH}^{-}$attached to the surface of the carbon.

\subsubsection{Applicability to SST Waste}

Adsorption/ion exchange technologies are expected to have a role in the treatment of SST wastes. The primary role will be the selective removal of metal and radionuclide ions from any very dilute aqueous stream. The technology for using ion exchangers is well developed for the nuclear industry. Ion exchangers have been used both for the separation and purification of selected components, as well as a final treatment of dilute wastewater before discharge. It is also possible that adsorbents will be used as a final treatment of wastewater containing small quantities of organics. This application has been very well developed for activated carbon.

Many of the adsorbents also offer potential advantages in disposal. Mineral adsorbents such as clays and zeolites are relatively inexpensive and should have excellent properties in both grout and glass formulations. In these cases it may be preferential not to regenerate but dispose after one use.

\section{5 .3 Cost}

Typical processing costs for ion exchange processes range from $\$ 4$ to $\$ 6 / 1000 \mathrm{gal}$ (De Renzo 1978). Adsorption process for removing organics typically range from $\$ 5$ to $\$ 20 / 1000$ gal. 


\subsubsection{Opportunities for Improved Processing}

There are some areas in which additional research is warranted. These areas include research to investigate materials that offer improved selectivity for specific radionuclides and heavy metals and/or offer a means for improved disposal of spent material. Most previous research using adsorbents has focused on the removal of organic contaminants from aqueous streams. However, a limited amount of information also suggests that a number of adsorbents can be used effectively to remove metal ions and other inorganic compounds. Very limited unpublished data using adsorbents to remove TRU, $\mathrm{Sr}$, Cs, and Tc showed that bentonite clays would be good candidates for the removal of $\mathrm{Sr}$ and $\mathrm{Cs}$, while coconut charcoal would be a good candidate for removing TRU and TC. In other published data (Jones and Freeman 1988; Sherman 1977; Schultz 1980), certain clays and synthetic zeolites were found to be effective adsorbers of $\mathrm{Cs}$ and $\mathrm{Sr}$.

More information is available that suggests many of these adsorbents will be applicable to the removal of certain heavy metals but have not yet been applied to radionuclides. Macrocycle materials bonded to silica gel are being developed to remove gold, silver, lead, cadmium, and mercury to the parts per trillion level, with adsorption capacities much higher than obtained with activated carbon (Haztech News 1989a). The material can be regenerated over 200 times. AlgaeSORB material has been used to reduce copper, gold, silver, and mercury to the low ppb range, and it also has an affinity for nickel, chromium VI, and cadmium (Haztech News 1989b). Cadmium was reported to be effectively removed using $r$ alumina (Peters, Ku, and Bhattacharyya 1985). Activated $(\tau)$ alumina was also found to be effective in the removal of arsenic (Schlicher 1985).

\subsubsection{References}

Bray, L. A., L. K. Holton, T. R. Myers, G. M. Richardson, and B. M. Wise. 1984. Experimental Data Developed to Support the Selection of a Treatment Process for West Valley Alkaline Supernatant. PNL-4969, Pacific Northwest Laboratory, Richland, Washington.

Breton, M, P. Frillici, S. Palmer, C. Spears, M. Arienti, M. Kravett, A. Shayer, and N. Suprenant. 1988. Treatment Technologies for Solvent Containing Wastes. Noyes Data Corp., Park Ridge, New Jersey. 
De Renzo, D. J., ed. 1978. Unit Operations for Treatment of Hazardous Industrial Wastes. Noyes Data Corp., Park Ridge, New Jersey.

Haztech News. 1989a. March 23, p. 41.

Haztech News. 1989b. October 20, p. 160.

Huang, C. P. 1984. Concurrent Removal of Toxic Heavy Metals and Organic Substances by Activated Carbon Process from Contaminated Groundwater. PB85-218972, National Technical Information Service, Springfield, Virginia.

Jones, E. O., and H. D. Freeman. 1988. Design of Engineered Sorbent Barriers. PNL-SA-15723, Pacific Northwest Laboratory, Richland, Washington.

Peters R. P., Y. Ku, and D. Bhattacharyya. 1985. "Evaluation of Recent Treatment Techniques for Removal of Heavy Metals from Industrial Wastewaters." In Separation of Heavy Metals and Other Trace Contaminants, R. W. Peters and B. M. Kim, eds., AICHE Symposium Series 243, Volume 81. American Institute of Chemical Engineers, New York.

Schlicher, R. J. 1985. "Evaluation of Recent Treatment Techniques for Removal of Heavy Metals from Industrial Wastewaters." AICHE Symposium Series No. 243 , Vol 81, pp. 165-203.

Schultz, W. W. 1980. Removal of Radionuclides from Hanford Defense Waste Solutions. RHO-SA-51, Rockwel1 Hanford Operations, Richland, Washington.

Sherman, J. D. 1977. "Ion Exchange Separations with Molecular Sieve Zeolites." Presented at the 83rd National Meeting American Institute of Chemical Engineers, Houston, Texas, March 20-24. Linde Molecular Sieves Ion Exchange Bullet in No. F-4290, Union Carbide Corporation, Linde Division, New York.

U.S. Environmental Protection Agency (EPA). 1983. Treatability Manual Volume Three Technology for Control/Removal of Pollutants. EPA/600/2-82-001c, Washington, DC. 


\subsection{MEMBRANE SEPARATION}

Membrane separation technologies encompass a number of processes that use a membrane barrier to selectively separate components from a process stream and transport them to a second stream. Processes included in this technology are:

- reverse osmosis

- electrodialysis

- facilitated membranes

- dialysis

- microfiltration

- ultrafiltration

- hyperfiltration

- reversible gel absorption

- electrophoresis.

\subsubsection{Process Description}

Two characteristics are used to differentiate each of these processes. The first characteristic deals with the type of membrane used and the resulting size and charge of ions, molecules, and particles that are allowed to pass through the membrane in addition to water. The second characteristic is the type of driving force used to force material through the membrane. Common driving forces are hydraulic pressure, component concentration, and voltage gradients.

In addition to these characteristics, membrane processes can be differentiated according to their primary application. These applications are divided into three main categories:

- removal of dissolved solids including anion and cations

- removal of colloidal particulate and large molecules

- removal of particulate. 
Four of the membrane processes are used primarily to separate dissolved inorganic ions from water:

- reverse osmosis

- electrodialysis

- facilitated membranes

- dialysis.

There are five processes that use membrane separation principles to separate large molecules and colloids from water.

- microfiltration

- ultrafiltration

- hyperfiltration

- reversible gel absorption

- electrophoresis.

All of these processes possess the same operational characteristic in that ions and molecules below a certain size are effectively allowed to pass through the membrane unimpeded.

\section{Reverse 0smosis}

In reverse osmosis, homogeneous membranes prevent transport of solid particulate and colloids and serve as a diffusional barrier to water, dissolved solids, and organic molecules. However, because water has a significantly greater diffusivity than most other components, reverse osmosis effectively acts as a barrier to most dissolved components. Since reverse osmosis membranes are homogeneous, they do not contain micropores. Instead, porosity is achieved by the space between atoms within the molecular structure of the membrane. These spaces are typically less than 10 angstroms $(0.00001 \mu \mathrm{m})$ in diameter.

The term reverse osmosis was derived from the term osmosis. When a body of pure water is separated by a membrane from an impure body of water, and if the membrane only allows water to pass through it, then the water will pass 
from the pure body to the impure body in order to dilute it. The amount of pressure across the membrane needed to oppose this flow is called the osmotic pressure. In reverse osmosis, a hydraulic pressure gradient greater than the osmotic pressure is applied to reverse the flow so that water flows from the impure side to the pure side.

\section{Dialysis}

In dialysis small molecules and concentrated dissolved salts diffuse across the membrane to a pure water stream because of the concentration gradient of the species. Larger molecules and colloids remain behind because of their larger size. Since a concentration gradient is used as the only gradient to facilitate diffusion, the final concentration of the "pure" water stream must necessarily be less than that in the concentrated stream. Thus selective separation is achieved at the expense of dilution.

\section{Facilitated Transport Membranes}

Facilitated transport membranes are diffusional barriers that rely on component (chemical or ion) concentration gradients as the driving force. However, the membranes are designed to incorporate a solvent and extractant to allow only certain ions to pass through the membrane in a manner based on solvent extraction principles. This process is also discussed under solvent extraction technology.

\section{Electrodialysis}

Electrodialysis differs from dialysis in that a voltage gradient is applied to drive ions of dissolved inorganic salts through the membranes. In electrodialys is each channel through which the wastewater passes is composed of two different membrane walls. One wall allows only cations to pass and the other allows only anions to pass. When the voltage is applied to this channel, both ions are allowed to diffuse out of the channel in the appropriate direction. By placing a "pure" siream between two of these channels it will receive both ions. However, because the order of the two different membranes is effectively reversed, the ions are trapped. The voltage gradient makes it. possible to concentrate the ions in these channels. Ideally, electrodialysis results in nonselective concentration of all ions, and is considered to be a 
concentrating step much like evaporation. However, because the diffusivity of different ions varies, there may be some degree of selective separation.

\section{Ultrafiltration}

Ultrafiltration processes use microporous membranes to restrict the size of material allowed through the membrane. They operate similarly to more conventional filtration techniques such as filter presses in that a pressure gradient is applied across the membrane to force water through, and they achieve selective separation of components in a wastewater stream according to the size of the molecule or particle. In the context of particle separation, ultrafiltration is considered separately under liquid particulate filtration. Ultrafiltration membranes are capable of separating large organic molecules that are dissolved in the wastewater. Ultrafiltration membranes have small pores ranging in diameter from 0.001 to $0.01 \mu \mathrm{m}$ (Cushnie, Crampton, and Roberts 1983) and can retain molecules with molecular weights ranging from 500 to about 1 million (Freeman 1989). U1trafiltration has been used to remove complexed toxic metals (cadmium and mercury) from metal-finishing water (Haztech 1990).

\section{Microfiltration}

Microfiltration encompasses filter systems with pore diameters ranging from 0.01 to $1.0 \mu \mathrm{m}$ (De Renzo 1978), bridging the gap between ultrafiltration and conventional filtration. Like ultrafilters, microfilters can be used to remove particles from the water. In this context, microfiltration is considered separately under liquid particulate filtration. Microfiltration membranes have pores that typically range from 0.01 to $0.1 \mu \mathrm{m}$ in diameter (Cushnie, Crampton, and Roberts 1983) and can separate molecules with a molecular weight greater than 1 million and colloidal material. Microfilters with larger pore diameters are made from porous plastic tubing rather than membranes. Microfilters based on membranes are sometimes included as an extension of ultrafiltration rather than a separate category. 


\section{Hyperfiltration}

Hyperfiltration membranes are microporous membranes whose pore sizes bridge the gap between homogeneous membranes, such as those used in reverse osmosis, and ultrafiltration membranes. Hyperfiltration membranes can retain molecules with a molecular weight as low as 100 (Freeman 1989). Like microfiltration membranes hyperfiltration membranes are sometimes treated as an extension of ultrafiltration.

\section{Reversible Gels}

Reversible gels are cross-linked polymer gels that undergo a dramatic volume change in water caused by small changes in either temperature or $\mathrm{pH}$ depending upon the gel. The surface of the gel is a highly cross-linked polymer web that acts as a filter for colloids and molecules with molecular weights of about 1500 or more (EPA 1986). They are included under membrane separations because of their similarity to ultrafiltration membranes in terms of filtering behavior. However, the gels are not formed as microporous membranes and are handled like absorbents in which they absorb water from one stream under one set of conditions and then regenerate by expelling water under a different set of conditions.

\section{Electrophoresis}

Electrophoresis is similar to electrodialysis in that voltage gradient is applied to a wastewater stream placed between two membranes. In this process, however, the membranes behave more like a reverse osmosis membrane in that only water and small ions are allowed to pass. Negatively charged colloids and particles are concentrated against the membrane closest to the anode, leaving a particulate-depleted zone near the other membrane (De Renzo 1978). A filter placed between the two membranes, which is permeable to the particulate, creates two channels so that a concentrated stream can be withdrawn from one channel and a dilute stream can be withdrawn from the other. One unique effect of this process is that uncharged particulate is not concentrated, thereby creating the potential for selective removal of certain colloidal and particulate components. Although electrophoresis processes use membranes that are permeable to inorganic ions, the process appears to be used 
exclusively for the separation and recovery of proteins and other charged colloids from uncharged material and dissolved ions.

\subsubsection{Applicability to SST Waste}

Membrane technologies can be used to remove inorganic ions, molecules, colloids, and particulate from water. In particulate removal application, membrane technologies are considered along with other liquid particulate separation techniques. Microfiltration and ultrafiltration are the two techniques for this application. They are discussed in more detail under that technology category in this report.

of the four membrane technologies that address separation of metal ions, only dialysis is not considered a likely candidate because it results in dilution of the separated ions. Reverse osmosis and electrodialysis are primarily concentrating processes. The main difference is that reverse osmosis separates pure water from the contaminated stream, thus concentrating both the ionic and non-ionic constituents of the contaminated stream. Electrodialysis removes the ions from the contaminated streams, thereby only concentrating the ionic components. Non-ionic components are retained with the contaminated stream. A major consideration in using either of these techniques is the adverse effects of salting out the dissolved ions, as they are concentrated, causing fouling. Similarly, the collection of other suspending particles on the membrane surfaces can result in fouling. Consequently, reverse osmosis and electrodialysis will most likely be used as a treatment for denitrated aqueous waste streams in which the main constituents are not near saturation.

of the five processes used to separate large molecules and colloids, only ultrafiltration and hyperfiltration processes appear to have some applicability in the removal of large organic molecules and complexed metals. Microfilters and reversible gel separate only relatively large molecules, limiting their applicability to SST waste. Electrophoresis is applicable to the separation of proteins and other charge colloidal material and does not appear to be applicable to SST waste. 


\subsubsection{Cost}

Typical cost for reverse osmosis is $\$ 1$ to $\$ 4 / 1000$ gal (De Renzo). Typical cost for electrodialysis is $\$ 1$ to $\$ 5 / 1000$ gal (De Renzo). Typical cost for microfiltration/u?trafiltration is $\$ 5$ to $\$ 10 / 1000$ gal (De Renzo 1978). Typical cost for reversible gel absorption is unavailable. Typical cost for electrophoresis is unavailable.

\subsubsection{Opportunities for Improved Processing}

Membrane separation technologies are generally considered to be commercial technologies. There does not appear to be any opportunities to significantly improve the technology through research. Opportunities to improve SST waste treatment should be based solely on their specific application in comparison to other technologies.

\subsubsection{References}

Cushnie, G. C. Jr., P. Crampton, and C. G. Roberts. 1983. An Investigation of Technologies for Hazardous Sludge Reduction at AFLW Industrial Waste Treatment Plants: Volume II: Literature Review of Available Technologies for Treating Heavy Metal Wastewaters. ESL-Tr-83-42, Engineering \& Services Laboratory, Air Force Engineering and Services Center, Tyndall Air Force Base, Florida.

De Renzo, D. J., ed. 1978. Unit Operations for Treatment of Hazardous Industrial Wastes. Noyes Data Corp., Park Ridge, New Jersey.

Freeman, H. M., ed. 1989. Standard Handbook of Hazardous Waste Treatment and Disposal. McGraw-Hill Book Company, New York.

Haztech News. 1990. June 14, p. 88.

U.S. Environmental Protection Agency (EPA). 1986. Hazardous Waste Treatment Technology. EPA/600/D-86, PB-86-145539, National Technical Information Service, Springfield, Virginia. 


\subsection{PRECIPITATION}

Precipitation is a well-developed technology in which a chemical is added to a solution to react with a dissolved ion and cause it to form an insoluble solid. Precipitation is a standard technology for separating dissolved heavy metal cations and certain anions from aqueous solutions.

\subsubsection{Process Description}

Precipitation is almost always carried out in conjunction with flocculation and clarification. The process can be accomplished in a single basin or in separated basins. Wastewater, chemical precipitants. and flocculants are continuously added to a rapid mix tank where precipitation and some or all of the flocculation occurs. Upon completion of the flocculation step the treated wastewater is allowed to settle in the stagnant, bottom portion of the agitated basin or discharged to a separate settling basin. Sludge is removed from the bottom of the basin, and the clarified effluent is discharged from the top.

Precipitation generally involves the addition of a soluble chemical agent which will react with the dissolved metal ion to produce an insoluble material that can be separated using liquid phase particulate removal technologies. In some cases, the chemical is only slightly soluble itself and may behave in a manner more characteristic of an ion exchange material.

Precipitation is strongly influenced by $\mathrm{pH}$. Thus, a specific cation/ anion pair has a specific pH at which its solubility is lowest. This is particularly true in hydroxide precipitation. Unfortunately, when a mixture of different metal cations is present, they will not necessarily share the same optimum $\mathrm{pH}$ and a compromise is necessary. Alternatively, though, coprecipitation of a mixture of metal cations often results in a more efficient removal of all metals than would be predicted from tests with individual metals at a specific pH.

The most common precipitating agents used for removal of metal cations are:

- soluble sulfides - sodium sulfide $\left(\mathrm{Na}_{2} \mathrm{~S}\right)$ and sodium hydrosulfide (NaHS) 
- insoluble sulfides - as ferrous sulfide (FeS)

- hydroxides- using lime $(\mathrm{CaOH})$, caustic $(\mathrm{NaOH})$, and magnesium oxide (MgO)

- carbonates - using sodium carbonate $\left(\mathrm{Na}_{2} \mathrm{CO}_{3}\right)$.

Sulfide precipitation produces metal sulfides with very low solubility in water. However, the use of soluble sulfides can produce hydrogen sulfide, which is a very toxic gas. Insoluble ferrous sulfide avoids this problem at the expense of consuming greater quantities of reagent and producing more solids in the form of the ferrous sulfide. Sulfide precipitation can process water containing chelating agents, and is capable of simultaneously reducing and precipitating $\mathrm{Cr}$ (VI) (Bove et al. 1984).

Hydroxides are also very insoluble although not as insoluble as the sulfides. Hydroxides, however, are much more sensitive to $\mathrm{pH}$, as previously discussed. This property can be used to separate different heavy metals by employing $\mathrm{pH}$ adjustment. Research using magnesium oxide indicated that the resulting sludge was more compact (Grosse 1986). Generally, hydroxide precipitation works best at relatively high ( 8 to 11) pH (Peters, Ku, and Bhattacharyya 1985). Chelating agents interfere with hydroxide precipitation (EPA 1983).

Carbonates produce metal salts with solubilities generally comparable to those of hydroxide precipitation for cadmium and lead. However, the carbonates have optimum $\mathrm{pH}$ values that are lower than those for hydroxides and produce a denser, more easily filtered sludge. Carbonate precipitation does not work well on zinc and nickel (Peters, Ku, and Bhattacharyya 1985).

There are other precipitation agents used for specific ions. Among these are:

- phosphates that can selectively remove trivalent cations from solutions also containing divalent and monovalent cations

- sodium borohydride, a reducing agent that can be used to precipitate metals from solution by reducing them to their insoluble elemental form. 
In addition, many metals have certain very insoluble salts. Soluble salts of the corresponding anion can then be used as a precipitating agent. For example, sodium chloride mixed with silver nitrate will produce the insoluble silver chloride salt.

Precipitation is a very well developed technology capable of reducing heavy metal ions in aqueous solutions to very low levels. A major advantage of precipitation is its simpie operation involving mainly the mixing of chemicals and removal of precipitate through sedimentation and filtration. Alternatively, the process lends itself to foam flotation for recovery of precipitates that have been treated with coagulants (Peters, Ku, and Bhattacharyya 1985). The main limitation to precipitation is that certain chemicals do not work well with complexed metals. Aiso, precipitation requires addition of excess chemicals to drive the reactions to completion, thus potentially increasing the volume of solid waste.

\subsubsection{Applicability to SST Waste}

Precipitation can be expected to be employed in the treatment of SST wastes following any operation in which heavy metals are concentrated above their solubility levels as a precipitate. Precipitation may also be applicable in separating certain radionuclides from solution, including strontium, yttrium, and uranium (Dupont 1986).

\section{7 .3 Cost}

Typical cost of precipitation ranges from $\$ 1$ to $\$ 2 / 1000$ gal (De Renzo 1978).

\subsubsection{Opportunities for Improved Processing}

The main areas in which process improvements can be made are in developing a data base for radionuclides for the various precipitation reagents. In addition, research should evaluate precipitation in conjunction with liquid phase particulate separation. In many cases, the poor efficiency for precipitation can be attributed to the inefficient particulate removal in those circumstances where the particles are small and in relatively low concentration. 


\subsubsection{References}

Bove, L. J., W. P. Lambert, L. Y. H. Lin, D. E. Sullivan, and P. J. Marks. 1983. Installation Restoration General Environmental Technology Development Final Report - Development of New Technology for the Removal of Contaminants from Groundwater Identification and Evaluation of Technologies. DRXTH-TE-CR84270, Roy F. Weston, Inc., Westchester, Pennsylvania.

De Renzo, D. J., ed. 1978. Unit Operations for Treatment of Hazardous Industrial Wastes. Noyes Data Corp., Park Ridge, New Jersey.

DuPont, A. 1986. "Lime Treatment of Liquid Waste Containing Heavy Metal, Radionuclides and Organics." In Proceedings of the 7 th National Conference on Management of Uncontrolled Hazardous Waste Sites.

Grosse, D. W. 1986. "A Review of Alternative Treatment Processes for Metal Bearing Hazardous Waste Streams." Journal of the Air Pollution Control Association 36(5):603-614.

Peters R. P., Y. Ku, and D. Bhattacharyya. 1985. "Evaluation of Recent Treatment Techniques for Removal of Heavy Metals from Industrial Wastewaters." In Separation of Heavy Metals and Other Trace Contaminants, R. W. Peters and B. M. Kim, eds., AICHE Symposium Series 243, Volume 81. American Institute of Chemical Engineers, New York.

U.S. Environmental Protection Agency (EPA). 1983. Ireatability Manual Volume Three Technology for Control/Removal of Pollutants. EPA/600/2-82-001c, Washington, $D C$. 


\subsection{BIOACCUMULATION}

In bioaccumulation, living organisms accumulate and concentrate certain heavy metals and other elements in their tissue. Bioaccumulation is a wellknown phenomenon, particularly in the way it relates to hazardous materials and the food chain. The phenomenon is also apparent in the use of biological processes to treat sewage and industrial wastes. Even though these processes are designed for removal of organic matter, they also accumulate a significant amount of heavy metals in the resulting sludge.

While bioaccumulation is accomplished, to at least some degree, by all living organisms, the term in this technology is generally restricted to microorganisms and a few aquatic plants such as duckweed and water hyacinths. More specifically in this report it is restricted to those applications involving living material.

\subsubsection{Process Description}

A bioaccumulation process involves growing living organism in a contaminated water to provide an opportunity for the biomass to adsorb heavy metals and other elements. Nutrients are added as necessary to sustain optimum metabolism.

Bioaccumulation in municipal waste is accomplished by bacteria in either an aerobic or an anaerobic environment. Thus, any of the more typical biological treatment processes such as activated sludge can be used as a means for bioaccumulation. However, such a system would be optimized for heavy metals and/or radionuclides rather than organics destruction. In fact, in the absence of sufficient organic carbon in the waste, other sources of carbon may be required. Until recently very little research had been directed towards the treatment of metal-bearing aqueous wastes, and the concept has been limited to evaluation of water from processes optimized for treating organics. However, recent research has identified specific bacteria that can remove zinc, cadmium, seleniuni, and tellurium from water and fungi that can remove a) uminum, nickel, and uranium.

In addition to their role as bioaccumulators certain bacteria and fungi are capable of dissolving certain metals from silicate ores and waste 
products. These microorganisms were isolated from various mines and mine wastes and then evaluated for their leaching abilities. Much of the research has centered on the leaching of sulfitic ores. In these situations the microorganisms that cannot use organic carbon for growth oxidize sulfides to sulfuric acid and dissolve the metals such as iron, zinc, cadmium, uranium, and copper as soluble suifates. Other research has investigated the use of bacteria to reduce iron and manganese sulfate to insoluble sulfides.

Recent research has also investigated the use of microalgae and certain aquatic plants for treating metal-bearing aqueous wastes. The basis of using microalgae for the treatment of metal-bearing wastes comes from the fact that algae are bioaccumulators of many trace minerals. Bioaccumulation of heavy metals is accomplished by two principal means: adsorption and precipitation onto the outer layer of the cells, and by adsorption and metabolism within the cel1. It is estimated that there are over 20,000 different species of algae (Robinson, Mak, and Trevan 1986), most of which possess the ability to concentrate metals.

Considerable research has been conducted on the performance of several algae strains for their ability to bioaccumulate certain heavy metals, including copper, zinc, cobalt, chromium, nickel, aluminum, cadmium, lead, mercury, and gold (Darnall and Gardea-Torresdey 1989). In the case of living cells, the bioaccumulation eventually results in toxicity levels that kill the algae which then settle out as sludge. Research has shown, however, that even dead algae display significant adsorption characteristics for metal ions on their cell walls. In fact, in several instances the rate of adsorption and the total loading of the metal ions is much higher than that achieved with the living algae. Considerable research is being directed towards incorporating dead algae and other dead aquatic plant material into adsorption materials such as silica gel and resins.

The key advantages of bioaccumulation technology are the apparent high adsorption capacity and degree of selectivity of microorganisms on a dry weight basis compared with other adsorbents. One disadvantage is that living microorganisms produce a primarily organic sludge that may require further processing to reduce the volume of solids to be disposed of as hazardous 
waste. Also, the conditions required to maintain an acceptable level of metabolism place constraints on the composition of the waste to be treated.

\subsubsection{Applicability to SST Waste}

It is difficult to ascertain the applicability of this technology to SSTs. Microorganisms such as algae, fungi, and bacteria are capable of adapting to very harsh chemical environments as might be experienced in SST wastes. Consequentiy, they may be applicable to any of the aqueous streams. However, the application of bacteria and fungi to conditions similar to those anticipated has not been demonstrated elsewhere. The tolerance for radiation exposure is limited for many microorganisms. Radiosensitive microorganisms are substantially impaired by as little as 10 Gy of gamma radiation. Microorganisms have been shown to adapt very rapidly and successfully to high radiation doses. For example, algae were found flourishing in the pool water at Ten Mile Island. The most likely application of bioaccumulation would be in the treatment of tertiary aqueous waste streams for the removal of trace amounts of heavy metals and radionuclides. In this application, the technology would be an alternative to adsorption/ion exchange technologies. One advantage in this technology is that it could be used in conjunction with treatment to destroy any remaining organics and nitrates in the waste in a single step.

\subsubsection{Cost}

Although still in the early stages of development, it can be anticipated that the technology will be designed and operated in a manner similar to any of the numerous existing biological treatment processes, and that treatment costs will be in the range of $\$ 1$ to $\$ 20 / 1000 \mathrm{gal}$.

\subsubsection{Opportunities for Improved Processing}

Bioaccumulation is a relatively new and innovative technology in which considerable improvement is possible. In the context of tertiary wastewater treatment, research needs to be conducted to develop a data base for bioaccumulation of radionuclides, as well as developing schemes to treat the resulting sludge. Research also needs to be conducted to identify and optimize microorganisms that are tolerant of harsh conditions. 


\subsubsection{References}

Darnal1, D. W., and J. Gardea-Torresday. 1989. Removal and Selective Recovery of Heavy Metal Ions from Industrial, Waste Waters. PB89-166763, New Mexico Water Resources Research Institute. Technical Completion Report for Project No. 14-08-001-G1286.

Robinson, P. K., A. L. Mak, and M. D. Trevan. 1986. "Immobilized Algae: A Review." Process Biochemistry 52:122-127. 


\subsection{BIOLOGICAL DEGRADATION}

Biological degradation technologies generally include biological treatment processes that use a microbial population to biodegrade organics and nitrates (biodenitrification) in aqueous wastes. Biodegradation processes are very well developed for the treatment of municipal sewage and industrial aqueous, organic wastes.

\subsubsection{Process Description}

In a biodegradation process, microorganisms (fungi, algae, or bacteria) are added to a contaminated wastewater and allowed to grow. These microorganisms metabolize hydrocarbons to form biomass. For biodenitrification, the microorganisms metabolize nitrate to obtain oxygen necessary for metabolizing the hydrocarbons. In either case, nutrients including hydrocarbon and/or nitrate must be added to sustain optimum metabolism.

This technology can be applied to organic sludge, slurries, and aqueous liquids. In these applications, the microorganisms convert the majority of the degradable organic matter into carbon dioxide, water, and light gas hydrocarbons. In biodenitrification applications, the predominant products are water and free nitrogen.

Biodegradation technologies encompass both aerobic and anaerobic treatment systems and include a variety of configurations. The more common processes are listed below:

\section{Aerobic Systems \\ activated sludge \\ trickling filters \\ rotating biological \\ filters \\ aerobic fluidized bed \\ submerged fixed film reactor}

aerobic lagoon
Anaerobic/ Aerobic Systems

membrane anaerobic/aerobic reactor system

facultative lagoons
Anaerobic Systems

anaerobic digestion anaerobic biodegradation 
Biodegradation can be used to treat a variety of organic compounds. Like chemical oxidation and reduction processes, the relative rate and degree of degradation can vary significantly. In addition, a number of other parameters can affect the performance of these processes. For example, certain metals such as $\mathrm{Pb}, \mathrm{Ni}, \mathrm{Cr}$, and $\mathrm{Zn}$ are particularly toxic to a number of microorganisms. Similarly, very high or low $\mathrm{pH}$, high total dissolved salts, and high organic loading can inhibit performance (EPA 1985). Many of these constraints can be met through dilution, selection, and acclimatization of the microorganisms, process design, and pretreatment to adjust $\mathrm{pH}$ and to remove selected toxic metals. Biological processes also produce a sludge composed of dead microorganisms, unreacted solids, and adsorbed heavy metals and radionuclides. This sludge may require further treatment and/or disposal.

\subsubsection{Applicability to SST Waste}

Biodegradation can be used to destroy organics and nitrates present in SST wastes. However, because of the hostile chemical and radioactive conditions in the initial waste and both the sludge and nitrate wastes streams, the technology will probably be limited to those secondary aqueous wastes produced in separation operations and tertiary aqueous waste streams that contain organics and less concentrated inorganics including nitrates. Biodegradation would have the greatest potential in the treatment of tertiary aste streams to remove trace quantities of nitrates and organics. In this application the advantage of additionally optimizing a system for bioaccumulation of trace heavy metals and radionuclides would make the technology a viable alternative to adsorption/ion exchange systems.

\subsubsection{Cost}

Typical costs for biodegradation processes range from $\$<1$ to $\$ 15 / 1000$ gal (De Renzo 1978).

\subsubsection{Opportunities for Improved Processing}

In general, biological degradation technology is a well-developed technology, particularly in the treatment of municipal waste. Research has mainly been directed toward the identification of microorganisms that are tolerant of hostile conditions and capable of degrading key organic compounds. Process 
research has been similarly directed toward techniques to facilitate the tolerance of microorganisms for high concentrations of toxic components.

\subsubsection{References}

De Renzo, D. J., ed. 1978. Unit Operations for Treatment of Hazardous Industrial Wastes. Noyes Data Corp., Park Ridge, New Jersey.

U.S. Environmental Protection Agency (EPA). 1985. Handbook Remedial Action At Waste Disposal Sites (revised). EPA/625/6-85/006, Cincinnati, Ohio. 


\subsection{CRYSTALLIZATION}

Crystallization is a purification process in which a single substance concentrated within a liquid or vapor mixture is allowed to crystallize. A "pure" solid is then created that in turn can be separated from the liquid. Crystallization is not normally considered a waste treatment process because most waste streams do not contain saturated or nearly saturated solutions of a crystallizable substance. A similar process is freeze crystallization (Section 4.11) in which water containing trace quantities of contaminants is allowed to freeze into pure ice crystals. Precipitation is also a form of crystallization in which supersaturation is accomplished through the formation of an insoluble compound.

\subsubsection{Process Description}

Crystallization processes all operate in a manner to change the conditions of a solution under carefully controlled conditions so that one of the solutes in the solution becomes supersaturated. Seed crystals are added to the solution under these conditions to promote the growth of uniform crystals which settle out in the bottom of a vessel and are collected. Supersaturation is usually achieved by evaporating water from the solution. An example of crystallization is the recovery and purification of table salt ( $\mathrm{NaCl}$ ) from seawater by evaporation. Crystallization can also be accomplished by decreasing the solubility of the desired compound in a saturated solution, by changing (usually decreasing) the temperature of the solution, or by a combination of the two processes.

The purity of the crystallized product is principally affected by two mechanisms. Some of the impurities contained in the residual solution (mother liquor) will be trapped in sma11 pockets, called occlusions, within each crystal. These occlusions will account for between $0.1 \%$ and $0.5 \%$ of the crystal volume (Perry and Chilton 1973). Further purification of these crystals can be accomplished by redissolving the crystals to release the trapped mother liquor and by recrystaliization, which retraps a mother liquor that now contains a much lower concentration of impurities. Impurities will also result from the drying of mother liquor on the outside of the crystals once they are removed from the solution. This solution may account for 
between $2 \%$ and $10 \%$ of the weight of the crystals (Perry and Chilton 1973). Washing the crystals with fresh or feed solvent is generally employed to reduce contamination by this mechanism.

Crystallization produces a small concentrated aqueous stream (mother liquor), requiring further treatment, as well as a contaminated aqueous stream used to wash the crystals. Crystallized solids may require recrystallization, which is essentially resolubilization and crystallization, in order to improve purity.

\subsubsection{Applicability to SST Waste}

Crystallization is a well-developed technology that is currently used as the method for producing commercial sodium nitrate (Lefond 1975). Crystal1ization as a waste treatment process is uniquely suited to the treatment of the nitrate brine. The main advantage of the process is that pure nitrate can be recovered from the contaminated brine. Contamination of the product crystal be reduced by up to 3 orders of magnitude than that achieved through complete evaporation, in a single stage. Additional purity can be achieved through recrystallization. In addition to producing nitrate salts, crystallization provides for nonselective concentration of all radionuclides, heavy metals, and other dissolved inorganic compounds as well as organics in the mother liquor. This facilitates more efficient recovery using other processes such as precipitation, ion exchange, or evaporation.

High-purity nitrate salts offer alternative opportunities for disposal. First, the opportunity exists for disposing of the nitrate by selling it to industry provided that it can be declared nonradioactive. Second, destruction of the nitrate by means such as incineration or chemical reduction could take place as a conventional process not requiring nuclear safeguards.

\subsubsection{Process Cost}

While specific economics for treating nitrate wastes are not available, the purchase cost of bulk chemicals principally produced using crystallizers, such as sodium chloride, glauber's salt, and sodium nitrate, typically range from $\$ 100$ to $\$ 300 /$ ton. This would place crystallization costs in the same range as incineration. The possibility of classifying the sodium nitrate as a 
nonradioactive pure compound could reduce grouting costs by 1 order of magnitude (assuming that it is grouted) and possibly become a resalable byproduct worth approximately $\$ 200 /$ ton, thus offsetting processing costs.

\subsubsection{Opportunities for Improved Processing}

Crystallization is we11-suited for producing bulk commodity chemicals, including sodium nitrate. However, its potential application to SST waste is unique because of the chemical mixture involved. Research is needed to determine the processing conditions to adapt crystallization technology to the selective separation and recovery of sodium nitrate from SST waste.

\subsubsection{References}

Lefond, S. J., ed. 1975. Industrial Minerals and Rocks. American Institute of Mining, Metallurgical, and Petroleum Engineers Inc., New York.

Perry J. H., and C. H. Chilton, eds. 1973. Chemical Engineer's Handbook, 5th ed., pp. 21-57. McGraw-Hill Book Co., New York. 


\subsection{FREEZE CRYSTALLIZATION}

Freeze crystallization separates water from solutions by cooling the solution until ice crystals form. The ice crystallizes as a pure substance in almost all cases. The ice crystals are separated from the remaining solution, washed of impurities, and remeited to produce pure water.

\subsubsection{Process Description}

Freeze crystallization is similar in many respects to crystallization, except that crystal formation occurs with the solvent (water) rather than a supersaturated solute. Furthermore, since ice floats, simultaneous crystallization of a salt can occur with recovery as a sludge if the resulting crystals are heavier than the solution. Like crystallization the advantage of freeze crystallization is that it nonselectively separates all contaminants from the water and concentrates them. Thus, it should not be adversely affected by complexing agents in the concentration and separation of heavy metals and radionuclides.

Based on literature obtained from Freeze Technologies, Raleigh, North Carolina, the niche for freeze crystallization is in the range of 1000 to $100,000 \mathrm{mg} / \mathrm{L}$ of total heavy metals; $3 \%$ to $7 \%$ organics; or $0.5 \%$ to $1.5 \%$ of a mixture of organics and heavy metals in water. These ranges appear to be based on economics of competing technologies outside these ranges for contaminants. De Renzo (1978) indicated that freeze crystallization has been tested at total dissclved solid (TDS) loads ranging from $30 \mathrm{ppm}$ to $10 \%$, including tests on ammonium nitrate wastes $(71,000 \mathrm{mg} / \mathrm{L}$ TDS with $99.6 \%$ remova 1$)$ and weak sulfuric acid wastes ( $5000 \mathrm{mg} / \mathrm{L}$ TDS with $95 \%$ removal). Freeman (1989) indicated that freeze crystallization was investigated extensively for desalinating seawater, and one system was commercialized for this application.

\subsubsection{Applicability to SST Waste}

The most likely SST waste treatment application of freeze crystallization technology is as an alternative to adsorption/ion exchange, membrane separation, and evaporation as a means of concentrating heavy metals and radionuclides in the presence of organics in denitrated aqueous waste streams. 
Freeze crystallization could possibly be applied to nitrate brine as an alternative to conventional crystallization. However, the anticipated amount of TDSs in a saturated brine would be well above the range of conditions tested. If it were to be applied it would likely need to be operated in a mode where both ice and sodium nitrate salts are removed simultaneously from the top and bottom of the brine, respectively.

\subsubsection{Process Cost}

Anticipated costs should range from $\$ 15$ to $\$ 100 / 1000$ gal (Freeman 1989 ; EPRI 1988).

\subsubsection{Opportunities for Improved Processing}

Freeze crystallization is an emerging technology that while limited in commercial applications is fairly well demonstrated as to its capabilities. In addition, processes based on this technology can be assembled using offthe-shelf equipment. The main barrier to implementation of the technology is the need to do pilot testing to obtain key design information.

\subsubsection{References}

De Renzo, D. J., ed, 1978. Unit Operations for Treatment of Hazardous

Inciustrial Wastes. Noyes Data Corp., Park Ridge, New Jersey.

EPRI Process Industry Coordination Office. 1988. "Freeze Concentration." TechCommentary 1(1). Battelle Memorial Institute, Columbus, Ohio.

Freeman, H. M., ed. 1989. Standard Handbook of Hazardous Waste Treatment and Disposal. McGraw-Hill Book Company, New York. 


\subsection{EVAPORATION}

Evaporation processes use heat to remove volatile solvents and/or water from inorganic or organic solids either in solution or slurry. Evaporation is also used for concentrating and/or salting out dissolved solids. Evaporators differ from driers in that the material in the evaporator is maintained as a solution or slurry rather than being allowed to dry to a solid-like material.

\subsubsection{Process Description}

The two main types of evaporators are thin film evaporators and flash evaporators. In thin film evaporators a rising or falling film of the liquid (slurry) in the evaporator is deposited on the heat transfer surface located within a vapor space. The heated surface causes a portion of the water to evaporate from the film, thereby concentrating the solids. Flash evaporators use a pump to circulate the solution through a heating element at an elevated pressure to prevent vaporization. The heated liquid is then circulated to a reservoir maintained at a lower pressure, which causes a portion of the liquid to flash to vapor.

Evaporators are used to concentrate metal plating wastes and radioactive liquids and sludge. They may al so be used as a means for separating and recovering solvent. This latter application is used in refining operations as a first separation of light organic components from heavy fractions. In this application the solvent may be distilled to separate olt various components.

\subsubsection{Applicability to SST Waste}

Evaporation processes are potentially applic ble to any of the aqueous waste streams that would be produced duing the processing of SST tank wastes. In these applications it would be used primariiy as a means for concentrating and/or precipitating out dissolved solids, icluting heavy metals and radionuclides, and/or sodium nitrate salts. In tre applicutions, evaporation may be used as a means for removing excess water prior to disposal, or as a concentration step prior to a separation step such as precipitation. Evaporation may also be used as a means of supersaturating dissolved solids in a crystalTization process. 
Evaporation may also be used for recovering nitric acid used in the dissolution of the insoluble sludge. Research on this encept is currently under way at PNL as a waste minimization technique for fuel reprocessing (Weygandt et a1. 1988; Jones 1990). The approach has also shown the potential for recovering nitric acid from the nitrate salts by first adding sulfuric acid to the brine and then evaporating off nitric acid. Sodium and other cations are recovered as sulfates that are more compatible in grout.

\subsection{2 .3 Cost}

Typical evaporation process costs range from $\$ 1$ to $\$ 2 / 1000$ gal (De Renzo 1978).

\subsubsection{Opportunities for Improved Processing}

Evaporation is a well-developed technology for a variety of applications, inciuding hazardous and radioactive waste treatment. The only area in which evaporation technology warrants additional research is in the context of adapting the ongoing PNL waste acid reclamation research to SST sodium nitrate treatment and for minimizing the consumption of nitric acid in those appicable SST waste treatment processes.

\subsubsection{References}

De Renzo, D. J., ed. 1978. Unit Operations for Treatment of Hazardous Industrial Wastes. Noyes Data Corp., Park Ridge, New Jersey.

Jones, E. O. 1990. Waste Acid Detoxification and Reclamation (WADR) 1989 Annual Report. PNL-SA-17654, Pacific Northwest Laboratory, Richland, Washington.

Weygandt, W. S., T. L. Stewart, T. M. Brouns, and E. O. Jones. 1988. Waste Acid Detoxification FY 1988 Annual Report. PNL-SA-16431, Pacific Northwest Laboratory, Richland, Washington. 


\subsection{CHEMICAL OXIDATION}

Chemical oxidation technology encompasses those chemical processes in which oxidizing agents are added to a waste stream at or near ambient conditions in order to oxidize susceptible components in the waste. This technology is a subset of chemical reduction/oxidation or REDOX technology whereby two different chemical species react in such a manner that the oxidation s'iate of one reactant is increased while the oxidation state of the other reactant is decreased. (Chemical reduction is covered in Section 4.14.) Technically, chemical reduction and oxidation are occurring simultaneously. Chemical oxidation generally refers to those reactions in which the oxidation of the target (and presumably toxic) element is intended.

\subsubsection{Process Description}

In a typical chemical oxidation process, liquid or gaseous oxidizing agents are mixed with wastewater in a mixing vessel and allowed to react over a period of time sufficient to achieve the desired degree of oxidation. organic compounds are degraded into carbon dioxide, water, and other organic compounds.

Chemical oxidation is widely used to treat a variety of both hazardous and nonhazardous chemicals. Iis primary use is in destroying cyanides and a variety of organic compounds. It has also been used to precipitate soluble iron and manganese (De Renzo 1978). One study (Cushnie, Hande1, and Roberts 1983) indicated that chemical oxidation may be applicable for precipitating $\mathrm{Cd}, \mathrm{Cu}$, and $\mathrm{Ni}$ as oxides and hydroxides.

The most common commercially available oxidation agents in the order of decreasing oxidation power are ozone, hydrogen peroxide, potassium, permanganate, hypochlorite (sodium-, calcium-), and chlorine. Other, less commonly used chemical oxidizing agents include calcium polysulfide, chlorine dioxide, fluorine, nitrates, nitrous acid, bromates, chromates, and chromic acid.

The choice of chemical oxidant is a tradeoff between cost, convenience, and oxidizing power. Chlorine is very low in cost but must be stored and administered as a gas. Hypochlorites and permanganates are more expensive but 
are the easiest to use because they are readily available and are easily stored in solid or liquid form. Hydrogen peroxide is intermediate in cost, but it must be handled with care because it releases heat and oxygen upon decomposition (Freeman 1989). Ozone is the strongest oxidant. However, it is very unstable and cannot be stored for any length of time. Therefore, it must be made onsite and is generally expensive.

A major limitation of chemical oxidation is tilat the oxidation reactions are frequently not complete. Thus, there is a prssibility that the intermediate products will be toxic and require furthor treatment.

Most recent research on chemical oxidation has been in improving the performance of the stronger oxidants: hydrogen peroxide and ozone. One technique has been to combine UV with ozone or hydrogen peroxide (Breton et a1. 1988). Ultraviolet light is known to accelerate the decomposition of certain functional groups that are highly resistant to chemical oxidation. Research has shown that combining the two results gives a synergistic effect, thus improving the efficiency of destruction. Research has also shown that ultrasonics and other methods of inducing cavitation in a wastewater solution can be used to improve overall destruction efficiency (Breton et al. 1988). Finally, several catalysts have been identified that improve oxidation of certain organics with hydrogen peroxide in an acidic solution. These catalysts include $\mathrm{Fe}(+2), \mathrm{Fe}(+3), \mathrm{Al}(+3), \mathrm{Cu}(+2)$, and $\mathrm{Cr}(+2)$ (EPA 1983).

Recent research at PNL and in the United Kingdom (Chemical and Engineering News 1989) has also identified an innovative electrochemical oxidation system in which organics are completely oxidized in a nitric acid solution. A catalyst such as $\mathrm{Ce}(+4)$ or $\mathrm{Ag}(+2)$ is used in the system to provide high oxidation potential for the system. One apparent advantage of this system is that the organics are completely decomposed to relatively innocuous gases at the anode, although some hydrogen is produced at the cathode.

\subsubsection{Applicability to SST Waste}

Chemical oxidation is used to destroy organic compounds and cyanides in aqueous solutions. Because of the relatively high cost of the chemical reagents, application is usually limited to waste streams containing $0.1 \%$ to 
$10 \%$ organics. This would make the process applicable to any of the SST waste streams containing organics. Because chemical oxidation is a REDOX reaction it may also occur with any inorganic compound whose constituents can be raised to a higher oxidation state. Thus, corsideration must be given to solid wastes that have been treated to remove metal or radioactive ions from solution, because chemical oxidation may resolublize those constituents if they are present in the solid. Conversely, the dissolved ions of many metals and radionuclides will generally be unaffected because they are already in an elevated oxidation state (Sims and Bass 1984).

\subsubsection{Cost}

Typical cost for conventional chemical oxidation is about $\$ 230 / 1000$ gal (De Renzo 1978). No costs were available for electrochemical oxidation.

\subsubsection{Opportunities for Improved Processing}

Chemical oxidation provides an alterative to incineration for destroying relatively low levels of organics in aqueous solutions. Research needs to be conducted to adapt this technology to the SST waste, particularly with respect to the heavy metals and radionuclides present. In particular research needs to evaluate the use of ultraviolet light, cavitation, and electrochemical concepts for improving the performance of the technology to completely degrade the organics present in the SSTs.

\subsubsection{References}

Breton, M, P. Frillici, S. Palmer, C. Spears, M. Arienti, M. Kravett, A. Shayer, and N. Suprenant. 1988. Treatment Technologies for Solvent Containing Wastes. Noyes Data Corp., Park Ridge, New Jersey.

Chemical and Engineering News. 1989. 67(24):27.

Cushnie, G. C., E. D. Hande1, and C. G. Roberts. 1983. An Investigation of Technologies for Hazardous Sludge Reduction at AFLW Industrial Waste Treatment Plants Volume 1: Sodium Borohydride Treatment and Sludge Handling Technologies. ESL-Tr-83-42, Engineering and Services Laboratory, Air Force Engineering and Services Center, Tyndall Air Force Base, Florida.

De Renzo, D. J., ed. 1978. Unit Operations for Treatment of Hazardous Industrial Wastes. Noyes Data Corp., Park Ridge, New Jersey. 
Sims, R., and J. Bass. 1984. Review of In-Place Treatment Techniques for Contaminated Surface Soils - Volume 1, Technical Evaluation. EPA-540-2-84003a, PB85-124881, U.S. Environmental Protection Agency, Cincinnati, Ohio.

U.S. Environmental Protection Agency (EPA), 1983. Treatability Manual Volume Three Techrol ogy for Control/Removal of Pollutants. EPA/600/2-82-001c, Washington. $\mathrm{DC} / \mathrm{C}$ 


\subsection{CHEMICAL REDUCTION}

Chemical reduction technology encompasses those chemical processes in which reducing agents are added to a waste stream at or near ambient conditions in order to reduce susceptible components in the waste. It is mainly used as a means of reducing the oxidation state of heavy metals.

Chemical reduction has primarily been used to reduce the hexavalent chromium to the less toxic and more easily precipitated trivalent chromium. The technology has been used commercially for the reduction of other heavy metals including mercury, silver, and lead; and studies have been conducted on cadmium, copper and nickel (Cushnie, Crampton, and Roberts 1983), hexavalent seleniuni (Sims and Bass 1984), and antimony (Unterberg et a1. 1987). Most of the heavy metals are precipitated as the reduced metal or insoluble salt. Chemical reduction has also had some use in the reduction of certain organi compounds, including several chlorocarbons such as trichloroethylene and chlorobenzene, mono, di- and tri-nitrophenols, kepone, and atrazine (Sims and Bass 1984) as well as ketones and amides (Freeman 1989). Similarly, the reaction rate of nitrate reduction is very slow at ambient or near ambient conditions, and some $\mathrm{NO}_{x}$ formation will occur. However, the levels of $\mathrm{NO}_{x}$ produced would be relatively low and could be treated. Also, the reaction takes place under ambient conditions. Preliminary research results reported by Rocky Flats (Meile and Johnson 1984), using a 10\% sodium nitrate solution were somewhat encouragirg. Chemical reduction is typically used on dilute waste streams where the TDSs are no more than a few thousand ppm (De Renzo 1978).

\subsubsection{Process Description}

Chemical reduction processes can be divided into two groups, conventional and electrochemical.

\section{Conventional Chemical Reduction}

In principle, these chemical reduction processes are similar to chemical oxidation processes in which a reducing agent is added to a wastewater to react with susceptibie components causing them to re reduced. The most commonly used reducing agents are sulfur dioxide, sodium metabisulfite, sodium bisulfite, ferrous sulfide, and ferrous suifate. other, less commoniy used 
reducing agents include hydrogen sulfide, hydrosulfites, calcium sulfite, sodium borohydride, metallic iron, metallic zinc, and metallic aluminum. Like chemical oxidation, the choice of reductant is based on relative reducing power, cost, and ease of application.

The chemical reducing agents can be divided into several groups:

1. Certain compounds produce sulfurous acid as the actual reducing agent and reduce the target element into a sulfate compound. These agents include sulfur dioxide, sodium metabisulfate, sodium sulfate, hydrosulfites, and calcium sulfite. Ferrous sulfate also reduces target elements to produce sulfate compounds through direct reduction.

2. Hydrogen sulfide, sodium sulfide, and ferrous sulfide all act to reduce metal ions and convert them into an insoluble metal sulfide. In this case, both reduction and precipitation are accomplished simuitaneousiy.

3. Sodium borohydride works in an alkaline solution in conjunction with $\mathrm{OH}^{-}$ions to reduce many metals to their elemental form. It is also frequently used in reducing organic compounds.

4. Iion, zinc, manganese, and aluminum undergo a substitution reaction in which they are oxidized to a soluble state in exchange for precipitation of the target metal ion as a reduced metal. This process is called cementation in the metals refining industries and is used to recover copper and cadmium from solution by deposition on iron or zinc scrap. The substitution is accomplished by passing the metal-contaminated wastewater through a bed of metal particles, or turnings. The process proceeds spontaneously with metal that are higher in the electromotive series. This phenomenon also occurs with other solids such as activated carbon (recovery of gold) and sulfur (precipitation of mercury) and is referred to as precipitation or adsorption.

\section{Electrochemical Reduction}

Metals can be reduced using electrochemical techniques. One technique, electrowinning, is also referred to as electrolytic recovery or electrolysis. In electrowinning, a metal-ion-laden wastewater is passed through an electroTytic cell. The metal ion is reduced as elemental metal on the cathode. At the anion, gases such as oxygen, hydrogen, and nitrogen are generated. The gases that are produced depend on the chemical composition of the solution. 
Electrowinning has been used to recover a wide variety of metals including gold, silver, cadmi um, nickel, nickel-iron alloy, copper, zinc, cobalt, and gallium. This technique has also been used for anodic oxidation of cyanide, which is present in many metal plating wastewaters.

In another related electrolytic operation, called electrorefining, an impure metal is placed in the solution as the anode and allowed to dissolve into solution. The electropotential is controlled so that the cathode redeposits oniy the desired metal. This technique has been used to refine bismuth, copper, gold, indium, lead, nickel, silver and tin.

A third variation of electrochemical reduction is electroplating. Electroplating processes are basically electrowinning or electrorefining processes except that the metal to be plated is added as a pure solution or pure anode, respectively. Electroplating has been used with antimony, arsenic, brass, bronze, cadmium, chromium, copper, gold, indium, iridium, iron, lead, nickel, palladium, platinum, rhodium, ruthenium, silver, tin, zinc, and lead/t in solder alloys.

Taken collectively it is apparent that electrochemical deposition processes can be used to remove virtually every metal from solution and convert them into a metallic form. However, information on electrowinning is almost always presented in the context of recovery and recycling of pure metals. Thus, it is difficult to ascertain its potential as a scavenger of a number of metals on a single electrode. However, some of the problems encountered in achieving purity suggest that this application to remove impure mixtures could be practical for SST Waste.

Another electrochemical reduction method involves the use of a sacrificial iron anode (Cushnie, Crampton, and Roberts 1983). In this process, an iron anode is allowed to dissolve, thereby releasing ferrous ions into solution. These ions can react as a reducing agent. The process has been commercially employed as a means for reducing $\mathrm{Cr}$ (VI) to $\mathrm{Cr}$ (III) in electroplating solutions. However, it generates three ferrous ions for every $\mathrm{Cr}$ ion reduced. Thus, any subsequent precipitation with hydroxide would incur a much larger amount of sludge as ferric hydroxide. The principal advantage of the process is that chromium is reduced at a neutral $\mathrm{pH}$. 


\subsubsection{Applicability to SST Waste}

Chemical reduction is typically used on dilute aqueous waste streams where the total dissolved solids are no more than a few thousand ppm (De Renzo 1978). Therefore, it would be most applicable for the denitrated aqueous waste streams. Chemical reduction can be used to precipitate heavy metals and presumably certain radionuclides from solution as a free element. It can also be used to reduce the oxidation state of other heavy metals such as selenium. This technology is necessary as a pretreatment for reducing $\mathrm{Cr}$ (VI) to $\mathrm{Cr}$ (III) in order to precipitate the chromium. The main advantage of chemical reduction is that the metals are often removed from solution as an element and thus generate a minimum of sludge. The recovered metals may also lend themselves to subsequent refining by a variety of processes.

The use of electrochemical reduction is less clear at this time in the context of nonselective metal ion reduction. The process may offer the advantage of either selective or nonselective removal of a number of heavy metals and possibly radionuclides as a mixture by applying a relatively high voltage. However, the economics of such a system are not known and thus cannot be assessed at this time. One advantage of electrochemical reduction over conventional chemical reduction is the removal of heavy metals without the addition of chemicals except to adjust optimum pH. Another advantage is the ability to stop the reaction by turning off the electrical supply.

\subsubsection{Process Cost}

Typical costs for chemical reduction range from $\$ 150$ to $\$ 250 / 1000$ gal (De Renzo 1987; Freeman 1989). Meaningful unit costs for electrochemical reduction processes were not available. Unit costs for electrowinning depend on the inlet and outlet concentrations required, as well as whether the metals are complexed. Byproduct credits are also important in overall economics.

\subsubsection{Opportunities for Improved Processing}

Chemical reduction is well developed for many other applications. However. chemical reduction and, in particular, electrochemical reduction proceses appear to offer potential opportunities for both removing heavy metals and radionuclides and purifying these materials. In addition, this technology 
should be applicable to the reduction of toxic anions such as pertechnate by reducing the metal to a lower oxidation state. Specific processes need to be investigated more thoroughiy in the context of the SST waste composition and unique disposal problems to better assess the true potential for the technology. This research should encompass both in-depth investigations of the metals refining and electruplating industries as well as experimental research.

\subsubsection{References}

Cushnie, G. C. Jr., P. Crampton, and C. G. Roberts. 1983. An Investigation of Technologies for Hazardous Sludge Reduction at AFLW Industrial Waste Treatment Plants; Volume II: Literature Review of Available Technologies for Treating Heavy Meta7 Wastewaters. ESL-Tr-83-42, Engineering \& Services Laboratory, Air Force Engineering and Services Center, Tynda 11 Air Force Base, Florida.

De Renzo, D. J., ed. 1978. Unit Operations for Treatment of Hazardous Industrial Wastes. Noyes Data Corp., Park Ridge, New Jersey.

Freeman, H. M., ed. 1989. Standard Handbook of Hazardous Was ce Treatment and Disposal. McGraw-Hill Book Company, New York.

Meile, L. J., and A. J. Johnson. 1984. Waste Generation Reduction--Nitrates FY 1983 Status Report. RFP-3619, Rockwe11 International, Golden, Colorado.

Sims, R., and J. Bass. 1984. Review of In-Place Treatment Techniques for Contaminated Surface Soils - Volume 1, Technical Evaluation. EPA-540-2-84$00^{2}$ ?, PB85-124881, U.S. Environmental Protection Agency, Cincinnati, Ohio.

Unterberg, W., R. W. Melvold, S. L. Davis, F. J. Stephens, and F. G. Bush III. 1987. Reference Manual of Countermeasures for Hazardous Substances Releases. EPA/600/2-87/069, U.S. Environmental Protection Agency, Cincinnati, Ohio. 


\subsection{HIGH TEMPERATURE WATER TREATMENT}

High temperature water treatment technology includes three processes that use high temperature to enhance chemical decomposition of organics in aqueous waste streams, without the need for incineration. These process are:

- wet air oxidation

- supercritical water oxidation

- catalytic destruction.

These processes are grouped together because they share similar processing objectives and operating conditions as well as ranges of applicability. Specifically, all three processes have been developed to provide complete and nonselective decomposition of organics in wastewater without resorting to incineration. All of these processes are characterized by the use of temperatures above the normal boiling point of water but below temperatures normally associated with incineration. The associated pressures required to maintain the water in a liquid or supercritical state range from about 300 to 4000 psi. Incineration processes, on the other hand, operate at temperatures that generally preclude using pressures much above 300 psi because of materials limitations. All three processes are applicable to a concentration range of approximately $1 \%$ to $10 \%$ organics. Within this range, the organics are ton costly to incinerate and yet are too toxic to biotreat effectively. Conventional chemical oxidation and hydrolysis are considered appropriate in this range, but both suffer from being selective to specific compounds. Separation processes can be used to concentrate the organics further but are generally prohibitively expensive.

\subsubsection{Process Description}

While the three technologies share a number of similarities, each operates under distinctly different conditions. A description of each process is given below.

\section{Wet Air Oxidation}

In wet air oxidation, the most developed of the three processes, dissolved or suspended oxygen-demanding components of a wastewater are heated and 
pumped into a high pressure reactor and subsequently oxidized using an oxygencontaining gas, such s air bubbling through the aqueous phase. Depending on the material to be ox,dized the temperature ranges from $150^{\circ} \mathrm{C}$ to $325^{\circ} \mathrm{C}$ (Freeman 1989). Correspondingly, the reactor is pressurized to 300 to 3000 psig to maintain a liquid water phase. Organic compounds are corlverted to carbon dioxide and water; organic sulfur is oxidized to sulfate; and organic nitrogen is converted to ammonia (Freeman 1989). Metals generally are converted to their highest oxidation state and remain in the aqueous phase as dissolved or suspended solids. Halogens also stay in the aqueous phase. With most organic compounds, $>99 \%$ destruction is achieved with residence times ranging from 15 min to $1 \mathrm{~h}$. Chlorinated aromatics are the one class of compounds that are not easity destroyed by the process.

\section{Supercritical Water Oxidation}

Supercritical water oxidation (SCWO) is similar to wet air oxidation, except that the system is operated at a temperature and pressure above the critical point of water $\left(374^{\circ} \mathrm{C}\right.$ and $\left.218 \mathrm{~atm}\right)$ that prevents the formation of a separated liquid water phase. Consequently, the mixing of water, air, and organics takes place in a single fluid phase, which improves the oxidation rates. Also, because higher temperatures and pressures are involved, the reaction rates are enhanced.

In laboratory and pilot studies, temperatures for SCWO range from $400^{\circ} \mathrm{C}$ to $650^{\circ} \mathrm{C}$ and pressures are about $250 \mathrm{~atm}$ (Freeman 1989). Residence times generally range from 1 to 5 min depending on the temperature, with some conversions above $99.9 \%$.

Although SCWO requires severe operating conditions, it offers the highest conversion for comparable residence times and should be the least selective in terms of organics treated. One potential problem is that the process experiences difficulties in treating wastes high in salt content (Freeman 1989). The process is still in the developmental stage.

\section{Catalytic Destruction}

Catalyic destruction employs a catalyst to convert hazardous organics in aqueous streams into methane, carbon dioxide, and hydrogen. While 
hydrolysis should $\mathrm{play}$ a role under the conditions of the reactor (typically $3000 \mathrm{psi}$ and $350^{\circ} \mathrm{C}$ ), the nickel catalyzes hydrogenolysis, methanation, and water gas shift reactions (Baker and Sealock 1988). The net effect is that essentially equilibrium quantities of carbon dioxide, methane, and hydrogen are produced. Inorganic nitrates are reduced to elemental nitrogen. Organic nitrogen in the form of amines has been shown to convert to ammonia.

Key advantages of the process are that since water is the only reactant, high pressure oxygen sources are not required. This feature results in simpler construction requirements compared with the other two processes. The process is also very rapid and relatively nonselective, with most orcanic compounds achieving $>99 \%$ destruction in less than $10 \mathrm{~min}$. Additional research is still required to determine whether halogenated hydrocarbons can be treated because of the potential for catalyst deactivation of halides.

\subsubsection{Applicability to SST Waste}

High temperature water treatment processes could be an appropriate technology for destroying organics and nitrates in SST waste where organic content is expected in the range of $1 \%$ to $10 \%$. Each process appears to offer tradeoffs between efficiency, applicability, cost, and level of development. Thus, it is not possible to give preference of any one process over the other at this time, particularly with catalytic destruction and supercritical oxidation sti1l in the developmental stage. The principal disadvantages of all three processes is the high pressures and relatively high temperatures required. However, this should be balanced against higher temperatures required for incineration and the lower degree of detoxification offered by biodegradation, hydrolysis, and chemical oxidation in this concentration range.

\subsubsection{Process Cost}

Over 150 wet air oxidation units have been sold primarily for treating municipal sludge (Breton et al. 1988). Costs for wet air oxidation are estimated by one manufacturer to range between $\$ 94$ and $\$ 250 / 1000$ gal (California DHS 1989). Freeman (1989) estimates operating and maintenance costs as $10 \mathrm{w}$ as $\$ 30 / 1000 \mathrm{gal}$ for a $70 \mathrm{gpm}$ unit. Capital cost would add about $\$ 15$ to $\$ 30 / 1000$ gal to this cost. 
Processing costs for supercritical water oxidation have been estimated to range from $\$ 100$ to $\$ 200 / 1000 \mathrm{gal}$ for 20 to $174 \mathrm{gpm}$ capacity systems (Freenan 1989).

Processing costs for catalytic destruction is projected to range from $\$ 20$ to $\$ 30 / 1000$ gal (Baker et al. 1989).

\subsubsection{Opportunities for Improved Processing}

All of the high temperature water treatment processes are relatively new technologies, with wet air oxidation considered to be commercial and the other two processes developmental. The main opportunity for developing any of these technologies is that they offer an alternative to incineration for destroying organic wastes in aqueous waste streams.

\subsubsection{References}

Baker, E. G., and L. J. Sealock, Jr. 1988. Catalytic Destruction of Hazardous Organics in Aqueous Solutions. PNL-649l-2, Pacific Northwest Laboratory, Richland, Washington.

Baker, E. G., L. J. Sealock, Jr., R. S. Butner, D. C. Elliott, G. G. Neuenschwander, and N. G. Banns. 1989. "Catalytic Destruction of Hazardous Organics in Aqueous Wastes: Continuous Reactor System Experiments. "Hazardous Waste \& Hazardous Materials 6(1):87-94.

Breton, M, P. Frillici, S. Palmer, C. Spears, M. Arienti, M. Kravett, A. Shayer, and N. Suprenant. 1988. Treatment Technologies for Solvent Containing Wastes. Noyes Data Corp., Park Ridge, New Jersey.

California Department of Health Services (DHS). 1989. Site Cleanup Treatment: Technologies, Summaries of Responses to July 1988 Solicitation of Interest. Sacramento, California.

Freeman, H. M., ed. 1989. Standard Handbook of Hazardous Waste Treatment and Disnosal. McGraw-Hill Book Company, Ne'w York. 


\subsection{ROASTING}

Roasting is a high temperature process used to change the chemical form of certain solid materials. Typically, roasting is used to oxidize sulfide metal ores to their corresponding oxides or sulfates. In certain applications roasting is used to chloridize other elements such as uranium, beryllium, niobium, zirconium, titanium, and vanadium in either an oxidizing or reducing atmosphere to the corresponding chloride (Gilchrist 1980). This latter application is used where the oxide form of the respective metals is too stable to easily be reduced to the pure metal. Roasting is also applied to hematite to produce inagnetite, and occasionally applied to the reduction of certain metal oxides to produce the metal prior to smelting or leaching. Some roasting operations are conducted to eliminate elements such as As, Sb, and $\mathrm{Zn}$ by volatilizing their corresponding oxides and recovering the fume. Rocky flats used roasting to convert pyrophoric uranium scrap into uranium oxide prior to encapsulation in Portland cement for disposal.

\subsubsection{Process Description}

Roasting can be accomplished in a rotary kiln or a shaft furnace. Solids are added to the furnace and heated to a high temperature that is still below the melting point of the principal cunstituents. A reactive gas is added to the reactor to chemically react with the solids. Since a chemical reaction is occurring that involves a component of the furnace atmosphere, mass transfer considerations must also be taken into account. Thus, multiple hearth furnaces, fluidized bed furnaces, and flash furnaces (in which pul. verized ore is injected through a burner with air, much like a puiverized fuel) are used to facilitate gas/solid mixing. In addition to having good mass and heat transfer, both furnace temperature and the furnace atmosphere must be considered jointly because often more than one oxidation state is possible for the metal being roasted, allowing for more than one kind of oxide to form.

\subsubsection{Applicability to SST Waste}

Roasting may offer a means for treating SST tank sludge to facilitate the separation of TRU and/or other components. It is not possible to 
determine the specific opportunities that may be available. However, it is likely that the sludge will be fairly finely divided and thus would be a in a form that would facilitate gas/solid interactions. Roasting may be applicable as a treatment in itself or as a pretreatment before leaching. As a pretreatment roasting would more than likely be used to oxidize the various components in the sludge into higher states, which in turn would be more soluble in an acid leach. As a separate treatment, roasting may produce volatile components that could be separated as a fume and subsequentiy recovered. Alternatively, the use of roasting to produce chlorides which lend themselves to alternative separation and recovery processes may be practical.

\subsubsection{Cost}

Process costs were unavailable for this technology. Presumably the costs would be comparable to those for calcining.

\subsubsection{Opportunities for Improved Processing}

Roasting is a well-developed process for many applications. However, its application to SST solids would require extensive research to determine the type of roasting techniques most suitable for recovery of specific materials.

\subsubsection{References}

Gilchrist, J. D. 1980. Extractive Metallurgy, 2nd Edition. Pergammon Press, Oxford, England. 


\subsection{CALCINING}

Calcination is a high-temperature process used to change the chemical form of certain solid materials. Calcining involves the thermal decomposition of hydrates, carbonates, and nitrates into water, carbon dioxide, and nitrogen (and/or $\mathrm{NO}_{x}$ ), respectively.

\subsubsection{Process Description}

Calcination is typically performed in rotary kilns, shaft furnaces, or fluidized bed furnaces (Rosenqvist 1984). Material to be calcined is added as a solid, slurry, or aqueous waste stream to a hot chamber and heated to the point where the solids decompose. Shaft furnaces are usually heated directly using coke in the furnace or indirectly by burning fuel $0 i 1$ in an adjacent chamber and passing the fiue gases through the furnace. Rotary kilns are fueled indirectly with oil, gas, or pulverized coal. Fluidized beds are fueled directly using fuel oil injected into the bed. Fuels are burned with excess air to ensure complete combustion of the fuel. Since decomposition of the material is the primary objective in calcination, adequate temperature and good heat transfer are the primary considerations in designing a process.

Calcining has been used in a number of applications, including smelting of metal ores, manufacture of cement and lime, treatment of oily petroleum sludges, and treatment of liquid radioactive wastes (Unterberg et al. 1987). The main advantage of calcining is that it can perform several actions in a single step, inciuding concentration of waste, separation of water, and destruction of organics, nitrates, and carbonates, as well as altering the chemical properties of the remaining solids. The main disadvantage of calcination is that it is an energy-intensive, high-temperature process and produces gaseous emissions such as $\mathrm{NO}_{x}$ and particulates, which require extensive flue gas treatment.

\subsubsection{Applicability to SST Waste}

For the SST wastes, the principal application would be in the calcining of various nitrates to their corresponding oxides. This could be applied either directiy to the brine or to any process where caustic soda is added and subsequently neutralized. An important consideration in calcining the brine 
is the large quantity of sodium present that will be converted to sodium oxide $\left(\mathrm{Na}_{2} \mathrm{O}\right)$. This substance is very alkaline and will hydrate to caustic soda. However, it may be possible to add a second component to convert the sodium to another compound such as a silicate or a carbonate. By performing a calcining operation on the nitrate brine evaporation of water and destruction of the organics and nitrate will also result.

\subsection{7 .3 Cost}

Processing costs for calcining typically range from $\$ 15$ to $\$ 20 / 1000 \mathrm{gal}$ (De Renzo 1978).

\subsubsection{Opportunities for Improved Processing}

Calcining is a well-developed technology for many applications. However, application of this technology to SST waste would require additional research to determine the operating parameters to produce a suitable solid residue for disposal.

\subsubsection{References}

De Renzo, D. J., ed. 1978. Unit Operations for Treatment of Hazardous Industrial Wastes. Noyes Data Corp., Park Ridge, New Jersey.

Rosenqvist, T. 1974. Principles of Extractive Metallurgy, pp. 228-255. McGraw-Hil1 Book Company, New York.

Unterberg, W., R. W. Melvold, S. L. Davis, F. J. Stephens, and F. G. Bush III. 1987. Reference Manual of Countermeasures for Hazardous Substances Releases. EPA $/ 600 / 2-87 / 069$, U.S. Environmental Protection Agency, Cincinnati, Ohio. 


\subsection{INCINERATION}

Incineration is a high temperature thermochemical process used to completely oxidize organic wastes in solid, gaseous, and liquid waste streams. Incineration is used to treat contaminated soils, organic debris, sludge, activated carbon, aqueous streams containing more than $5 \%$ to $10 \%$ organics, and gaseous streams containing organic contaminants. The principal products of incineration processes are flue gas, containing primarily carbon dioxide and water with trace amounts of fly ash and other gases, and ash, which is rich in minerals and any heavy metals. Flue gas from the incinerator is usually scrubbed for $\mathrm{NO}_{x}, \mathrm{SO}_{2}, \mathrm{HCl}$, and trace quantities of organic vapors and ash. The ash stream leaving the incinerator is quenched and subsequently disposed of in some form of landfill.

\subsection{Process Description}

All incinerators operate on the same general principles. Specifically, incineration is a gas phase oxidation process. Regardless of the original state of the organic material, the hydrocarbons within it must first be converted into a gas through volatilization, and pyrolytic decomposition to volatile gases, or through gasification of residual char to hydrogen and carbon monoxide. These gases are in turn mixed with oxygen and combusted to carbon dioxide and steam.

The efficiency of an incinerator to dispose of hazardous wastes depends on both the degree of vaporization of the original waste and the degree of oxidation of the vapors. In both cases, destruction efficiency is predominantly a function of time, temperature, and degree of mixing. In addition, the degree of oxidation is a function of the amount of oxygen available to achieve complete destruction. In a well-designed system, available oxygen and the degree of mixing are fixed with oxygen typically $50 \%$ greater than the amount required for complete combustion. Time and temperature can be varied by varying the size of the combustion chamber and the amount of supplemental fuel added for a given throughput of waste. Increasing time and/or temperature results in increased destruction efficiency. Residence times and temperatures on the order of $0.5 \mathrm{~s}$ and $1500^{\circ} \mathrm{F}$, respectively, are typically required for complete combustion of the gases. All types of incinerators 
achieve high destruction efficiencies. However, because of the high temperature involved, they also produce products of incomplete combustion (PICS), which are organic combustion products that often bear no relationship to the original waste. These products must be considered in evaluating the overali toxicity reduction, however.

The main differences in incinerator designs are based on the waste characteristics and the constraints they place on the volatilization of the waste. Thus, incinerators can be divided into chree classes based on the primary feed characteristics for which they are designed. These categories are flare and fume incinerators, liquid injection incinerators, and solid waste incinerators.

\section{Flare and Fume Incineration}

Flare and fume incinerators are designed specifically for combustible gases and vapors. However, because of limitations on particulate control they also process fine particulate and aerosols typically less than $50 \mu \mathrm{m}$ in diameter (Niessen 1978).

Flares are the simplest kind of incinerator. They are used specifically for burning combustible gas mixtures as they are released to the atmosphere. A typical flare consists of a pipe with pilot fuel injected at the top to ensure combustion of the waste gases. Steam is added within the pipe to increase turbulence and to aid in decomposing higher hydrocarbons, through steam cracking, and for consuming residual carbon by gasification. The most common application of a flare is to dispose of periodic releases of combustible gases.

Fume incinerators are more sophisticated than flares in that the combustion is contained in a chamber designed to provide sufficient residence time and to maintain a specified operating temperature. These incinerators are generally near a continuous source of waste gas. Because they are enclosed, fume incinerators can be provided with downstream particulate and acid gas scrubbing systems. Typical residence time ranges from 0.25 to $0.5 \mathrm{~s}$ and temperature ranges from $800^{\circ} \mathrm{F}$ to $1500^{\circ} \mathrm{F}$ (Brunner 1984). Some fume incinerators operate at lower temperatures and use a catalyst to obtain the high 
combustion efficiencies. These systems typically operate at about $650^{\circ} \mathrm{F}$ to $1000^{\circ} \mathrm{F}$ (Niessen 1978). Catalysts include platinum, palladium, rhodium, and copper chromite, as well as oxides of copper, chromium, manganese, nickel, and cobalt. One advantage of catalytic fume incinerators is that they generally produce less $\mathrm{NO}_{x}$. However, they must be used with a gas with low levels of noncombustible particles in order to prevent fouling of the catalyst.

\section{Liquid Incinerators}

Liquid incinerators are designed to combust organic liquid and pumpable sludge. They are similar in design to fume incinerators except that since the waste is in a nongaseous form it must be atomized using a burner nozzle as it is injected into the combustion chamber in order to facilitate volatilization and subsequent combustion. The combustion chamber can be either vertical or horizonta1. Generally, a vertical chamber fed from the top is used when inorganic salts or fusible ash is present in the liquid or sludge in significant quantities. Combustion chamber temperatures range from $1300^{\circ} \mathrm{F}$ to $2200^{\circ} \mathrm{F}$, and residence time ranges from 0.5 to $2.0 \mathrm{~s}$ (Theodore and Reynolds 1987).

Liquid injectors are generally suitable for liquids, slurries or sludge that have a viscosity of 10,000 SSU or less (Theodore and Reynolds 1987). A key design consideration is the ability to atomize the waste stream to sufficiently small droplets, typically 40 to $100 \mu \mathrm{m}$ or smaller to ensure complete vaporization of the waste in the combustion chamber (Theodore and Reynolds 1987).

Atomization depends very strongly on the waste stream to be incinerated, and burner nozzle designs are selected based on the solids concentration and particle diameter, as well as the viscosity of the waste stream. Preheating the feed to temperatures as high as $500^{\circ} \mathrm{F}$ is sometimes employed to reduce viscosity to an acceptable level (usually a viscosity of 750 SSU or less), provided that significant quantities of gases are not evolved. Depending on the atomizer, solids mesh sizes range from 35 to 200 and solids loading varies from $0.0 \%$ to $70 \%$ (Theodore and Reynolds 1987). Waste streams with a higher heating value (HHV) of appr sximately 8000 Btu/1b or greater can sustain combustion and achieve satisfactory destruction. Other design considerations relate to the combustibility of the waste, which depends on such fartors as 
the quantity, composition, volatility, and HHV of the organics in the mixture; the amount of water present; the quantity and composition of solids present; and the presence of key problem inorganic species such as halogens, sulfur, and phosphorous.

Generally, any waste stream can be combusted if sufficient auxiliary fuel is mixed to obtain the HHV necessary to sustain combustion (i.e., $8000 \mathrm{Btu} / \mathrm{lb})$. However, a rule of thumb is that liquid injection is suitable for waste streams containing $10 \%$ organics or greater, due to the cost of auxiliary fuel. Natural gas or propane are the preferred auxiliary fuels because they are already gaseous, but oil can also be used provided the incinerator nozzles are designed for multiple liquids.

Liquid injection incineration is a simple, very well developed process for incinerating hazardous wastes. This method is very efficient, routinely achieving greater than $99.99 \%$ for all organic species. For example, a destruction efficiency of greater than $99.9999 \%$ was reported for destruction of PCBcontaminated 1iquid in a full-scale unit (Breton et a1. 1987). Typical operating capacities for liquid injection incinerators range from 4 to $200 \mathrm{million} B \mathrm{Btu} / \mathrm{hr}$ of heat load with an average of $36 \mathrm{million}$ Btu/hr (Vogel et al. 1988). Maximum liquid capacities range from $25 \mathrm{gpm}$ for organic wastes to $65 \mathrm{gpm}$ for aqueous wastes.

\section{Solid Waste Incinerators}

Solid waste incinerators are designed primarity for combustion of organic solid wastes. However, they are also designed to handle liquid wastes. A11 designs consist of a primary and a secondary combustion chamber. The first chamber is used to decompose and volatilize organic solids and liquids to gases and vapors. Depending on the amount of air added to this chamber some combustion of the gases also occurs. The second chamber, usually called an afterburner, is designed like a fume incinerator for complete combustion of the gases and vapors. In some systems the second chamber is designed to acrept liquid wastes too.

Solid waste incinerators contain more unique process configurations than any other hazardous waste technology except perhaps biodegradation. This is 
due in large part to the oriving forces to destroy hazardous organic wastes, and the technical difficulties introduced by the processing of solids.

The driving force in the design of a solid waste incinerator is decomposition and volatilization of the organic solids and adsorbed liquids.

Successful decomposition and volatilization of the solids and liquids depend on efficient convective and radiative heat transfer to the solids surfaces. Thus, an interplay among primary chamber temperature, solids agitation, air addition, solid waste dimensions, and solids residence time muct be balanced. In addition, ash particulate entrainment must be considered because of the potential for toxic solids such as heavy metals to be carried over with the flue gas and enter the environment. Other considerations include the possibility that processing solids at too high of a temperature can cause the ash to melt and form a slag within the chamber, which may result in damage.

Finally, solid waste incinerators are designed to maximize flexibility of the size and form of the solid waste being handled.

Principal solid waste incinerator designs include:

- rotary kiln

- multiple hearth

- fluidized bed

- circulating fluidized bed

- multi-solid fluidized bed

- high temperature fluid wall

- controlled air
- infrared

- solar

- pyrolytic

- low temperature decomposition

- enriched oxygen

- cement kiln/lime kiln

- boilers.

Other innovative high temperature thermal decomposition processes use molten solids and plasmas as the means of transferring heat to the solids. Because of the unique operating requirements and principles, they are treated as different categories in this study.

Within the designs listed above the first six are based on different methods of achieving solids mixing to facilitate surface exposure to the primary chamber temperatures. The second six designs are based on different 
methods to minimize ash particulate entrainment in the flue gas by minimizing the volume of nitrogen added with the air. The last two designs are based on the use of existing configurations originally designed for uses other than hazardous wastes.

Regardless of the specific design, all of the solid waste incinerators share many common design features. Solids are added to the primary chamber, which is typically operated at temperatures ranging from $800^{\circ} \mathrm{F}$ to $2300^{\circ} \mathrm{F}$ with the solids residence time ranging from a few minutes to as much as 1 hour, depending on the rate of decomposition of the solids. Usually, the solids and sludge contain $10 \%$ or greater organics to minimize or eliminate the need for supplemental fuel. However, solids with only trace quantities of hazardous wastes have been incinerated. Heat to the primary chamber is provided by combusting a portion of the combustible gases generated or by providing a supplemental fuel or heat source (electric heaters or solar heat). Gas residence time within the primary chamber typically ranges from one to several seconds. Gases leaving the primary chamber are fed directly into the afterburner in which the gases are completely combusted. Gases leaving the afterburner are treated to remove particulate and acid gases.

A11 solid waste incinerators are inherently more complex in design and operation than the other types of incinerators because of the special solids handling requirements. However, many of the designs are we 11 developed and can consistently achieve conversion efficiencies greater than $99.99 \%$.

\section{Gas Particulate Removal}

Heavy metal contamination of incinerator flue gas is becoming an important issue in determining the acceptability of incineration as a means for treating wastes. A similar concern has also been raised regarding the suitability of incineration of radioactive wastes. Total loading of solid particulate in incinerator flue gas is regulated by RCRA to no more than $0.08 \mathrm{gr} / \mathrm{DSCF}$ corrected to $50 \%$ excess air. This corresponds to about $180 \mathrm{mg} / \mathrm{NM}^{3}$ of air corrected for $7 \%$ oxygen in the stack gas. However, there 
are no subordinate limits regarding specific toxic components of the particulate. Consequently, concern has been raised by the public regarding the acceptability of the current limit for the protection of the environment from heavy metals in the flue gas.

A number of processes are typically used to remove particulate from flue gas streams. These processes include wet scrubbers (venturi), baghouse filters, electrostatic precipitators, high efficiency barrier type filters, HEPA filters, and porous metal/ceramic filters.

Baghouse filters are the simplest and most efficient of the particulate filters. Baghouse filters consist of woven or felted fabric through which dust. 1 aden gases are forced. As dust builds up on the fabric the pressure drop across the filter increases. Consequently, periodic cleaning is required. An important feature of baghouse filters is the high efficiency (>99\%) removal of small particles as small as $1 \mu \mathrm{m}$ (Brunner 1984). They are also capable of collecting substantial quantities of particles as small as $0.01 \mu \mathrm{m}$ (Theodore and Reynolds 1987). Limitations include requirements for low humidity, relatively low gas temperature $\left(200^{\circ} \mathrm{F}\right.$ to $\left.550^{\circ} \mathrm{F}\right)$, and the need for periodic cleaning.

Electrostatic precipitators are also very efficient, with particulate removal efficiencies ranging from $86 \%$ to $98 \%$ for $1-\mu \mathrm{m}$ particles, depending on the specific design-and application. They are not limited by temperature and do not need periodic cleaning. Besides a slightly lower collection efficiency than baghouse filters, electrostatic precipitators also are sensitive to the resistivity of the particles to be collected and gradual loss of efficiency with time (Brunner 1984).

Wet scrubbers depend on the entrainment of liquid droplets in the flue gas to collect particulate by impingement. Wet scrubbers offer the dual purpose of collecting gaseous components such as $\mathrm{HCl}$ and $\mathrm{NO}_{x}$ gases in addition to particulate and do not require periodic cleaning. While many wet scrubber designs are much less efficient at collecting 1 - $\mu$ m particles, a venturi scrubber is capable of removal efficiencies approaching the more efficient electrostatic precipitators (Brunner 1984). 
HEPA (high efficiency particulate air) filters are used where extremely high particulate removal efficiencies are required. They were originaliy devel zped for the control of particulate at nuclear facilities. They are typically made of a glass fiber mat, pleated to increase its unit surface area, and mounted in a wooden frame. A series of frames are mounted in a filter band to provide the required flow capacity. HEPA filters are capabic of removing over $99.97 \%$ of particles $0.3 \mu \mathrm{m}$ and greater (Brunner 1984). Like fabric filters, HEPA filters eventually become loaded but can be replaced for a low cost.

Porous metal and ceramic filters are designed to withstand temperatures as high as $925^{\circ} \mathrm{C}$. Nomiral nore sizes range from 0.5 to $100 \mu \mathrm{m}$. Typical removal efficiencies are $99.999 \%$ for particles larger than $0.5 \mu \mathrm{m}$ (Baker et al. 1986). Porous metal filters have been used conmercially in catalyst recovery, nuclear waste calcination, and other situations where particulate removal is desired from hot gas streams. Disadvantages of these filters include high cost, slow sintering at high temperature, plugging, and possible failure due to thermal shock. Ceramic filters are being developed to withstand even higher temperatures and to collect very fine particles. These filters suffer many of the same problems as porous metal filters. Further development is continuing on ceramic filters for use in coal gasification systems.

\subsubsection{Applicability to SST Waste}

Incineration is considered to be the best available technology for destroying hazardous organic wastes. This technology should be considered for any process stream containing organics. The best SST waste application of incineration would be the destruction of an organic waste stream once it has been treated to remove heavy metals and nitrates. A liquid incinerator would be the most appropriate configuration in this application. Current concentrations of organics in the SST waste range from $1 \%$ to $10 \%$. Any separation process applied to the aqueous phase to remove nitrates would cause a corresponding increase in the organics concentration.

It may also be practical to incinerate a mixture of nitrates and organics. Nitrates decompose at incineration temperatures and should serve as an 
oxidant for the organics. In this application, however, it is likely that additional fuel would be required to consume all of the nitrates in a controlled manner. It will also be necessary to treat the flue gas for $\mathrm{NO}_{\mathrm{x}}$. Liquid incineration may again be the most suitable process, assuming that the nitrates are dissolved or in a very fine particulate form.

Combustion technology would also be applicable to certain secondary and tertiary solid wastes, including spent ion exchange resins, and biodegradation and bioaccumulation sludges. In these applications, the total volume of contaminated solids can be significantly reduced by destroying the organic components and Teaving a contaminated ash for subsequent disposal.

\subsubsection{Cost}

Typical incineration costs for liquids raige from about $\$ 50$ to $\$ 400 /$ ton (approximately $\$ 200$ to $\$ 1600 / 1000$ gal (Unterberg et al. 1987).

Typical incineration costs for solid wastes range from $\$ 400$ to $\$ 800 /$ ton (Unterberg et a1. 1987). However, large-capacity systems (15 ton/day) could reduce these costs by about $1 / 2$.

\subsubsection{Orportunities for Improved Processing}

The primary concern regarding the applicability of incinerators is the apparent problem of particulate removal from the flue gas. Gas particulate removal technologies are very well developed. Baghouse filters, electrostatic precipitators, and venturi scrubbers are capable of removing particulate to levels required to meet current RCRA criteria. HEPA filters are capable of meeting radioactive particulate criteria. A concern with the technology relates to the need to maintain filtration during system upsets. Because radioactive residues would be involved in the treatment of SST wastes, protection filtration systems must be able to withstand transients such as pressure surges without experiencing failure. Research in this area of concern would need to be conducted in concert with incinerator design.

\subsubsection{References}

Baker, E. G., M. D. Brown, R. H. Moore, L. K. Mudge, and O. C. Elli iott. 1986. Engineering Analysis of Biomass Gasifier Product Gas Cleaning Technology.

PNL-5534, Pacific Northwest Laboratory, Richland, Washington. 
Breton, M, P. Frillici, S. Palmer, C. Spears, M. Arienti, M. Kravett, A. Shayer, and N. Suprenant. 1988. Ireatment Technologies for Solvent Containing Wastes. Noyes Data Corp., Park Ridge, New Jersey.

Brunner, C. R. 1984. Incinerator Systems Selection and Design. Van Nostrand Reinhold Company, New York.

Niessen, W. J. 1978. Combustion and Incineration Processes. Marcel Dekker, Inc., New York.

Theodore, L., and J. Reynolds. 1987. Hazardous Waste Incineration. John Wiley and Sons, New York.

Unterberg, W., R. W. Melvold, S. L. Davis, F. J. Stephens, and F. G. Bush III. 1987. Reference Manual of Countermeasures for Hazardous Substances Releases. EPA/600/2-87/069, U.S. Environmental Protection Agency, Cincinnati, Ohio.

Vogel, G. A., A. S. Goldfarb, R. E. Zier, A. Jewell, I. Licis. 1988.

"Incinerator and Cement Kiln Capacity For Hazardous Waste Treatment." In Proceedings of The 5 th National Conference on Hazardous Waste and Hazardous Materials, pp. 224-227. April 19-21, Las Vegas, Nevada. 


\subsection{MOLTEN SOLID SEPARATION}

Molten solid separation technology includes those processes that use a molten phase to achieve a desired separation of components. These processes are used in the mineral processing and metal refining industries to concentrate and purify minerals.

\subsubsection{Process Description}

Smelting, fire refining, metal-metal refining, and zone refining are processes used for molten solid separation. Each of these is discussed below.

\section{Sri.elting}

Smelting is a melting process in which the components of a solid, upon melting, are separated into two or more layers, which may be slag (composed of mineral oxides), speiss (composed of metal arsenides), matte (composed of metallic sulfides), or metal. Some constituents may also convert into vapors. While smelting is a molten phase reaction and separation technique it is typically performed in a reducing environment using coke as the reductant to produce the desired metal phase.

While the goal of smelting is generally to obtain a relatively pure metal, the smelting process could be used as a means for distributing other materials preferentially into one or more of the other phases. For example, slags are typically molten silicates, containing aluminates, phosphates, antimonates, borates, and fluorides as well as other possible acid constituents (Gilchrist 1980). CaO and $\mathrm{FeO}$ are added as fluxes to reduce the melting point of the slag. Mattes typically collect iron, copper, nickei, cobalt, zinc, lead, gold, silver, and platinum metals as the corresponding sulfides. In this application, sulfur can be added in the form of gypsum or pyrites. Spiess is basically an iron arsenide, which may contain a variety of other elements such as copper, cobalt, lead, antimony, and tin.

\section{Fire Refining}

Fire refining is used to adjust the composition of a metal through chemical reactions that render certain impurities insolubie in the molten metal. Typical reagents are oxygen, sulfur, chiorine, carbon, lime, and zinc. 
Fire refining can also be used to recover specific impurities. For example, lead can be used to collect noble metals as a lead alloy (Gilchrist 1980). Fire refining using oxygen causes lead to separate as lead oxide, leaving behind the molten noble metals. In fire refining, impurities cannot be completely removed, and some contamination of the metal with the reagent usually occurs; however, the process can have some application in the purification and/or concentration of certain components in the molten state.

\section{Metal-Metal Refining}

Metal-metal refining encompasses two techniques, whereby separation and/or concentration of impurities can be obtained using the different properties of different metals or metal alloys. For example, tin contaminated with iron can be purified by careful cooling to solidify and separate $\mathrm{FeSn}_{2}$ as an alloy from molten tin. Another example would be purifying lead containing silver. In this case zinc is melted with the lead to form two iminiscible liquid phases. The silver preferentially dissolves in the zinc to form a number of intermetallic compounds (Rosenqvist 1974).

\section{Zone Refining}

Zone refining is a special case of crystallization in which the solvent is a molten material. Zone refining is used to produce high-purity elements, including semiconductors such as silicon and germanium, and metals such as nickel, lead, plutonium, and uranium (De Renzo 1978). In zone refining, the impure material in the form of a long rod is passed tinrough a heated zone to create a molten state. As the bar leaves the heated zone, the material refreezes as a purer material, causing the impurities to collect at the solid liquid interface. Repeated melting and freezing by passing the material through additional zones in the same direction gradualiy sweeps the impurities to one end of the bar, leaving the other end increasingly pure.

\subsubsection{Applicability to SST Waste}

Molten solid separation technologies may have application to the separation of components from the SST tank insoluble sludge. One of the more likely applications of this type of processing would be in conjunction with glass forming either simultaneously or as a separate step. Glass is essentially a 
slag and certain components in the sludge such as iron, phosphorous, and chromium can create problems with the glass by the formation of a separate phase. By intentionaliy encouraging these separations by the addition of chemical reagents to the melt, including another metal, it may be possible to remove these impurities as a separate phase. The remaining glass phase would be further modified as necessary to achieve the proper disposal form formulation. The most likely processing techniques in this application are smelting or fire refining. Metal-metal refining and zone refining are less likely to be applicable to a glass-forming process. However, there may be applications for these processes in the purification of individual components that had already been separated.

\subsubsection{Cost}

Process costs for the molten solid separations processes were not available.

\subsubsection{Opportunities for Improved Processing}

Smelting offers an alternative method for separating specific components from SST solids. However, extensive research would be required to ascertain the potential of each process for improving the partitioning of these components. Research of fire refining would depend on the type of smelting process developed.

\subsubsection{References}

De Renzo, D. J., ed. 1978. Unit Operations for Treatment of Hazardous Industrial Wastes. Noyes Data Corp., Park Ridge, New Jersey.

Gilchrist, J. D. 1980. Extractive Metallurgy, 2nd Edition, pp. 274-286. Pergammon Press, 0xford, England.

Rosenquist, T. 1974. Principles of Extractive Metallurgy, pp. 228-255. McGraw-Hil1 Book Company, New York. 


\subsection{SAFETY CONSIDERATIONS}

In general, the relative safety of different technologies for treating SST waste is difficult to compare. Many of the technologies are not applicable to the same specific waste streams, waste stream components, or treatment objectives. In addition, specific safety and health hazards imposed by the radionuclides for any one process will vary according to type and concentration of specific radionuclides present. Even in those cases where they are the same, pretreatment or post-treatment requirements imposed by each process may introduce additional safety considerations that cannot be accounted for in a simple comparison of two technologies.

While it is not possible to directly compare technologies, it is possible to determine whether a particular technology would involve operating parameters that would raise the hazard level by either increasing the likelihood of failure or increasing the degree of hazard due to a failure. Table 5.1 summarizes several operational parameters for each technology evaluated in this study. The parameters, discussed below, are temperature, pressure, solids handling, generation or addition of gases, and addition of corrosives. Except where noted the range of each operational parameter applies to all of the processes considered in each technology under typical operating conditions.

Temperature is a safety consideration for several reasons. At temperatures above $212^{\circ} \mathrm{F}$ water will flash to steam, causing contaminants to become airborne. At temperatures above approximately $1200^{\circ} \mathrm{F}$, many materials become limited in the amount of pressure they can withstand without failure.

Pressure is another safety hazard because it can lead to equipment failure as well as an increase in the rate of gas release. Generally, pressures less than about $50 \mathrm{psia}$ are not a major concern. In contrast, at pressures greater than about 300 psia, many materials are limited in their operating temperature.

Solids primarity present an operational problem in that processing equipment is subject to a lower level of reliability and a higher maintenance requirement than comparable systems processing only liquids. This is 
particularly true where solids and slurries are to be pumped to high pressures. Higher maintenance results in greater exposure to the workers.

Gases that are either added to or generated by a process present a hazard mainly because they are not readily contained in the event of a system failure. Furthermore, in processes where gases are generated, a system upset can cause pressure excursions that can potentially lead to system failure.

Corrosives can present a handling hazard to workers and can also lead to system failure. Therefore, increased inspection and maintenance is usually required. 


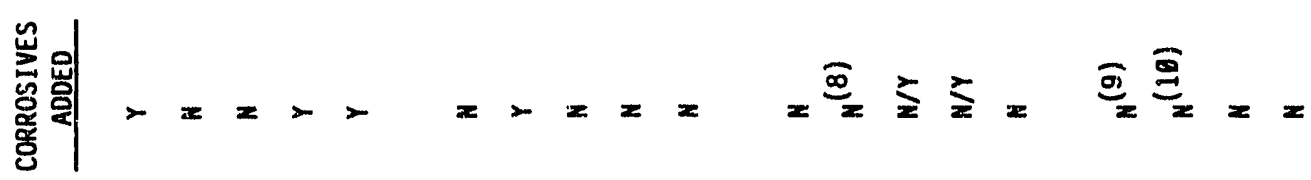

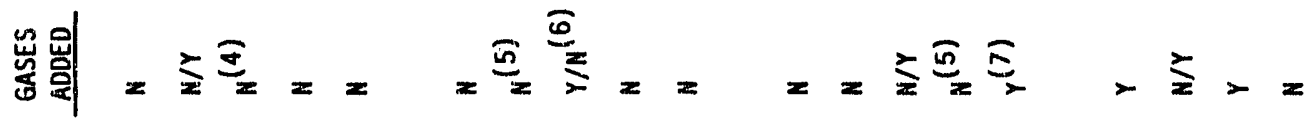

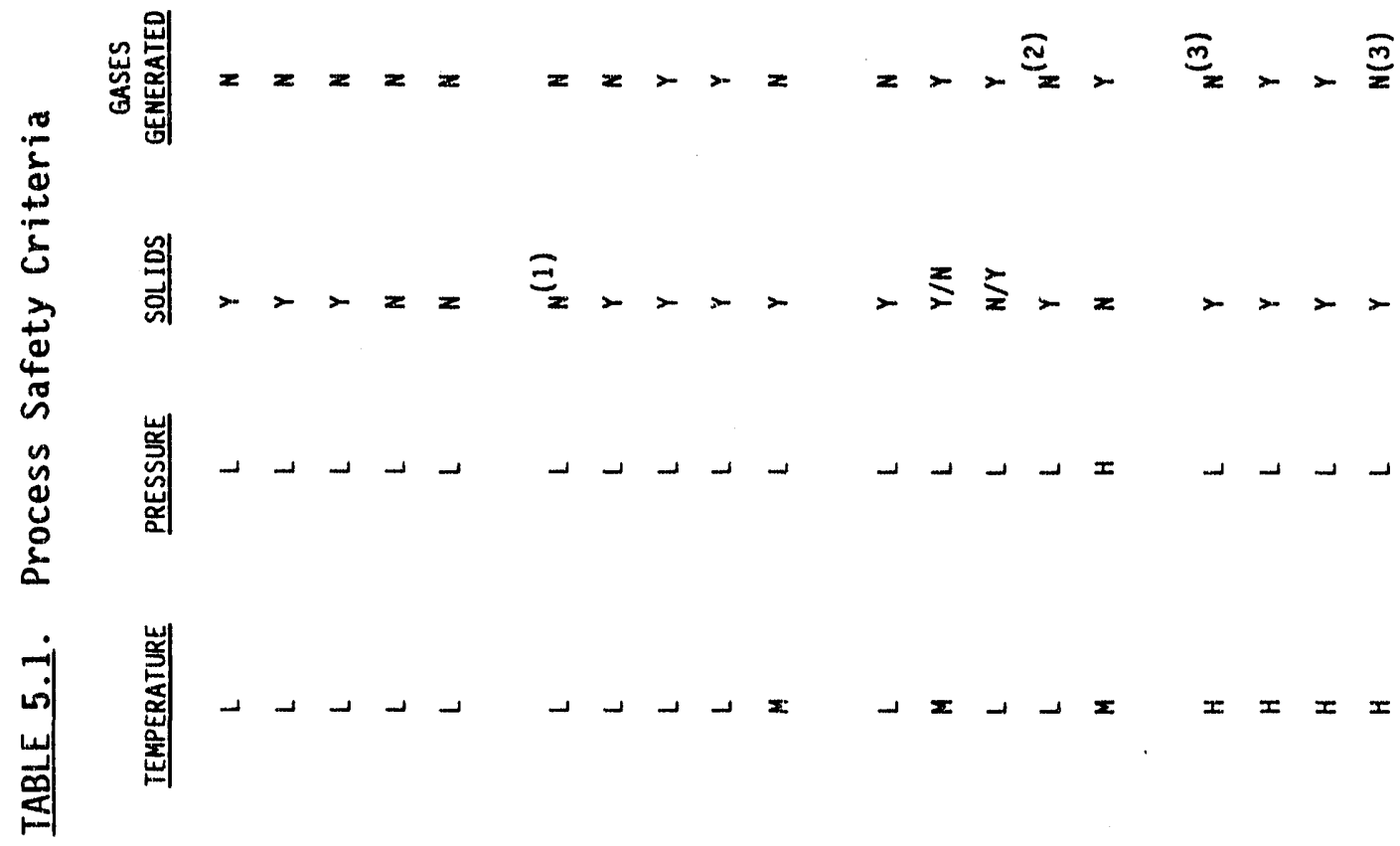

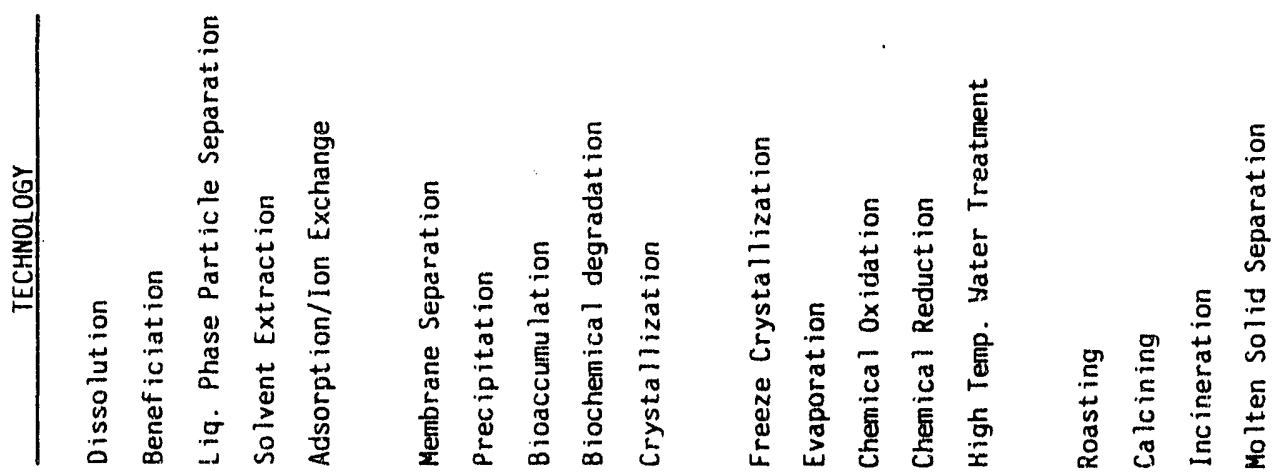

5.3 


\section{LEGEND}

$L=<50$ psia, $<212^{\circ} \mathrm{F}$

$M=>50 \mathrm{psi}^{2} 30 \mathrm{psia}>212^{\circ} \mathrm{F}<1200^{\circ} \mathrm{F}$

$H=>300$ psia, $>1200^{\circ} \mathrm{F}$

$Y=Y e s$

$N=N_{0}$

$Y / N, N / Y=$ either condition predominated by first condition.

NOTES

(1) Reverse osmosis cannot tolerate solids.

(2) Reduction of organics may generate gases.

(3) Volatile metals may be generated.

(4) Flotation requires addition of air.

(5) Certain chemical agents are gases.

(6) Carbon dioxide required to grow algae.

(7) Catalytic destruction does not require gases.

(8) Sulfuric acid added in acid reclamation process.

(9) Corrosives may be added for chloride roasting.

(10) Corrosive solids may be generated. 
APPENDIX A

POTENTIAL CHEMICAL COMPONENTS OF CONCERN 
APPENDIX A

\section{POTENTIAL CHEMICAL COMPONENTS OF CONCERN}

The results of three studies were used to assess and group the major chemicals of potential concern. An ongoing study at PNL is being conducted by P. F. Salter, N. K. Nakaoda, and G. A. Whyatt. The purpose of this study is to characterize the SST tank components and relate them to feedstock requirements necessary to dispose of the SST wastes as borosilicate glass and grout, as is currently planned for disposal of DST waste. The preliminary results of this study provide an estimate of the concentration of elements in the SST waste based on two data bases. The first clata base was generated using a computer model called TRAC to estimate the inventory of 60 chemicals and 30 radioactive isotopes based on fuel production records, fuel and waste processing flow sheets, and tank transfer records. The second data base centered on samples that have been analyzed from 15 SSTs for up to 34 chemicals and 8 radionuclides for both solid and liquid phases.

A second study conducted by M. J. Klem (1990) identified over 300 different chemicals known to be present at Hanford and that are of potential concern for SST waste because they may be present in the tanks. Consequently, these chemicals would be subject to federal and state regulation. Many of these chemicals can be grouped according to key constituents: nitrates and nitrites, organics, toxic metals, radionuclides, and ammonium salts.

The third study was incorporated into an environmental impact statement for the disposal of Hanford defense high-level, transuranic, and tank wastes (DOE 1987). It provides an inventory of principal chemicals and radionuclides present in the sludge, saltcake, and interstitial liquid in the SSTs.

The chemicals identified in these three studies were grouped here according to major categories chosen because of similar chemical behavior and disposal concern in terms of regulatory constraints and chemical behavior. The major chemicals and assigned categories are discussed in the following sections. 


\section{MAJOR SST CONSTITUENTS}

The major classes of SST constituents are nitrates and nitrites; organics and inorganic complexants; radionuclides; heavy metais; other inorganics; and water. Radionuclides can be further subdivided based on quantity present, regulatory requirements for disposal, and variations in chemical behavior. Each of these major classes of constituents and subcategories of radionuclides is discussed below.

\section{Nitrates and Nitrites}

There are approximately 130,000 tons of sodium nitrate in the SSTS, accounting for approximately $72 \%$ of the total tank contents and over $90 \%$ of the salt cake portion of tank waste (DOE 1987). Sodium nitrite accounts for an additional $3 \%$ of tank contents.

Sodium nitrate is a potential disposal problem because it is very water soluble and can adversely impact the performance of grout and other potential disposal waste forms. Sodium nitrate concentrated in wastes to more than $10 \%$ is classified as a hazardous waste according to Washington State codes (WAC 173-303-084 and WAC 173-303-101). Other nitrates present in the tank are of concern mainly because they contain toxic metals and radioactive components and are relatively soluble. Nitrates are also considered to be reactive wastes, placing constraints on required treatments and Jisposal methods. Sodium nitrite is regulated by RCRA as a hazardous waste in levels exceeding $0.1 \%$ (Toxic Category B).

Wastewater containing concentrated scdium nitrate results in adverse impacts on a number of processes, including ion exchange, precipitation, and biological processes. It is considered to be a reactive oxidant and must be accounted for in any thermal process where conventional fuels or other reductants (i.e., ferrocyanides and organics) are present. Because sodium nitrate accounts for nearly $3 / 4$ of the total SST waste and represents a significant quantity, it may be desirable to consider purification and recycling of the nitrate as a product rather than disposal as a waste. Sodium nitrate valued at $\$ 200 /$ ton would represent up to $\$ 25$ million of byproduct credit, as well as $\$ 130$ million in deferred disposal costs as an LLW. 


\section{Organics/Inorganic Complexants}

Approximately $2 \%$ to $5 \%$ of the SST contents are organic compounds that originate primarily from leaching and solvent extraction processes used in the recovery of plutonium. Typical compounds are tri-butyl phosphate and EDTA. However, any number of compounds may exist today as a result of radiolysis and hydrolysis reactions. In addition to the organics there may be other inorganic complexants and organometallic compounds in the SST wastes such as nickel-ferrocyanide and ammonium compounds. While these compounds are usualiy classed separately from organics they share certain traits that justify their collective consideration with the organics. Specifically, the inorganic complexants and the organics interfere with many of the metals separation processes such as ion exchange and precipitation. Also, processes used to destroy organics generally apply to the destruction of inorganic complexants, ammonium compounds, and cyanide complexes.

Many of the organic compounds are considered to be toxic and/or, in the case of nickel-ferrocyanide, a potential reductant for reaction with nitrate. In addition the presence of organics in the SST wastes poses several other problems. First, they are a source of hydrogen currently produced in some of the SSTs and can be expected to be a source of hydrogen in any future waste form provided there is a significant amount of radiation and organic in the waste. Second, the presence of some organic compounds in grout can result in a degradation in the performance of the grout. Third, the presence of organics in waste degrades the performance of several separation processes such as solvent extraction, leaching, ion exchange, and precipitation.

\section{Radionuclides}

A total of 25 radioactive elements including 42 different radioactive isotopes were identified by Salter, Nakaoda, and Whyatt as potentially present in the SST wastes. Within this group, 15 elements were identified as of special concern because of their relative abundance in the SST wastes according to TRAC estimates and/or because they are singled out as specific isutopes of concern. These isotopes are discussed below. 


\section{Transuranics}

Based upon TRAC records, TRU wastes in the SSTs are predominantly composed of plutonium-238, 239, 240, and 241 and americium-241. Other iscitopes of plutonium and americium, as well as neptunium and curium, are indicated as present in the tanks but at levels that are 2 or more orders of magnitude lower. TRU wastes are of concern for both safety and regulatory reasons. These elements are fissile materials and must undergo special handiing to prevent a critical mass from forming. Consequently, there are significant constrainis on the size, configuration, and operating procedures for many unit process operations. One impact of constraints of TRU on processing is that standard cost estimating methods are limited in applicability. TRU elements are also a regulatory concern because the amount present is the principal means for determining the appropriate method of disposal. Specifically, a waste that is found to contain more than $100 \mathrm{nCi} / \mathrm{g}$ alpha radiation is $\mathrm{clas}$ siffed as a TRU waste and disposed of at the Waste Isolation Pilot Plant (WIPP) in New Mexico. A level of $10 \mathrm{nCi} / \mathrm{g}$ or lower must be achieved in order to classify the waste as a Class $A$ LLW.

TRU components affect glass and grout waste forms primarily in terms of fissile material constraints in the case of TRU waste, and heat generation in both glass and grout. TRU materials do not have an adverse effect on the chemical integrity of either waste form. While the total amount of TRU waste accounts for less than $: 00 \mathrm{ppm}$ in the SST waste, the desirability to separate it from the waste to minimize the total quantity requiring disposal as TRU waste may justify consideration of recovering it as a recyclable product.

\section{Strontium}

Strontium-90 accounts for the majority of the radioactivity in the SSTs. It is a beta emitting radioactive material with a half-life of 28 years. The principal concern with strontium is its contribution to the total radioactivity and heat generation in either waste form. Strontium is limited to $1.0 \mathrm{Ci} / \mathrm{m}^{3}, 44.0 \mathrm{ci} / \mathrm{m}^{3}$, and $4600 \mathrm{ci} / \mathrm{m}^{3}$ in $\mathrm{Class} A, B$, and $\mathrm{C} L \mathrm{LW}$, respectively. It has a relatively iow solubility in basic solutions without complexants and is considered compatible with either glass or grout.

\section{A. 4}




\section{Cesfum}

Cesium-137 is a radioactive isotope that is very water soluble in its predominant forms (except for wastes containing nickel-ferrocyanide). However, it has only a 30-year half-life and is not considered to be particulariy toxic, chemically. The principal concern with cesium is that it is a highly radioactive beta emitter, second only to strontium as a contributor to the total radioactivity of the SSTs. Thus, its presence in either waste form contributes to the total radioactivity and heat generation of the waste form. Cesium is 1 imited to $1.0 \mathrm{ci} / \mathrm{m}^{3}, 44.0 \mathrm{ci} / \mathrm{m}^{3}$, and $4600 \mathrm{ci} / \mathrm{m}^{3}$ in Class $A, B$, and $C L L W$, respectively.

\section{Samarium}

Samarium is a member of the lanthanide series. While its isotope samarium-151 accounts for only about. $1 \%$ of the total radioactivity in the SSTs, it ranks third as a contributor to the total radioactivity. It is of concern because it is chemically similar in behavior to TRU elements and will tend to follow the TRU components in many of the separation processes. Thus, it could become a major contributor to the total radioactivity of the TRU waste fraction.

\section{Technetium}

Technetium is a radionuclide with a 210,000-year half-iife. It is principally of concern because of potentially toxic effects. It is also of concern in the disposal of SST wastes because in its most predominant oxidation state ( +7 as pertechnetate) is very soluble in water. Consequently, it should separate with other water soluble species from the insoluble sludge in the SST wastes during removal. There does not appear to be a problem with immobilizing technetium in glass. Unfortunately it is more readily leached from grout than most other inorganic wastes of concern. However, because it is so water soluble, it is difficult to remove from aqueous waste streams that contain the components to be grouted. Because it is radioactive, technetium is limited to $0.3 \mathrm{ci} / \mathrm{m}^{3}$ and $3.0 \mathrm{Ci} / \mathrm{m}^{3}$ in $\mathrm{Class} A$ and $C L L W$, respectively. 


\section{Uranium}

The TRAC records indicate that uranium-238 and 235 are the main isotopes present in the SST waste. Uranium-235 accounts for about $0.6 \%$ of the total uranium. Uranium-238 poses no significant safety or regulatory hazards other than being a contributor towards total alpha decay radioactivity and heat generation within a waste form. Uranium appears to be compatible with either grout or glass. However, being an actinide it will tend to partition with TRU, adding unnecessary mass to this fraction.

DOE (1987) estimated that there are approximately 1400 metric tons of uranium associated with the sludge in the SST waste. This accounts for about $0.8 \%$ of the totai tank contents and $2.6 \%$ of the sludge. This concentration is well above the levels of $0.05 \%$ to $0.2 \%$ found in commercially processed ore (Kent 1983). Therefore, it should be considered for separate recovery as a recyclable product if the opportunity arises. With a value of $\$ 30 / 1 \mathrm{~b}$, uranium in the tanks would represent $\$ 90$ million in byproduct credit as well as $\$ 1.5$ million in deferred disposal cost as grout. The value of depleted uranium, however, could be significantly lower.

\section{Other Radionuclides}

Several other radionuclides are present in small but still significant quantities. The principal concern with these radionuclides is regulatory. These isotopes and the LLW Timits for Class A and C, respectively, are as follows:

- iodine-129-0.008 Ci/m and $0.008 \mathrm{Ci} / \mathrm{m}^{3}$

- carbon-14 $-0.8 \mathrm{ci} / \mathrm{m}^{3}$ and $8.0 \mathrm{ci} / \mathrm{m}^{3}$

- nickel-63-3.5 ci/m and $700 \mathrm{ci} / \mathrm{m}^{3}$

- cobalt-60-700 $\mathrm{ci} / \mathrm{m}^{3}$ and no limit

- tritium - $40 \mathrm{ci} / \mathrm{m}^{3}$ and no limit.

of the remaining radioisotopes identified by TRAC, only tin-126 and selenium-79 are in quantities comparable to some of the radionuclides of concern in terms of radioactivity. 


\section{Heavy Metal's}

SST waste contains a number of heavy metals of regulatory concern because of their toxicity. Their presence is responsible for classifying most of the SST waste as mixed waste. The principal toxic heavy metals present in the SST waste are: barium, cadmium, chromium, copper, lead, mercury, nickel, silver, and selenium. (Selenium, while not actually considered a metal, is usually included with the heavy metals.) of the metals, both chromium and silver are in quantities that make them potentially recoverable. Estimates made by Salter, Nakaoda, and Whyatt suggest that chromium could be present in quantities exceeding 700 tons and silver exceeding 600 tons. Collectively their value would be about $\$ 10$ million as byproducts. In addition, recovery could reduce disposal costs and improve both grout and glass as waste forms.

\section{Other Constituents of Concern}

The characterization of the materials in the SSTs and their compatibility with borosilicate glass and grout by Salter, Nakaoda, and Whyatt has identified a number of materials that could have an adverse effect on the waste forms. These concerns were categorized for each waste form as follows:

\section{Borosilicate Glass}

- potential concern - $\mathrm{Ag}, \mathrm{K}, \mathrm{Mg}, \mathrm{Na}, \mathrm{PO}_{4}, \mathrm{~Pb}, \mathrm{Si}$

- possible concern - $\mathrm{A}$ l, Ba, Ca, $\mathrm{Cr}, \mathrm{CN}, \mathrm{Bi}, \mathrm{Hg}$

- unknown effects - Te, Mo, Li, Rb, Pr, Pm, Te, Be, Ta, Eu, Gd.

Grout

- concern - TRU, $\mathrm{NO}_{3}$

- potential concern - $\mathrm{Na}$, Organics, $\mathrm{Cr}, \mathrm{F}, \mathrm{Hg}, \mathrm{NO}_{2}, \mathrm{NO}_{3}, \mathrm{PO}_{4}, \mathrm{Am}, \mathrm{Cs}, \mathrm{I}$, $\mathrm{Pu}, \mathrm{Sr}, \mathrm{Tc}$

- unknown effects - Ce/Pr, Cs, Sb/Te, Nb, Ni, Sn, Sm, Zr, Se.

Of the components known, potential and possible, all but $\mathrm{F}, \mathrm{Mg}, \mathrm{PO}_{4}, \mathrm{Si}$, $A T$, and $B i$ are considered in one of the previous chemical groups. Each of these components is a major constituent in the SST waste. Consequentiy, their behavior is going to be strongly influenced by the mineralogy of the tank 
contents. These components are of little concern in most conventional industrial processes except those in the mineral refining industry, and limited specific information exists on treatment in the context of hazardous waste components. These components are not specifically addressed here but, rather, as incidental to the treatment of other components.

Water

Water by itself is not a problem but becomes a problem when it is used in processing SST waste. Water may be required in the initial retrieval of SST waste from the tanks. It will also be added in many separation processes such as ion exchange, solvent extraction, and $\mathrm{NO}_{x}$ removal (in thermal processes). To some extent the process water can be disposed of with the grout. However, this use must be qualified on how impurities in the water affect the quality of the waste form. Excess water or water that is unsuitable for grout will need to be further treated before it can be released to the environment.

\section{REFERENCES}

Kent, J. A. 1983. Riegel's Handbook of Industrial Chemistry. Van Nostrand Reinhold Company, New York.

Klem, M. J. 1990. Inventory of Chemistry Used at Hanford Site Production Plants and Support Operations (1944-1980). WHC-EP-0172, Westinghouse Hanford Company, Richland, Washington.

U.S. Department of Energy (DOE). 1987. Environmental Impact Statement Disposal of Hanford Defense High-Level Transuranic and Tank Wastes, Volume 2. DOE/EIS-0113, Washington, DC. 


\section{APPENDIX B}

\section{ELIMINATION OF VARIOUS TREATMENT TECHNOLOGIES}




\section{ELIMINATION OF VARIOUS TREATMENT TECHNOLOGIES}

Of the 16 technologies eliminated from further consideration, 12 were identified as not applicable. The 12 technologies eliminated were size reduction; hydrolysis; distillation; steam stripping; thermal stripping; photolysis; oil/water separation; dehalogenation; chlorinolysis; electro-kinetic separation; gas phase plasma destruction; and dewatering/drying.

Size reduction was eliminated because of the assumption that this oper. ation would be performed as part of the retrieval operation. Dewatering/ drying was eliminated because grout can tolerate a substantial amount of water in the feed, and glassification would evaporate any excess water and produce a dry waste. Distillation was eliminated because the complexity of the organics do not lend themselves to fractionation. Steam stripping, thermal stripping, and $0 i 1 /$ water separation were also eliminated because of the complexity of the organics. Hydrolysis, photolysis, dehalogenation, and chlorinolysis were eliminated because they are chemical-specific in their application. The complexity of the waste stream makes it unlikely that these processes would outperform other options for destroying the organics.

Gas phase plasma destruction technology, which includes plasma arc, plasma torch, and microwave plasma destruction processes, appears to be still in the developmental stages. The literature review suggested that these systems would not offer significant advantages over more conventional incinerator systems that are already commercially available for application to SST wastes. However, these systems could warrant reconsideration if incineration should be selected for specific applications. These processes could also be considered as innovative methods of heating in molten solid processes such as smelting.

Three of the 16 eliminated technologies (flow equalization, neutralization, and coagulation/flocculation) were applicable only as preconditioning steps and would not, by themselves, contribute to the separation, recovery, or destruction of contaminants. These processes are considered as integral to 
the application of other technologies and were eliminated from separate consideration.

Finally, two gas phase treatment terhnologies were eliminated from separate consideration: gas phase particle separation and gas phase component separation. Both technologies could be treated as stand-alone processes. However, they are specific to the treatment of product gas streams from several processes and thus are closely integrated with these other process options. In general, these technologies include well-developed processes. They are briefly discussed in Section 4.17 and Appendix $E$ for treating flue/residual gas streams. In addition, particulate removal processes are discussed as a technology within the incineration technology because metal particulate pollution from incinerators is becoming a sensitive issue that has a major impact on the acceptability of incineration as a treatment technology. 
APPENDIX C

DISCUSSION OF TREATMENT OPTIONS FOR PRIMARY WASTE STREAMS 


\section{APPENDIX C}

\section{DISCUSSION OF TREATMENT OPTIONS FOR PRIMARY WASTE STREAMS}

Within the primary waste streams (initial waste, insoluble sludge, nitrate brine) much of the partitioning of the waste into the major categories of HLW, LLW, TRU, and hazardous waste is initiated. Treatment of the initial waste is primarily oriented around the separation of the TRU-contaminated sludge from the water-soluble nitrate brine. Treatment of the insoluble sludge is oriented towards conditioning the solids to remove undesirable components adversely affecting the final waste form, and reducing the total volume of waste that must be disposed of as TRU and/or HLW waste. Treatment of the nitrate brine is oriented towards the conditioning of the brine to meet the requirements of the final waste form and minimizing the volume of waste that must be disposed of as LLW.

\section{INITIAL WASTE STREAM TREATMENT}

The initial waste stream is defined as a slurry mixture of insoluble sludge components in an aqueous solution containing dissolved saltcake components. Since sodium nitrate is the principal soluble component comprising over $80 \%$ of the soluble components, it will be at or near its saturation concentration in order to minimize the amount of water required to dissolve it. In fact, since sodium nitrate has such as high solubility $192.1 \mathrm{~g}$ per $100 \mathrm{~cm}^{3}$ of cold water), it is likely that the minimum water required to produce a pumpable slurry of the insoluble solids will be sufficient to solubilize the sodium nitrates.

The initial waste stream components can be roughly divided into two major groups. Sodium nitrate brine and organics and insoluble fractions. Almost all of the TRU is expected to be in the insoluble fraction, and thus easily separated from the other fraction. The main criteria for selecting treatment options for this waste stream are:

- tolerance for particulates in aqueous phase 
- tolerance for saturated nitrate

- ability to maintain partitioning of TRU to insoluble sludge

- ability to minimize quantity of sludge

- ability to separate or eliminate one or more of the three major groups.

Sixteen treatment options eliminated because they did not meet one or more of these criteria are as follows:

- membrane separation

- adsorption/ion exchange

- solvent extraction (liquid-liquid)

- high temperature water treatment

- dissolution

- precipitation

- bioaccumulation

- biodegradation
- crystallization

- freeze crystallization

- evaporation

- roasting

- molten solid separation

- chemical reduction

- incineration

- calcining.

Three technologies were eliminated because of their intolerance for particulates. High temperature water treatment processes are technically capable of tolerating particulates but all operate at high pressures. Large quantities of particulates significantly compound the ability to pump and subsequently process the slurry. Dissolution was eliminated because it would likely change the partitioning of the TRU. Also any other applicable dissolution technique would probably perform better on just the insoluble sludge fraction. Precipitation was eliminated because it would unnecessarily add dissolved heavy metals and radionuclides to the insoluble sludge. Bioaccumulation and biodegradation would also add to the total quantity of sludge. Furthermore, the combination of brine, heavy metals, and radionuclides would create a very hostile environment and produce very unfavorable conditions for growth. These biological technologies may be used on the other waste streams once the adverse components are eliminated. 
Crystallization, freeze crystallization, and evaporation would simply remove water and reconcentrate the SST contents, rendering them unpumpable and effectively untreated. Roasting is not applied to a slurry but roasting is incorporated in part by incineration and calcining technologies. Molten solid separation would have a difficult time processing the waste stream because of the enormous quantity of gas generated by the water and sodium nitrate. Chemical reduction could be used to degrade organics and nitrates present in the initial waste but would cause precipitation of heavy metals or would significantiy alter the $\mathrm{pH}$ of the waste stream, leading to possible dissolution of some of the sludge components. Incineration and calcining technologies could also be used to decompose organics and nitrates, but would convert most of the sodium to an oxide or carbonate and significantly increase the total solids to be handled.

In the end, only three technologies were considered to be reasonably applicable to the initial waste stream:

- liquid phase particulate separation

- beneficiation

- chemical oxidation.

The applicability of these three technologies is discussed below.

\section{Liquid Phase Particulate Separation}

Liquid phase particulate separation is by far the most applicable technology for treating the initial waste stream. This operation, in conjunction with limited water washing, separates the insoluble sludge from the dissolved solids and organic components as well as adjusting the water content for subsequent processing or disposal. A key consideration in applying this technology is the degree of partitioning of the particulates between the filtrate and the sludge. The process options available for separating solids from aqueous slurries include:

- screens and sieves

- granular bed (sand) filtration

- cake filters 
- sedimentation/clarification

- flotation

- microfiltration

- ultrafiltration.

Collectively, the first four processing techniques are straightforward, commoniy practiced methods for separating and recovering solid particulates from aqueous solutions. The specific process, or combination of processes, to be used depends on the size and density of the materials being collected, as well as the percent of solids in solution. Screens and sieves are generally used for coarse classification according to size and are more likely to be part of a retrieval operation. Cake filters, including vacuum filtration and filter passes, are used primarily for concentrating sludge when sedimentation is not sutisfactory or when further dewatering of sediments is desired. Gran. ular bed filtration and sedimentation technologies are satisfactory for reducing solids concentrations in the aqueous phase to about 2 to $50 \mathrm{ppm}$ depending on the process chosen and the stream characteristics (Freeman 1987; McArdle 1987). Process costs can be as low as < $\$ 1.00 /(1000 \mathrm{ga} 7)$ for sedimentation and granular bed filtration. Cake filter processing costs typically range from $\$ 5$ to $\$ 10$ per ton of solids removed (De Renzo 1978).

Flotation is also a well-developed technology capable of reducing particulate loadings as low as 20 to 100 ppm (EPA 1983). It is also used as a means for separating oil from water when required as a pretreatment for adsorption/ion exchange processes. Flotation depends on the ability of the particles and oil to attach to small bubbles and rise to the surface to be collected. Flotation usually requires the addition of small amounts of surfactants and other chemical modifiers to promote this phenomenon and to facilitate collection of the particles and bubbles as a froth at the top. Consequently, the particulate and oil removal benefits of the technology must be considered in the context of the possible consequences of chemical addition.

Any of the processes discussed above is capable of meeting particulate criteria for other treatment technologies that are sensitive to particulate 
levels. However, the levels of particulate may still constitute a significant contribution to the total radioactivity of the treated aqueous stream because the particulates contain small quantities of insoluble radionuclides.

Microfiltration and ultrafiltration processes are membrane separation processes that are particularly well suited to the removal of small particles, typically less than $10 \mu \mathrm{m}$ in diameter, and are capable of reducing particulate concentrations to less than 1 ppm (Cushnie, Crampton, and Roberts 1983). Since these processes address a different class of solids than the other separation processes they should be considered in the context of a separate rather than alternative process. Microfiltration and ultrafiltration processing costs typically range from $\$ 5$ to $\$ 10 / 1000$ gal (De Renzo 1978). The concentrated stream of suspended solids removed from these processes will range in solids content from up to $20 \%$. This stream may need to be segregated from other solids streams because the small particles will behave as a colloidal suspension.

\section{Beneficiation}

Beneficiation technologies are traditionally used to separate and concentrate specific minerals in a body of ore; the minerals are separated because their properties differ. Here, the main application of beneficiation technologies would be in the treatment of the initial SST waste stream to separate the suspended solids into two or more streams containing different mineral components of concern. The technical feasibility of applying any of the beneficiation techniques to the initial SST waste stream depends on satisfactory partitioning of key elements based on the properties of their corresponding compounds. A major factor in achieving a successful partition depends on the ability to obtain relatively pure compounds in the particle size to be processed. If the particles contain several mineral crystals of significantly different physical properties then the key property such as magnetic susceptibility is correspondingly diluted. Therefore, assessing the potential of beneficiation requires that the mineral characteristics of the tank sludge first be determined. Beneficiation techniques of interest to SST wastes include:

- hydrautic concentration 
- high gradient magnetic separation

- dense media separation

- flotation.

\section{Hydraulic Concentration}

Hydraulic concentration includes a variety of well-developed processes which separate minerals using flowing water according to differences in nurticle size and density. The three principal processes are jigs, concentration tables, and Humphrey's spiral. Although all three types have potentially applicability to SST waste, Humphrey's spiral appears to offer the best combination of low water consumption, moderate capacity, and broad range of particle sizes efficiently removed. Humphrey's spiral is simple in design and reliable in operation. It has been used to stparate particles as small as $75 \mu \mathrm{m}$ in diameter (Perry and Chilton 1973). It has been used in the recovery and concentration of chromium and rare earth minerals from beach sands (Lefond 1975). Processing costs are typicaliy less than $\$ 0.10 /$ ton (Perry and Chilton 1973). The main potential application would be in the separation of heavy metal actinides and lanthanides from some of the lighter carbonate, silicate, and phosphate minerals.

\section{High Gradient Magnetic Separation}

High gradient magnetic separation (HGMS) processes separate minerals according to their magnetic susceptibility. HGMS uses high-intensity magnetic fields to separate both ferro- and paramagnetic materials from diamagnetic materials. Paramagnetic materials include several compounds containing $\mathrm{Cu}$, $\mathrm{Cr}, \mathrm{Ni}, \mathrm{Fe}, \mathrm{Mn}, \mathrm{Ce}, \mathrm{Co}, \mathrm{Pu}, \mathrm{U}$, and Am. Materials containing nitrates, sulfates, and phosphates of aluminum, sodium, bismutr, and zirconium are generally considered to be diamagnetic. Consequently, HGMS could be used either to concentrate TRU or to deplete problem sludge components such as phosphates. HGMS is hest appiied to particles ranging from 1 to $100 \mu \mathrm{m}$ in diameter, with an optimum diameter of $30 \mu \mathrm{m}$ (De Renzo 1978). HGMS processes have high processing capacity (6 to $1000 \mathrm{gpm}$ with $15 \%$ solids), relatively simple design and operation, and relatively moderate processing cost $\$ 1$ to $\$ 5 / 1000$ gal. 


\section{Dense Media Separation}

Dense media separation is a sink float method of gravity separation in which a finely ground dense material such as magnetite is mixed with water to produce a slurry that closely duplicates a true heavy liquid with a specific gravity that can be varied from 1.25 to 3.4. Dense media separation is $1 \mathrm{im}$ ited to particles larger than $210 \mu \mathrm{m}$ (Currie 1973). Howevor, it is capable of separating particles differing in specific gravity by as little as 0.005 (Perry and Chilton 1973), with separation efficiencies above 90\% (American Cyanamid 1953). The advantages of dense media separation are the ability to separate materials of only slightly different specific gravities; a high capacity (20 to 200 toris $/ h$ ); and moderate costs $\$ 4$ to $\$ 6 /$ ton.

\section{Flotation}

Flotation is a process by which target minerals are made preferentially buoyant through the addition of certain chemicals. It is considered the principal means for concentrating many metal ores including copper, silver, and nickel. Generally the process has been adapted to sulfides of these minerals and would not be directly ripplicable to the initial SST wastes. However, it is also used in the phosphate mining industry to enrich phosphate ore. Thus, it may be applicable as a means of partitioning phosphate into concentrated and depleted fractions. Flotation is generally applicable to particles ranging from 20 to $100 \mu \mathrm{m}$ in diameter (Currie 1973). The main advantages of the technology are a large capacity (500 to 10,000 ton/day); a moderately low cost (\$0.65 to $\$ 2.40 /$ ton); and a tolerance of alkaline environments.

\section{Chemical Oxidation}

Chemical oxidation is a process widely used to treat a variety of both hazardous and nonhazardous chemicals. Its primary use is in destroying cyanides and a variety of organic compounds. Because of the relatively high cost of the chemical reagents, its application is usually limited to waste streams containing $0.1 \%$ to $5 \%$ organics (Breton et a 1.1988 ). This amount would make the process applicable to the initial waste stream. The most common

\section{7}


commercially available oxidation agents in the order of decreasing oxidation power are:

- ozone

- hydrogen peroxide

- potassium permanganate

- hypochlorite (sodium-, calcium-)

- chlorine.

There are also other, less commonly used chemical oxidizing agents that may be suitable in treating the initial waste. Chemical oxidation appears to show promise for precipitating certain heavy metals (specifically $\mathrm{Cd}$, $\mathrm{Cu}$, and Ni) as oxides and hydroxides (Cushnie, Handel and Roberts 1983). Since sodium hydroxide was used to precipitate much of the SST sludge and the tanks have been maintained in an alkaline environment, it is unlikely that chemical oxidation would cause any further oxidation and/or precipitation of the heavy metals from solution. If dissolved metals are complexed using organics, then chemical oxidation could cause some further precipitation. Conversely, the oxidation of heavy metals or radionuciides in the sludge could result in their dissolution. Another limitation of chemical oxidation is that the oxidation reactions are frequently not complete. Thus, there is a possibility that the intermediate products will be toxic and require further treatment.

\section{INSOLUBLE SLUDGE TREATMENT}

Ideally, the insolubie siudge waste stream comprises all filtered solids in the initial waste stream that remain after a water wash. Consequently, the solids are free of most organics, nitrates, cesium (except as ferrocyanides), and technetium. The principal components in the sludge are metal hydroxides, the actinides, lanthanides, rare earths, and heavy metals as hydroxides, phosphates, aluminates, and silicates.

Since virtually all of the TRU components and $\mathrm{Sr}$ are contained in the sludge, treatments would be performed to either separate the TRU components and $\mathrm{Sr}$ from the rest of the sludge in order to reduce the volume of waste 
ultimately requiring disposal as HLW or TRU waste, or to remove only those constituents in the sludge that are detrimental to the anticipated HLW or TRU waste form.

Four techniques are applicable to separating components from insoluble solids:

- beneficiation

- dissolution

- roasting

- molten solid separation.

\section{Beneficiation}

Beneficiation of the insoluble sludge would involve the same process options as for the initial waste, except that the solids would need to be resuspended in water as a slurry. In actual practice, beneficiation could probably be conducted with the wash water since trace amounts of nitrates and organics should not adversely affect performance. Beneficiation could be used as a single treatment with the single objective of concentrating TRU or HLW into a smaller volume, with the TRU-HLW depleted fraction being suitable for LLW disposal. Alternatively, the sludge may be split into two fractions with both containing significant TRU but with one fraction depleted in undesirable, non-TRU components, such as phosphates, and thus suitable for disposal. The other fraction would require further treatment or an alternative disposal form. The main purpose in splitting the fractions would be to reduce the volume requiring further treatment. At the same time, partitioning certain minerals to the two fractions may mean that a second treatment with one of the other applicable methods would be more effective.

\section{Dissolution}

Dissolution, or leaching, is a standard technique for separating specific components within a solid by selectively dissolving the solid. Solubilizing is usually accomplished using acids such as nitric, sulfuric, hydrochloric, and hydrofluoric acids, or caustic. The degree of dilution depends on the material to be dissolved. 
Dissolution can be applied to the insoluble sludge to partition the TRU and non-TRU components. Laboratory research at PNL has shown the potential for selectively dissolving TRU from double shell tank (DST) sludge using concentrated nitric acid. However, a significant proportion of the non-TRU components is also dissolved, and the remaining sludge still contains some TRU. Additional research should improve the performance of this approach.

It may also be possible to selectively dissolve non-TRU components from the sludge both to reduce volume and to improve the composition in terms of waste form requirements. For example, sulfuric acid can be used to remove phosphates from some ores. Dilute hydrochloric acid has been used to dissolve rare earth hydroxides after a caustic digestion of monazite (cerium phosphate) ores (Lefond 1975).

In an extreme case it may be desirable to completely dissolve the siudge in acid. This may be desirable if selective leaching techniques result in unsatisfactory partitioning of TRU and $\mathrm{Sr}$ components, and if subsequent processing of the dissolved solids can achieve the necessary partitioning of the TRU components.

One advantage of dissolution is that it takes place at ambient to moderately high temperatures and typically involves only the solid and liquid phases. However, if acids or caustic are used, additional solids will ultimately be generated upon neutralization, requiring subsequent recovery and disposal. Similarly, dissolution always produces an aqueous stream containing dissolved solids, which will require additional treatment.

\section{Roasting}

Roasting is a high temperature process used to change the chemical form of certain solid materials. Typically, roasting is used to oxidize sulfide metal ores to their corresponding oxides or sulfates. In certain applications roasting is used to chloridize other elements such as uranium, beryllium,

niobium, zirconium, titanium, and vanadium in either an oxidizing or reducing atmosphere to produce the corresponding chioride (Gilchrist 1980). This 1atter application is used where the oxide form of the respective metals is too stable to easily be reduced to the pure metal. 
Roasting may be applicable as a treatment in itself for the insoluble sludge or as a pretreatment prior to dissolution. As a pretreatment, roasting would likely be used to oxidize or reduce the various components in the sludge, which in turn would be more soluble in an acid leach. As an alternative to dissolution, roasting may be used to produce volatile components that could be separated as a fume and subsequently recovered. The use of roasting to produce chlorides, which in turn lend themselves to other separation and recovery processes, may also be practical.

\section{Molten Solid Separation}

Molten solid separation technologies include the various ore smelting and metal refining techniques that use a molten phase to achieve separation. Included within this category are smelting, fire refining, metal-metal refining, and zone refining. One of the most likely applications of molten solid separation techniques to insoluble sludge would be in conjunction with glass forming either simultaneously or as a separate step.

In the smelting process, the components of a solid, upon melting, are separated into two or more layers that may be slag (composed of mineral oxides), speiss (composed of metal arsenides), matte (composed of metallic sulfides), or metal. Some constituents may also be converted into vapors. While the goal of smelting is generally to obtain a relatively pure metal, the smelting process could be used as a means for distributing other materials preferentialiy into one or more of the other phases. For example, slags are typically molten silicates containing aluminates, phosphates, antimonates, borates, and fluorides as well as other possible acid constituents (Gilchrist 1980).

Glass that has been produced to dispose of TRU waste is essentially a slag, and certain components in the sludge such as iron, phosphorous, and chromium can create problems with the glass by the formation of a separate phase. By intentionally encouraging these separations through addition of chemical reagents, including another metal, it may be possible to remove these impurities as a separate phase. The remaining glass phase could be further modified as necessary to achieve the proper disposal formulation. 
The other three molten solid separation techniques are usually applied to a relatively pure material to achieve greater purity. Consequently, they would not likely apply to the insoluble sludge but could be considered as a subsequent treatment of any of the phases produced during smelting or glass formation.

\section{NITRATE BRINE TREATMENT}

The principal difference between the nitrate brine waste stream and the initial waste stream is that all solids have been removed. Presumably all of the TRU components and uranium have also effectively been removed and are no longer of concern in terms of partitioning. In addition, organics may have been entirely or at least partially degraded. Key components of concern in the nitrate brine are sodium nitrate and sodium nitrite, cesium, and technetium. The nitrate and nitrite are primarily of concern because of their very high concentration and resistance to stabilization techniques such as grout. Technetium and cesium are of concern because of their effect on the classification of LLW. In addition, both cesium and technetium tend to be resistant to stabilization techniques. Heavy metals and organics are also important as the chemical constituents that classify SST waste as mixed waste and thus RCRA regul ated.

Since all solids have been removed from the nitrate brine, the above discussed solid treatment technologies no longer apply:

- beneficiation

- liquid phase particle separation

- dissolution

- roasting

- molten solid separation.

Furthermore, since the sodium nitrate concentration is very high, two other technologies are probably less suitable:

- membrane separation

- freeze crystallization. 
Both of these processes involve concentration of the brine, causing precipitation of the nitrate. In membrane technologies, these salts would foul membranes. In freeze crystallization, the simultaneous formation of ice and salts in large quantities would make subsequent separation exceedingly difficult.

The technologies that are suitable for treating the nitrate brine can be grouped according to their effect on the waste stream:

- removal of dissolved radionuclides and heavy metals from solution

- removal of sodium nitrate from solution

- detoxification of brine through destruction or degradation of nitrates and organics.

\section{Removal of Heavy Metals and Radionuclides from Solution}

Five technologies can be used to separate heavy metals and radionuclides from the nitrate solution:

- adsorption/ion exchange

- bioaccumulation

- solvent extraction

- chemical reduction

- precipitation.

\section{Adsorption/Ion Exchange}

Adsorption/ion exchange is considered a traditional technology for the selective removal of heavy metals and radionuclides from solution. Ion exchange materials, such as zeolites, and ion exchange resins have been used commercially to separate cesium and strontium from aqueous wastes including those with high nitrate concentrations. Research at PNL. has also suggested that certain adsorbents have good selectivity towards the separation of technetium as a pertechnetate anion. Other research has identified a number of adsorption materials that have potentially attractive selectivity and/or adsorption capacity compared with more traditional ion exchange materials (Haztech 1989a, b). 
Both adsorption and ion exchange materials remove a large number of heavy metal ions and radionuclides according to their selectivity. Some adjustment of the $\mathrm{pH}$ of the brine may be necessary in order to optimize selectivity of some materials. Adsorption/ion exchange also is capable of concentrating the removed ions in the regeneration solution as much as 30 times.

\section{Bioaccumulation}

Bioaccumulation is a process by which living organisms accumulate and concentrate heavy metals and other elements in their tissue. Bioaccumulation of heavy metals is accomplished by: 1) adsorption and precipitation onto the outer layer of the cells and 2) by adsorption and metabolism within the cell. Considerable research has been conducted on the performance of several algae strains for their ability to bioaccumulate certain heavy metals including copper, zinc, cobalt, chromium, nickel, aluminum, cadmium, lead, mercury, and gold (Darnall and Gardea-Torresday 1989). In the case of 1 iving cells the bioaccumulation eventually results in toxicity levels that kill the algae, which then settle out as sludge. This research has shown that even dead algae display excellent adsorption characteristics for metal ions on their cell walls. In fact, in several instances the rate of adsorption and the total loading of the metal ions is much higher than that achieved with the living algae. Considerable research is being directed towards incorporating dead algae and other dead aquatic plant material into adsorption materials such as silica gel and resins.

It is difficult to ascertain the applicability of this technology to SSTs. Microorganisms such as fungi and bacteria are capable of adapting to very harsh chemical environments as might be experienced in SST wastes. Consequently, they may be applicable to the brine. The tolerance for radiation exposure, however, is limited for many microorganisms. Radiosensitive microorganisms are substantially impaired by as little as 10 Gy of gamma radiation. One potentially attractive application of bioaccumulation techniques would be in conjunction with biodegradation of the organics and the nitrates. This technology is discussed later in this section. 


\section{Solvent Extraction}

Solvent extraction is a well-developed technology for selectively separating heavy metals and radionuclides from aqueous solutions. Solvent extraction is used extensively in the nuclear industry for the separation and recovery of radionuclides. Considerable research has been directed towards the recovery of TRU and strontium from solution. This research has led to the development of the TRU extraction (TRUEX) and strontium extraction (SREX) processes (Logsdail and Mills 1985).

One advantage of solvent extraction is that it often achieves better separation and recovery than can be achieved with ion exchange. However, the process is more expensive and the resulting concentration of the pure component after stripping is generally limited to a factor of about 10 . Consequently, it is usually limited to applications where the concentrations of the material to be removed is much higher than that in which ion exchange is used.

Recent research on new solvent extraction techniques has been conducted to significantly improve the ability to concentrate the removed materials and thereby reduce cost and improve the range of applicability. These techniques include the use of thermally unstable complexants, membrane facilitated separation techniques, and supercritical solvents. Thermally unstable complexants and membrane facilitated separation techniques achieve improved separation through a higher concentration of the separated material in an aqueous stripper solution. Supercritical solvents achieve concentration by flash evaporating to gas at lower pressure, causing the materials to concentrate and precipitate in the remaining solvent.

\section{Chemical Reduction}

Chemical reduction reduces the oxidation state of heavy metals. Its primary application has been in the electroplating industry to reduce hexavalent chromium to less toxic and more easily precipitated trivalent chromium. Chemical reduction has also been used commercially for the reduction of other heavy metals including mercury, silver, and lead. In addition, studies have been conducted on cadmium, copper and nicke) (Cushnie, Crampton, and Roberts 1983), hexavalent selenium (Sims and Bass 1984), and antimony (Unterberg

\section{15}


et al. 1987). Most of the heavy metals are precipitated as the reduced metal or metal hydroxide. Chemical reduction has also had some use in the reduction of certain organic compounds.

The most commonly used reducing agents are sulfur dioxide, sodium metabisulfite, sodium bisulfite, ferrous sulfide, and ferrous sulfate. Less common agents include sodium borohydride and reduced metals. The majority of these chemical reducing agents add to the total inventory of chemicals requiring disposal. However, when metal-contaminated wastewater is passed through a bed of particles or turnings of certain reduced metals such as iron, zinc, or aluminum, they undergo a substitution reaction called cementation. In this reaction they are oxidized to a soluble state in exchange for precipitation of the target metal ion as a reduced metal. As a result, there is no net addition of material to the waste stream, except to balance charge, and all of the metals extracted are replaced by a single metal. The process proceeds spontaneously with metals that are higher in the electromotive series.

Metals can also be reduced through electrochemical techniques known as electrowinning, electro-refining, and electroplating, which are used by the metals refining industry to recover and purify a large number of different heavy metals. These processes may offer the advantage of either selective or nonselective removal of a number of heavy metals and possibly radionuclides as a mixture by applying a relatively high voltage. Electrowinning is a technique for separating and recovering a specific metal from a mixture of metals in solution. Electroplating is a similar process except a mixture of metals is not used. Electro-refining is a technique in which an impure metal is placed at the anode and allowed to dissolve into solution. The pure metal is recovered in the same manner as electrowinning. Of the three processes, electrowinning is the only one directly applicable to the nitrate brine. However, information on electrowinning is almost always presented in the context of recovery and recycle of pure metal. Thus, its potential as a scavenger of a number of metals on a single electrode needs to be explored further.

\section{Precipitation}

Precipitation is a standard technology for separating dissolved heavy metal cations and certain anions from aqueous solutions. Precipitation 
usually involves the addition of a soluble chemical agent which will react with the dissolved metal ion to produce an insoluble material that can be separated using liquid phase particulate removal technologies.

Precipitation can be used to treat the nitrate brine to remove heavy metals. However, the nature of the nitrate brine is such that all metals that could have been removed as hydroxides will have already accomplished. Therefore, the only application of precipitation would be the addition of a chemical that would result in an even lower solubility for the heavy metals. This would include the addition of agents to produce sulfides, which are much less soluble than hydroxides, or a metal specific chemical such as a chloride to remove silver. One limitation to precipitation is that it does not work well with complexed metals. Therefore, it may be necessary to treat the brine for organics. Precipitation also requires addition of excess chemicals to drive the reactions to completion, thus potentially increasing the volume of solid waste.

\section{Removal of Sodium Nitrate from Solution}

Because sodium nitrate is highly soluble, it may account nearly half of the mass of the brine solution. Therefore, any process that can selectively separate it from the brine will significantly reduce the quantity of aqueous waste requiring treatment to remove heavy metals and radionuclides.

Crystallization is a purification process in which a single substance concentrated within a liquid or vapor mixture is allowed to crystallize, thus creating a "pure" solid that in turn can be separated from the liquid. Evaporative crystallization is used for the recovery and purification of table salt $(\mathrm{NaCl})$ from seawater. Another crystallization method involves decreasing the solubility of the desired compound in a saturated solution by changing (usually decreasing) the temperature of the solution. These two crystallization processes can also be combined.

The purity of the crystallized product can be affected by two mechanisms. Some of the impurities contained in the mother liquor (residual liquid) result when it dries on the outside of the crystals. This contamination, which may account for between $2 \%$ and $10 \%$ of the weight of the crystals, can be 
removed by washing the crystals. A small portion of the impurities will also be trapped in small pockets, called occlusions, within each crystal. These occlusions will account for between $0.1 \%$ and $0.5 \%$ of the crystal volume. These crystals can be further purified by redissolving the crystals to release the trapped mother liquor and then recrystallizing.

Crystallization is a well-developed technology that is currently used as the method for producing commercial sodium nitrate and may be uniquely suited to the treatment of the SST nitrate brine. The main advantage of the process is that it may be possible to purify the nitrate sufficiently with recrystallization to delist it as an LLW. In addition to producing nitrate salts, the process provides for nonselective concentration of all radionuclides, heavy metals, and other dissolved inorganic compounds as well as organics in the mother liquor. This will facilitate more efficient recovery using other processes such as precipitation, ion exchange, or evaporation.

Detoxification of Brine Through Destruction or Degradation of Nitrates and/or Organics

Eight technologies have the potential for degrading nitrates and organics in the brine:

- biodegradation

- chemical reaction/evaporation

- chemical oxidation

- chemicar reduction

- high temperature water treatment

- calcining

- incineration

- roasting.

\section{Biodegradation}

Biodegradation technologies include biological treatment processes that. use a microbial population to biodegrade the organics and nitrates (bionitrification) in aqueous wastes. In biodegradation, microorganisms convert the 
majority of the degradable organic matter into carbon dioxide, water, and light hydrocarbons such as methane. In biodenitrification applications, the predominant products are water and free nitrogen.

Biodegradation technologies are very well developed for the treatment of municipal sewage and industrial aqueous, organic wastes. For most applications, biodegradation processes have limits imposed on the waste composition because of the requirement that life be sustained. Among the limitations are (EPA 1985):

- toxic metals - $\mathrm{Pb}, \mathrm{Ni}, \mathrm{Cu}, \mathrm{Cr}$ and $\mathrm{Zn}$ are particularly toxic to microorganisms.

- $\mathrm{pH}$ - typically limited to between 6 and 9 .

- dissolved salts - typically limited to 10 to $16 \mathrm{~g} / \mathrm{L}$.

- organic load - typically less than $10 \%$ organics.

Many of these limitations can be met through dilution. In addition, microorganisms have been known to acclimate to very harsh conditions including very high saline content in brackish water. However, under the combination of harsh conditions anticipated in the nitrate brine, it is questionable whether the microorganisms can perform satisfactority if they survive.

As previously mentioned, the main opportunity offered by biodegradation, even if dilution is required, is to combine it with bioaccumulation. If the two activities took place together, the brine would be converted into innocuous gases, metal-contaminated sluuge, and residual water in a single step.

\section{Chemical Reaction/Evaporation}

One special process was identified that combines a chemical reaction with evaporation to recover nitrate as nitric acid. In this process, concentrated sulfuric acid is added to the nitrate brine solution where it reacts reversibly with the sodium nitrate to produce sodium sulfate and nitric acid. The nitric acid is evaporated, leaving behind the sodium sulfate (Considine 1974). All other metal nitrates in the brine should also convert to the corresponding sulfate. This process, which was originally developed during the last century to produce nitric acid from saltpeter (sodium nitrate), is 
unique in that it offers the opportunity to purify and recycle nitric acid while converting the sodium into a less soluble salt. The less soluble salt should be more compatible with LLW disposal options such as grout. Interestingly, this process may also provide a means for separating cesium from the solution by taking advantage of the higher solubility cesium sulfate, which would remain in soliltion.

\section{Chemical Oxidation}

The applicability of chemical oxidation technology to the treatment of organics in the nitrate brine would be the same as it was for treatment of the initial waste. The main difference would be the absence of the insoluble solids. Chemical precipitation of complexed metals in solution is still a possibility, though.

\section{Chemical Reduction}

Chemical reduction can be used both to degrade organics and to reduce nitrates. However, the reduction of organics is usualiy incomplete and additional treatment to treat intermediate products is usually required.

\section{High Temperature Water Treatment}

High temperature water treatment technologies are traditionally used to degrade organics in aqueous liquids at elevated temperatures and pressures. The high temperature increases reaction rates so that complete degradation can be achieved in a relatively short time. High pressure is required to prevent the water from boiling.

High temperature water treatment processes include three processes:

- wet air oxidation

- supercritical oxidation

- catalytic destruction.

Al1 three processes are considered potentially suitable for the degradation of organics in the nitrate brine. Each can achieve more complete degradation of organics than conventional chemical oxidation and reduction processes but at the expense of higher operating temperatures and pressures. 
They offer an alternative to incineration without the ash entrainment problems.

One interesting feature of applying these processes in the presence of nitrates is that the nitrate will serve as an oxidant. Research with catalytic destruction has shown that simultaneous destruction of nitrates and organics produces elemental nitrogen as a product (Baker and Sealock 1988).

\section{Calcining/Incineration/Roasting}

Calcining, incineration, and roasting are considered collectively because of their similarity in design and operation and because the waste stream lends itself to using all three simultaneously. Calcining is a high temperature process used to change the chemical form of certain solid materials through thermal decomposition. It involves the thermal decomposition of solids typically to remove chemically bound water (as hydrate), carbon dioxide (as carbonate), or $\mathrm{NO}_{\mathrm{x}}$ (as nitrates). Calcining can be used to remove nitrate from the nitrate brine by changing sodium and other mineral nitrates to their corresponding oxides.

Incineration refers to the thermal decomposition and complete oxidation of organic compounds. The temperature required for combusting the organic fraction of the brine will also cause the nitrates to decompose. In fact, the nitrates, which are considered oxidants, will provide some of the oxygen need to oxidize the organics.

Roasting is a high temperature process used to change the chemical form of certain solid materials. Typically, roasting is used to oxidize sulfide metal ores to their corresponding oxides or sulfates. Alternatively, roasting is sometimes used to reduce an oxide to metal prior to leaching or smelting. The application of roasting to the nitrate brine has to take place in a somewhat broader sense. Since nitrates are oxidants, they can be used to oxidize a number of elements in the absence of air. On the other hand, if strong reductants, such as fuel oil or natural gas, are used they would in turn reduce the nitrates. Two important examples are the reactions between sodium nitrate and carbon to produce carbon dioxide, nitrogen, and sodium carbonate 
and the reaction of sodium and nitrate and sulfur to produce sulfur dioxide, sodium sulfate, and nitrogen.

Collectively, the three processes provide the means for converting the sodium into a compound other than nitrate and decomposing the nitrates into a gas. They also will provide for the evaporation of water and destruction of the organics in one step. Thus, significant concentration and volume reduction will be achieved.

A principal consideration in calcining the brine is the large quantity of sodium present that will convert to sodium oxide $\left(\mathrm{Na}_{2} \mathrm{O}\right)$. This substance is very alkaline and will hydrate to caustic soda. In combination with roasting it may be possible to add a second component to convert the sodium to another compound such as a silicate, sulfate, or carbonate.

A second consideration shared by both calcining and incineration approaches is that a majority of the nitrate will be converted to $\mathrm{NO}_{\mathrm{x}}$. This will then need to either be scrubbed from the flue gas or further converted to elemental nitrogen, in a separate gas phase step. Again, by adding excess reductant it may be possible to achieve complete reduction of the nitrate to elemental nitrogen. However, in conducting such an operation special consideration should be given to heat dissipation through dilution because of the explosive reaction rates that are possible when solid phase oxidants and reductants are heated. 


\section{REFERENCES}

American Cyanamid Company, Mineral Dressing Division. 1953. "Heavy-Media Separation Processes for Mineral Concentration." Mineral Dressing Notes, No. 19. New York.

Baker, E. G., and L. J. Sealock, Jr. 1988. Catalytic Destruction of Hazardous Organics in Aqueous Solutions. PNL-6491-2, Pacific Northwest Laboratory, Richland, Washington.

Breton, M, P. Frillici, S. Palmer, C. Spears, M. Arienti, M. Kravett, A. Shayer, and N. Suprenant. 1988. Treatment Technologies for Solvent Containing Wastes. Noyes Data Corp., Park Ridge, New Jersey.

Considine, D. M., ed. 1974. Chemical and Process Technology Encyclopedia, pp. 159-160. McGraw-HiTl Book Co., New York.

Currie, J. M. 1973. Unit Operations in Mineral Processing. Best-Printer Co. LTD, Vancouver, B.C.

Cushnie, G. C. Jr., P. Crampton, and C. G. Roberts. 1983. An Investigation of Technologies for Hazardous Sludge Reduction at AFLW Industrial Waste Ireatment Plants; Volume II: Literature Review of Available Technologies for Treating Heavy Metal Wastewaters. ESL-Tr-83-42, Engineering \& Services Laboratory, Air Force Engineering and Services Center, Tyndall Air Force Base, Florida.

Cushnie, G. C., E. D. Hande1, and C. G. Roberts. 1983. An Investigation of Technologies for Hazardous Sludge Reduction at AFLW Industrial Waste Treatment Plants Volume I: Sodium Borohydride Treatment and Sludge Handling Technologies. ESL-Tr-83-42, Engineering and Services Laboratory, Air Force Engineering and Services Center, Tyndall Air Force Base, Florida.

Darnal1, D. W., and J. Gardea-Torresday. 1989. Removal and Selective Recovery of Heavy Metal Ions from Industrial, Waste Waters. PB89-166763, New Mexico Water Resources Research Institute. Technical Completion Report for Project No. 14-08-001-G1286.

De Renzo, D. J. 1978. Unit Operations for Treatment of Hazardous Industrial Wastes. Noyes Data Corp., Park Ridge, New Jersey.

Freeman, H. M., ed. 1989. Standard Handbook of Hazardous Waste Treatment and Disposal. McGraw-Hill Book Company, New York.

Gilchrist, J. D. 1980. Extractive Metallurgy, 2nd Edition, pp. 274-286.

Pergammon Press, Oxford, England.

Haztech News. 1989a. March 23, p. 41.

Haztech News. 1989b. October 20, p. 160. 
Lefond, S. J., ed. 1975. Industrial Minerals and Rocks. American Institute of Mining, Metallurgical, and Petroleum Engineers Inc., New York.

Logsdail, D. H., and A. L. Mills, ed. 1985. Solvent Extraction and Ion Exchange in the Nuclear Fuel Cycle. Ell is Horwood Limited, Chichester.

McArdle, J. L., M. Arozarena, and W. E. Gallagher. 1987. A Handbook on Treatment of Hazardous Waste Leachate, PIE Associates, Inc., Cincinnati, Ohio. EPA/600/8-87/006, Hazardous Waste Engineering Research Laboratory, Office of Research and Development, U.S. Environmental Protection Agency, Cincinnati, Ohio.

Perry J. H., and C. H. Chilton, eds. 1973. Chemical Engineer's Handbook, 5th ed. McGraw-Hill Book Co., New York.

Sims, R., and J. Bass. 1984. Review of In-Place Treatment Techniques for Contaminated Surface Soils - Volume 1, Technical Evaluation. EPA-540-2-84003a, PB85-124881, U.S. Environmental Protection Agency, Cincinnati, Ohio.

U.S. Environmental Protection Agency (EPA). 1988. Technological Approaches to the Cleanup of Radiologically Contaminated Superfund Sites. EPA/540/288/002, Washington, DC.

U.S. Environmental Protection Agency (EPA). 1983. Treatability Manual Volume Three Technology for Control/Removal of Pollutants. EPA/600/2-82-001c, Washington, DC.

Unterberg, W., R. W. Melvold, S. L. Davis, F. J. Stephens, and F. G. Bush III. 1987. Reference Manual of Countermeasures for Hazardous Substances Releases. EPA/600/2-87/069, U.S. Environmental Protection Agency, Cincinnati, Ohio. 
APPENDIX D

TREATMENT OPTIONS FOR SECONDARY WASTE STREAMS 
APPENDIX D

\section{TREATMENT OPTIONS FOR SECONDARY WASTE STREAMS}

The three waste streams considered to be secondary waste streams are listed below:

- sodium nitrate salt

- aqueous waste

- aqueous siurry.

The primary treatment objective for these waste streams is to concentrate and separate key components as necessary to remove unwanted contaminants and to concentrate and recover key fractions of the primary waste streams.

\section{SODIUM NITRATE SALT TREATMENT}

Sodium nitrate salt would be a large volume secondary process stream resulting from the crystallization of the nitrate brine. Ideally, this salt would be pure; however, it is also possible that other salts will coprecipitate. Sodium nitrate salts pose two problems. First, sodium as a cation is generally very soluble regardless of the salt it forms. Second, nitrates as a class of salts are also very soluble compared to other salts. Consequently, neither is amenable to typical LLW disposal options.

Treatment alternatives for sodium nitrate are limited to two general approaches. The first would be to purify the salt or a chemical derivative of the salt to the point where it is either acceptable as a byproduct for recycle or delisted as a RCRA and/or radioactive waste. The second approach would be to convert the compound to a less soluble sodium salt and destroy the nitrate portion as elemental nitrogen.

Purification of Sodium Nitrate and Nitrate Derivatives

As was previously discussed under treatment of nitrate brine, crystallization of sodium nitrate is capable of reducing impurities as much as 3 orders 
of magnitude in a single operation. Additional purification of similar magnitude can be achieved by redissolving the crystallized salt to release contaminants trapped as occlusions of the mother liquor and then recrystallizing the salt. Newly trapped mother liquor would be correspondingly diluted during the dissolution step.

A potential problem with crystallization is the simultaneous crystallization of another hazardous or radioactive salt. One approach to overcome this problem would be to use the temperature dependence of different salts on their solubility. By cooling a nearly saturated salt solution to a lower temperature the more temperature sensitive salt will supersaturate first and produce the desired separation.

Another approach is to add chemicals to the solution to change the properties of the constituents. An example would be to react the sodium nitrate salts with sulfuric acid and evaporate nitric acid from the mixture. This method was previously described in the treatment of nitrate brine in Appendix C. A second example would be adding another salt such as potassium chloride and producing chloride salts that have different solubilities for the impurities. In both cases, the addition of chemicals increases the total mass of potentially contaminated salts. Therefore, the use of this approach depends upon the ability to purify the salts to acceptable levels for delisting or recycling.

\section{Decomposition of Nitrate}

Decomposition of the nitrate would be directed towards producing a less soluble disposal form for the sodium without necessarily purifying it. The sodium nitrate salts can be decomposed to eliminate the nitrogen by any of the methods identified for treating the nitrate brine (biodegradation, chemical reduction, calcining, incineration, and evaporation). The main difference in treating this waste stream is that the sodium nitrate salt would be relatively pure. Therefore, all of the operations would be inherently less hazardous.

This difference is particularly important for the biodegradation processes. By eliminating high levels of radiation and toxic heavy metals it would be much easier to design a biodenitrification process. The main 
disadvantages of this approach would be that the nitrate salt must be resolubilized, producing a new aqueous waste stream, and a biomass sludge will be produced that may still require special disposal. The main advantage of this approach would be that biodenitrification would take place under carefully controlled ambient conditions.

Calcining and incineration would also be beneficially influenced by increased purity. By removing impurities, the potential for the airborne release of heavy metals and radionuclides would be significantly reduced.

All of the above degradation processes retain the sodium in some form that would need to be disposed of or recycled. In the biodegradation process, the microorganisms will incorporate other elements into their biomass, creating a residue that is a mixture of compounds. Precipitation/evaporation will produce a relatively pure sodium sulfate, which has a market in the glass, paper, rayon, coal-tar, and soap industries. Chemical reduction processes will most likely produce caustic soda $(\mathrm{NaOH})$. Calcining and incineration will produce either caustic soda, sodium carbonate, or some other salt depending on how heat is provided and whether other minerals are added.

\section{AQUEOUS WASTE TREATMENT}

The aqueous waste stream encompasses any aqueous waste produced from the primary treatment of the insoluble sludge and the nitrate brine. It is also expected to be used during many secondary waste stream treatments to further concentrate or separate TRU and other radionuclides including strontium, cesium, and technetium; heavy metals; and other constituents of concern. It is probabiy the single most important waste stream category from the stand. point of mixed waste treatment because of the opportunities it affords for the selective separation and recovery of a number of materials. The outstanding characteristics of this waste stream are the presence of dissolved materials and the absence of significant quantities of sodium nitrate and sodium nitrite. In general a number of dissolved components would be expected to be present but, under certain circumstances, may be significantiy reduced through prior processing. 
Two important variables in the composition include the possible presence of organic components and the concentration of the various components. Organics may be present in any waste stream derived from the nitrate brine, provided they had not been previously removed. Organics may also be introduced in solvent extraction or dissolution processes in the form of complexing agents and/or solvents. The concentration of individual dissolved components will depend on prior processing. For example, the dissolution of the insoluble sludge stream will create relatively low concentrations of certain components such as TRU because of their low concentrations in the sludge. However, subsequent processing such as solvent extraction and ion exchange will concentrate these levels by 1 or more orders of magnitude.

The applicability of any specific technology or combination of technologies to dilute aqueous waste streams depends very strongly on the objective of the treatment and the waste stream components involved. In general, all treatment options of dilute waste streams will center on the selective separation and concentration of certain dissolved solids. Thus, the selection of a specific technology depends primarily on the ability to separate and concentrate within the context of all previous and subsequent operations.

Technologies for treating dilute aqueous waste streams can be divided into three major categories according to their primary function:

- destruction of organics

- nonselective concentration of components

- selective separation and concentration of components.

\section{Elimination of Organics}

In treating the waste streams to separate and concentrate dissolved solids the elimination of organic components is generally considered only when their presence interferes with performance or creates a hazard (as could be the case with cyanides) in subsequent processing. The only exception is when the organics constitute the main hazardous constituent within the waste stream. The specific methods for eliminating organics from the waste include:

- chemical oxidation 
- chemical reduction

- high temperature water treatment

- adsorption/ion exchange

- incineration

- biodegradation.

The applicability of chemical oxidation, chemical reduction, high temperature water treatment, and biodegradation technologies would be the same as those for the nitrate brine waste. However, sodium nitrate would not be present in the waste and would not be a consideration in weighing the advantages and disadvantages of each of those choices.

Adsorption/ion exchange technologies are considered in the treatment of dilute aqueous wastes when previous treatments result in low concentrations (generally less than $1 \%$ ) of organics that are amenable to adsorption. These processes would include the three processes mentioned above, which can result in incomplete destruction of the organics, or solvent extraction in which trace amounts of solvent remain. In general, traditional adsorbents, such as activated charcoal, would be used instead of ion exchange material. In certain cases, ion exchange materials can be used to remove organic acids. Adsorption techniques are limited in their ability to remove most complexing agents, however, and would not be suitable for this application.

Incineration technologies would be applicable in aqueous waste streams in which the organic content is relatively high. Economics generally dictate that the organic content be above 10\%, although other considerations may make the incineration of wastes streams with lower organic content practical. As with nitrate brine streams, the presence of significant quantities of dissolved heavy metals and/or radionuclides may not be desirable because these materials will likely be carried out as fly ash requiring efficient removal from the flue gas.

Nonselective Concentration of Components

One of the major barriers to applying separation, recovery, and/or disposal techniques to dilute aqueous waste streams is that many technologies do 
not work well when the concentrations are too low-the main cause of the contamination of the SSTs. All hazardous dissolved solids generally must be concentrated enough to either be precipitated or stabilized in a solid disposal waste form. For precipitation, the concentration must produce sufficient solids upon addition of a precipitating agent. For stabilization, sufficient water must be removed to maximize the concentration of contaminants in the waste form.

The degree of concentration of the separated components achieved by many separation techniques is insufficient for precipitation or solidification. Three methods can be used for concentrating dissolved solids as well as organics but generally do not selectively remove separated components:

- evaporation

- freeze crystallization

- membrane separation.

\section{Evaporation}

Evaporation, a thermal process for removing water from solution, is usually used for concentrating dissolved solids and refractory organics but can also separate volatile organic components. In many cases, one or more dissolved components can be caused to precipitate out by exceeding their saturation concentration. Evaporation is a well-developed technology for concentrating dissolved solids. The main disadvantage of this technology is that the energy requirements for evaporating water are very high. The main advantage is that aqueous solutions can be concentrated to high levels in a single step.

\section{Freeze Crystallization}

Freeze crystallization is a thermal process in which heat is removed from solution, causing water to freeze. Freeze crystallization is very much like crystallization, except the solvent (water) is crystallized rather than the solute (salt) and freezes as a pure crystal. These crystals can be contaminated by occlusions of mother liquor within the crystals and wetting of 
the crystal surfaces with mother liquor. As with crystallization, most of the latter can be removed with rinsing.

While freeze crystallization is primarily a water removal process, since ice crystals float and are removed from the surface of the crystallization tank, dissolved solids that precipitate once their saturation concentration is exceeded can be removed from the bottom of the crystallizing vesse1. Similarly, phase separation of organics from water in the mother liquor can be used to selectively remove organics. These separation techniques are still in the developmental stages and may not be desirable or necessary in applying the technology. Freeze crystallization is a less energy-intensive process than evaporation but is more complex because of the need to generate and subsequently reprocess large volumes of ice crystals.

\section{Membrane Separation}

Membrane separation technologies use a membrane barrier to selectively separate components from a process stream and transport them to a second stream. Reverse osmosis and electrodialysis are primary membrane separation processes for concentrating dissolved solids. Reverse osmosis uses hydraulic pressure to force pure water from a contaminated stream and through the barrier to create a pure water stream. Consequently, it is considered to be a nonselective separation technique. For electrodialysis, a voltage gradient is applied across the membrane, causing charged cations and anions to move through the membranes. Ideally, electrodialysis results in nonselective concentration of a 11 ions and is considered to be a concentrating step much like evaporation. However, nonionic dissolved species are not affected by the voltage and will not be concentrated. Also, because the diffusivity of different ions varies, some degree of selective separation may occur.

\section{Selective Separation and Concentration of Components}

Selective separation technologies are generally applied as a means of separating specific components from an aqueous mixture. In addition, most of these processes achieve some degree of concentration. Six technologies are applicable for selective separation of dissolved solids:

- solvent extraction

\section{7}


- adsorption/ion exchange

- chemical reduction

- precipitation

- bioaccumutation

- membrane separation.

\section{Solvent Extraction}

Solvent extraction is a physical process by which selected dissolved components in one solution are transferred to another solution considered to be insoluble in the first solution. The second solution is further processed to recover and concentrate the components of concern.

Solvent extraction is used extensively in the nuclear industry for the separation and recovery of radionuclides. Two solvent extraction process with specific applicability to SST wastes are TRUEX and SREX. The main advantage of solvent extraction is that it can be very selective in the removal of specific components. This is particularly important for the recovery of relatively pure TRU and strontium, as well as other valuable small-quantity materials.

The disadvantage of solvent extraction is that it usually accumplishes very little concentration of the extracted components. Three unique approaches are currentily under development which have the potential for eliminating this disadvantage:

- thermaliy unstable complexants (TUCS)

- supercritical solvents

- facilitated transport membranes.

TUCs are organic complexants that are easily degraded, causing them to lose their complexing capability. By using these agents to improve ion solubility in the stripping portion of a solvent extraction process higher concentrations can be achieved. Subsequent destruction of these complexants makes it possible to apply another separation technology that would otherwise be adversely affected. 
Supercritical solvents achieve greater concentration because of two unique properties. Under supercritical conditions many organic solvents behave like polar solvents and have a high solubility for dissolved ions. Also, the supercritical fluids can be depressurized, which effectively evaporates the solvent, leaving behind precipitated solids.

Facilitated membranes use a membrane with solvent properties to separate the extraction and stripper sections of the process. The diffusional gradients that can be imposed across the membrane make it possible to achieve concentration increases of up to 3 orders of magnitude (Noble, Koval, and Pellegrino 1989).

All of these concepts are in the developmental stage. Successfur application of these innovations is not necessary for solvent extraction to be used in treating dilute aqueous waste streams. However, any of theso techniques, if successful, would more than likely increase the range of applicability of the technology.

\section{Adsorption/Ion Exchange}

Adsorption/ion exchange technologies are well developed for the treatment of ditute aqueous waste streams. Ion exchange processes in particular have been used throughout the nuclear and electroplating industries for the selective removal, recovery, and purification of many radionuclides and heavy metals. They typically achieve a higher degree of concentration in the regeneration stream than the stripper solution of a solvent extraction column, a)though, overal?, the selectivity is relatively modest. Adsorption and ion exchange processes work on the principle that the flow nf dissolved components having an affinity for the adsorption/ion exchange material is retarded compared to water flow. A column containing the adsorbent or ion exchange material is operated as a batch until the target material begins to appear in the effluent. The column is then taken out of service and flushed to regenerate the column and recover the separated components. Selectivity is limited by the relative order and magnitude of retardation achieved by the various components within the contaminated stream. 
Adsorption/ion exchange technology is considered a primary candidate for the separation and recovery of many of the SST components, including many heavy metals and radionuclides. However, improvements can be achieved by identifying and developing new adsorbents and ion exchange material for specific components in the waste stream.

\section{Chemical Reduction}

Chemical reduction is primarily used as a means of reducing the oxidation state of heavy metals and making them more susceptible to precipitation. Chemical reduction is typically used on dilute waste streams where the total dissolved solids are no more than a few thousand ppm.

Chemical reduction is usually approached in three different ways. The first approach is to add a chemical to the wastewater to react with one of the ions in solution and reduce the oxidation state in that ion. A common application of this approach is to add a sulfide compound, such as sodium sulfide, to a wastewater and reduce $C r(V I)$ as chromate to $C r(I I I)$ as chrome sulfide. Many of the sulfide precipitation reactions involve chemical reduction.

The second approach is cementation in which the solution is passed through a bed of reduced metal particles or turnings. If the metal is higher in the electromotive series than the dissolved metal to be reduced, then as the solution passes through, the reduced metal will spontaneously exchange with the metal in solution causing it to plate out on the particles. This technique is used in the metal refining industry to remove copper and other heavy metals from solution.

The third approach is to apply an electromotive force to the solution, which causes the metal cations to migrate towards the anode and plate out as reduced metals. This approach includes electrowinning, electroplating, and electro-refining.

Each of these approaches may have applicability to the treatment of dilute aqueous waste streams. However, the specific merits of each approach and the specific process to use will require additional research. 


\section{Precipitation}

As was previously described in the treatment of the nitrate brine, precipitation is a standard technology for separating many dissolved materials from solution. As before, the applicability of precipitation to aqueous waste streams depends on whether the chemical to be removed is in a sufficient concentration to be precipitated and whether there are any complexing agents that will inhibit precipitation.

\section{Bioaccumulation}

The applicability of bioaccumulation to the treatment of aqueous wastes is generally the same as that for the nitrate brine. The principal limitation of the technology is the toxicity of the waste stream to the living biomass. In many cases secondary waste streams contain a smaller number of toxic components than would be encountered in the nitrate brine. However, the concentration of these components may be much higher than before. Consequently, the applicability of this technology would depend on the specific composition of the waste stream.

\section{Membrane Separation}

As previously discussed, membrane separation processes are relatively nonselective in separating individual components from water. However, ultrafiltration and hyperfiltration are capable of separating large molecules and colloids from dissolved solids and water. One innovative application of this characteristic is the selective removal of complexed ions. Recent research sponsored by the EPA SITE program has shown that cadmium and mercury could be effectively removed from an alkaline solution (Haztech News 1989, 1990).

\section{AQUEOUS SLURRY TREATMENT}

The denitrated aqueous slurry waste stream would comprise any solids produced as a result of precipitation, evaporation, freeze crystallization, and biological operations. Although the solids are assumed to be mixed with water, the presence of water is not used as a criterion for selecting treatments. Instead, it is assumed that the water content can be adjusted as necessary using standard dewatering techniques. It is also assumed that the

\section{11}


solids may or may not contain organics. In particular the solids produced in biological processes would be expected to contain a significant quantity of organic material. Although they are usually not treated as a distinct waste stream, spent adsorbents and ion exchange materials could also be considered in this category of waste stream because they will be contaminated solids requiring disposal along with the other solids.

In some cases, further treatment of aqueous denitrated slurry streams may not be necessary for disposal other than to dewater the slurry to the appropriate water content. In other cases, further treating the solids may be desirable, especially for volume reduction, improved compatibility with waste form, or separation and recovery of specific components.

In general, applicable technologies for treating the aqueous denitrated slurries are the same as those used in treating the insoluble sludge:

- dissolution

- beneficiation

- roasting

- molten solid separation.

In addition two other technologies are considered applicable to this waste stream:

- calcining

- incineration.

The applicability of any of these technologies depends to a great extent on the composition of the solids. For example, biological process sludge, ion exchange resins, and other organic adsorbents will contain a large quantity of organic carbon relative to the quantity of hazardous materials. In these cases incineration, roasting, or calcining processes may be appropriate for consuming the carbon and converting the mineral ash into a suitable form. Also, solubility of hydroxide solids resulting from precipitation is very sensitive to $\mathrm{pH}$. This sensitivity offers an opportunity for selective dissc. ution of specific components from a mixture by adjusting $\mathrm{pH}$. Other solids, 
such as metal sulfides, are similar to mineral ore bodies and could be further refined by any of the above methods.

Important considerations in treating aqueous denitrated slurries is whether the composition of the solids lend themselves to selective separation or volume reduction, and whether the solids properties need to be improved before disposal. In addition, the composition of the waste stream regarding the presence and concentration of radioactive and fissile components needs to be corsidered regarding the safety and costs of further refining. For example, volume reduction of a delisted slurry may not be cost effective even though the operation is relatively safe. The same operation may be cost effective if the untreated solids must be disposed of as an LLW.

Since the composition of the solids is important to determining the need and practicality of further treatment it is very important to consider treatment of this stream jointly with those separation operations that produce sol. ids. A separation process that, by itself, is not attractive could become the preferred route because of subsequent solids treatment. A good example might be the use of activated charcoal as a disposable adsorbent rather than regenerating it. Although it is an expensive material, incinerating the charcoal and disposing of the ash may be less expensive than regenerating the charcoal and thereby creating a new aqueous waste stream requiring further treatment. A systems study of the various combinations would be required to evaluate these possibitities.

\section{REFERENCES}

Noble, R. D., C. A. Koval, and J. J. Pellegrino. 1989. "Facilitated Transport Membrane Systems." Chemical Engineering Progress, March 1989.

Haztech News. 1989. December 14, p. 192.

Haztech News. 1990. June 14, p. 88. 


\section{APPENDIX E}

TREATMENT OPTIONS FOR TERTIARY WASTE STREAMS 
APPENDIX E

\section{TREATMENT OPTIONS FOR TERTIARY WASTE STREAMS}

The three tertiary waste streams are listed below:

- tertiary wastewater

- flue/residual gas

- process solids/sludge.

The key criterion of these waste streams is that they are destined for discharge or disposal but may possess one or more chemical components in trace amounts exceeding regulatory requirements. The primary objectives for these waste streams is to make them suitable for disposal.

\section{IERTIARY WASTEWATER TREATMENT}

Tertiary wastewater can potentially become the largest quantity of material discharged to the environment. On a unit weight basis more than $11 \mathrm{~b}$ of water will likely be required to separate each pound of water-soluble components from insoluble components in the initial waste. Comparable quantities of water will be necessary if acid dissolution is used to treat the insoluble sludge. Other processes, such as ion exchange and solvent extraction, that may be used to treat secondary waste streams can also require substantial quantities of water. Obvious tactics to minimize the amount of water required for overall processing is to treat and recycle the water to the various operations including the formulations of final waste forms such as grout. However, even this strategy may require tertiary water treatment techniques to remove incompatible components.

The primary objective of tertiary water treatment is to purify the water. This objective is in contrast to secondary treatment whose objective is to separate and concentrate specific impurities in the water. The principal components in this waste stream could be any of the original components in the SSTs but in very low concentrations. In addition new contaminants may be 
introduced which may need further treatment, e.g., solvents, complexing agents, and inorganic chemical reagents.

\section{Traditional Treatment Technologies}

In principle, any technology that can be used to treat the denitrated aqueous waste described in the previous section can be used for tertiary waste treatment. However, only three technologies are traditionally considered to be economical:

- biodegradation

- bioaccumulation

- adsorption/ion exchange.

The applicability of both biodegradation and bioaccumulation technologies is improved for this waste stream because the presence of components considered toxic to the living matter would most likely be below chronic levels. Furthermore, optimization of biodegradation, biodenitrification, and bioaccumulation capabilities through research could provide a broad degree of treatment in a single step. The main disadvantage of these technologies is that the sludge produced by the biomass may be toxic and require further treatment and disposal.

Both adsorption and ion exchange are commonily used for the tertiary treatment of industrial wastewater prior to discharge. Their applicability to the various components in the waste would be the same those described for the denitrated aqueous waste. One disadvantage of both technologies is that the adsorbents and ion exchange materials must eventually be further treated and disposed of as a hazardous and/or radioactive waste. However, both technologies use materials that can be regenerated many times before they lose their adsorption and ion exchange properties. In addition, it may be possible to identify and develop materials that optimize removal of key components, regeneration requirements, and compatibility of spent materials with waste disposal forms. 


\section{Additional Treatment Technologies}

Solvent extraction, membrane separation, and evaporation may also warrant consideration for treating the tertiary waste stream. Traditional solvent extraction technology is usually not favored over ion exchange processes because at low concentrations costs are comparatively high and solvent losses an significant relative to the dissolved ions removed. However, facilitated transport membranes have the potential to improve the concentration of ions in the stripping solution by as much as 3 orders of magnitude (Noble, Koval, and Pellegrino 1989) as well as significantly limiting the loss of solvent. These potential capabilities may extend the range of economic applicability of solvent extraction to much lower concentrations.

Evaporation and membrane separation technologies are also not normally favored economicaliy for tertiary treatment of water, but as previously mentioned, a large portion of the wastewater may be used in the formulation of final waste forms such as grout. Assuming that the characteristics of the wastewater are satisfactory, these technologies might be applied to removed excess quantities of water as pure water, leaving behind a more concentrated stream suitable for formulation of the final waste forms. The advantage of this approach would be the elimination of further treatment of the excess water by the other traditional technologies. This would in turn eliminate the generation of hazardous solid wastes such as biomass solids and spent adsorbents.

\section{FLUE/RESIDUAL GAS TREATMENT}

A number of technologies either use or generate gases (see Appendix B). Some of the more noteworthy processes are those that degrade organics, e.g., incineration and chemical oxidation. Other processes, such as roasting, may add excess gases that are only partially consumed and must include provisions for venting. Typical flue gas contaminants include toxic gases such as $\mathrm{NO}_{\mathrm{x}}$, $\mathrm{CO}, \mathrm{H}_{2} \mathrm{~S}, \mathrm{HCl}$, volatile organic liquids either as gases or as entrained mists, and entrained heavy metals and radionuclide particulates.

A number of commercial technologies are available for treating these various contaminants in gas streams. These technologies include: 
- gas adsorption processes using liquids and solids to remove gases such as $\mathrm{HCl}$ and $\mathrm{H}_{2} \mathrm{~S}$

- fume incinerators to destroy combustible gases such as $C O$ and organic gases and vapors

- gas phase catalytic reduction processes to convert $\mathrm{NO}_{x}$ to elemental nitrogen and water

- gas phase particulate removal systems to collect heavy metals and radionuclide particulates.

Each of these technologies uses processing techniques unique to the treatment of gases. The initial review of the literature indicated that none of the SST flue/residual gas contaminants pose processing constraints that cannot be addressed using one or more of the above technologies. Thus, there did not appear to be innovative adaptations or improvements required for treatment of these waste streams. Therefore, a detailed evaluation of these general categories was not made. Two technologies do warrant discussion here because of their importance to the adaptation of other technologies. These technologies involve $\mathrm{NO}_{x}$ reduction and gas particulate removal.

$\mathrm{NO}_{x}$ is a gaseous mixture of nitrogen oxides that is generated in small quantities in incinerators. It is of concern because of its interaction with other airborne contaminants to produce acid rain and ozone. It is usually minimized by controlling combustion of major sources such as automobiles and industrial incinerators and boilers. In treatment of the nitrates in the SSTs, calciners and incinerators are proposed that would produce a very high concentration of $\mathrm{NO}_{x}$ in the flue gas. The viability of these treatment options is coupled to the ability to reduce $\mathrm{NO}_{x}$ to elemental nitrogen and water. A standard commercial process for reducing $\mathrm{NO}_{x}$ is catalytic reduction using ammonia. This process has been used in power plants fueled by coal, 0il, and natural gas to reduce $\mathrm{NO}_{x}$ by over $80 \%$ (Donnelly and Brown 1989; Faucett, Maxwe11, and Burnette 1977; Kiovsky, Koradia, and Lim 1980; Koyanagi and Suyama 1989). Other commercial processes have used either methane, carbon dioxide, or hydrogen as the reducing gas (Kohl and Reisenfeld 1979).

Gas phase particulate removal is a we11-developed commercial technology. In recent years public concern has been raised regarding heavy metal 
particulate removal in hazardous waste incinerators. This concern centers around the higher levels of heavy metals in the fly ash (ash in the flue gas) than is encountered in other combustion processes. Because of this concern, gas phase particulate removal is discussed in more detail in conjunction with incineration technology (Section 4.18).

\section{PROCESS SOLIDS/SLUDGE}

Process solids and sludge are considered to be any treated solid waste suitable as a feedstock for disposal as a waste form. The most obvious wastes in this category are those produced from the precipitation of dissolved solids caused by the addition of precipitation reagents or evaporation. Undissolved solids remaining after the dissolution of the insoluble solids also would be in this category. In addition, sludge produced from biological processes and spent adsorbent/ion exchange materials would be included. For the purposes of this report it is assumed that these materials no longer need pretreatment and are considered to have met the necessary requirements for disposal.

\section{REFERENCES}

Donnelly, J. R., and B. Brown. 1989. "JoY/Kawasaki Selective Catalytic Reduction De-NO Technology." Presented at the Air and Waste Management Association 82nd Annual Meeting \& Exhibition, Anaheim, California, June 25-30.

Faucett, H. L., J. D. Maxwe11, and T. A. Burnette. 1977. Technical Assessment of NO Removal Processes for Utility Applications. EPRI AF-658, Electric Power Research Institute, Palo Alto, California.

Kiovsky, J. R., P. R. Koradia, and C. T. Lim. 1980. "Evaluation of a New Zeolitic Catalyst for $\mathrm{NO}_{x}$ Reduction with $\mathrm{NH}_{3} . "$ Ind. Eng. Chem. Prod. Res. Dev. 19:218.

Kohl, A. L., and F. C. Riesenfeld. 1979. Gas Purification. Gulf Publishing Company, Houston.

Koyanagi, T., and K. Suyama. 1989. "Development of SCR System by MHI for Clean Gas." Presented at the Air and Waste Management Association 82nd Annual Meeting \& Exhibition, Anaheim, California, June 25-30.

Noble, R. D., C. A. Koval, and J. J. Pellegrino. 1989. "Facilitated Transport Membrane Systems." Chemical Engineering Progress, March 1989. 


\section{DISTRIBUTION}

No. of

Copies

\section{OFFSITE}

12 DOE Office of Scientific and Technical Information

\section{ONSITE}

2 DOE Richland Field office

J. H. Anttonen

J. M. Hennig

5 Westinghouse Hanford Company

G. R. Bloom (3)

J. J. Holmes

R. G. Cowan
No. of

Copies

29 Pacific Northwest Laboratory

E. G. Baker

A. A. Gerber (10)

R. T. Hallen

L. K. Holton

E. O. Jones (3)

D. E. Kurath

J. R. Morrey

R. K. Quinn

P. A. Scott

L. J. Sealock

S. C. Slate

J. L. Straal sund

Technical Report Files (5)

Publishing Coordination 

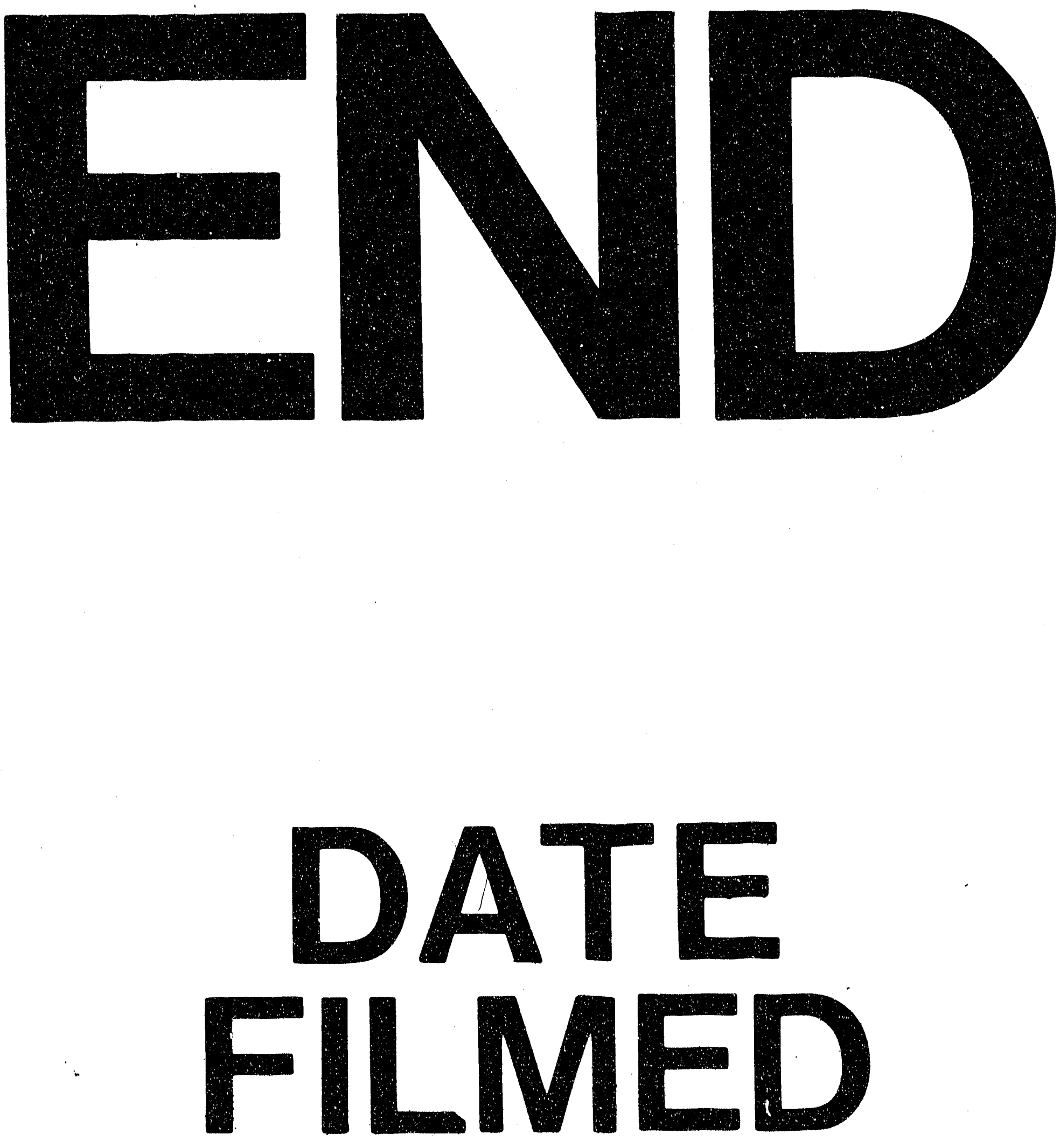

I

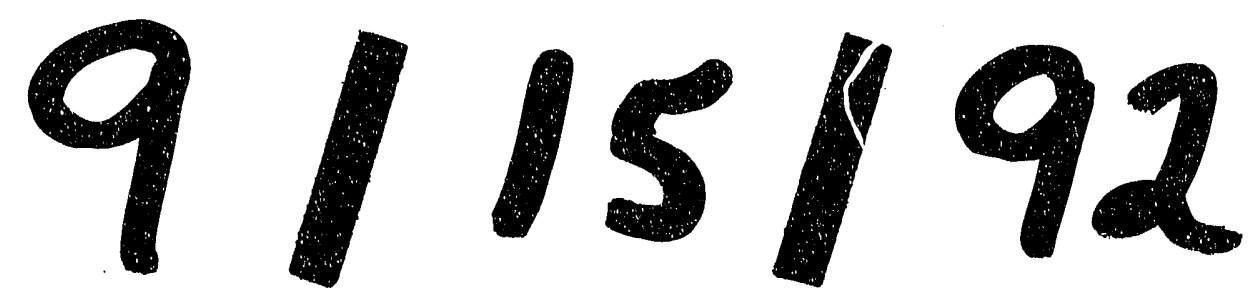


